\title{
DISTRIBUTED POWER GENERATION FOR LEBANON
}

Market Assessment and Policy Pathways

MAY 2020
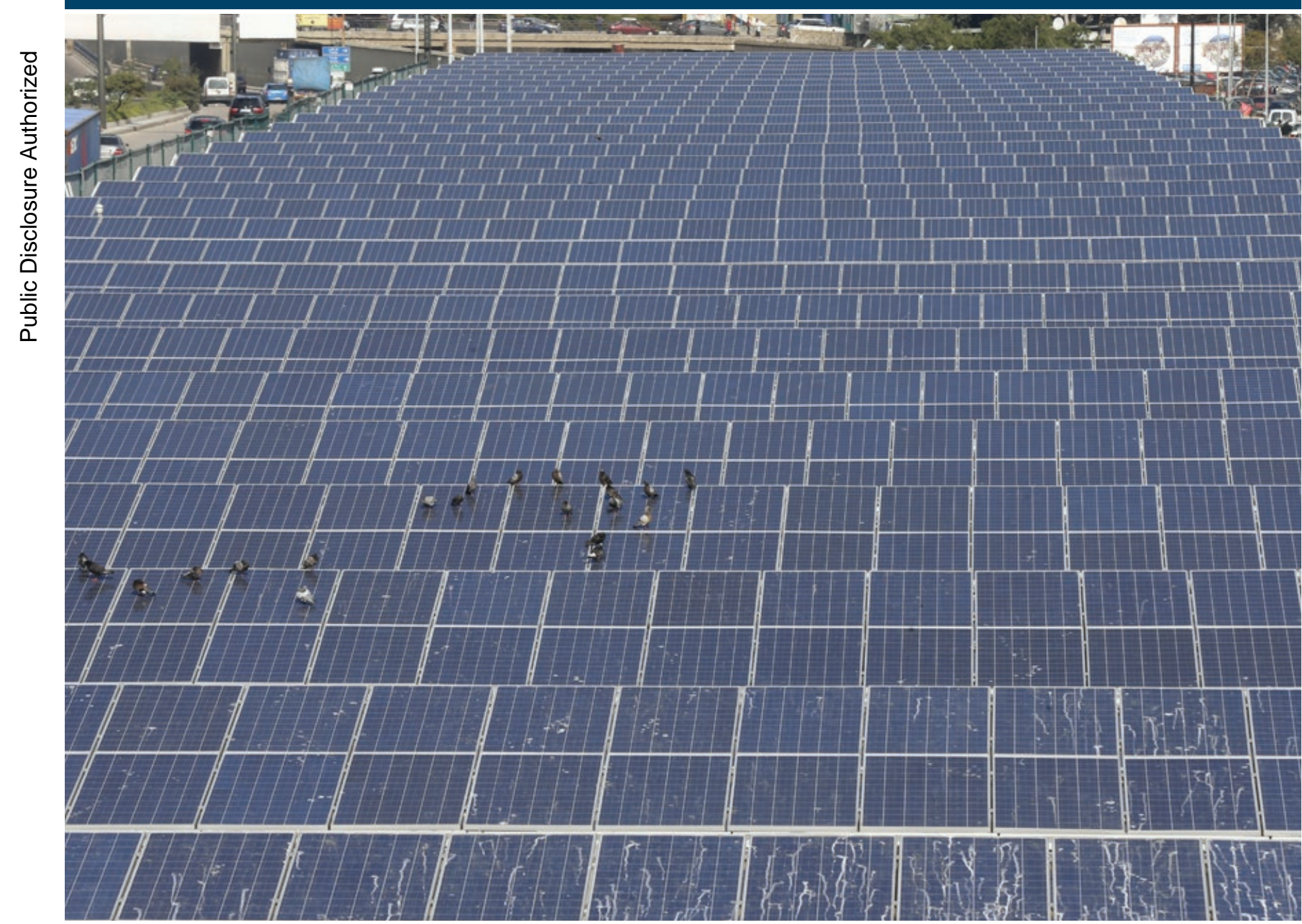


\section{DISTRIBUTED POWER GENERATION FOR LEBANON}

Market Assessment and Policy Pathways

MAY 2020

Ali Ahmad 
(C) 2020 May I International Bank for Reconstruction and Development / The World Bank 1818 H Street NW, Washington, DC 20433

Telephone: 202-473-1000;

Internet: www.worldbank.org

Some rights reserved

This work is a product of the staff of the World Bank. The findings, interpretations, and conclusions expressed in this work do not necessarily reflect the views of the World Bank, its Board of Executive Directors, or the governments they represent. The World Bank does not guarantee the accuracy of the data included in this work. The boundaries, colors, denominations, and other information shown on any map in this work do not imply any judgment on the part of the World Bank concerning the legal status of any territory or the endorsement or acceptance of such boundaries. Nothing herein shall constitute or be considered to be a limitation upon or waiver of the privileges and immunities of The World Bank, all of which are specifically reserved.

\section{Rights and Permissions}

This work is available under the Creative Commons Attribution 3.0 IGO license (CC BY 3.0 IGO) http://creativecommons.org/ licenses/by/3.0/igo. Under the Creative Commons Attribution license, you are free to copy, distribute, transmit, and adapt this work, including for commercial purposes, under the following conditions:

Attribution-Please cite the work as follows: ESMAP. 2020. "Distributed Power Generation for Lebanon: Market Assessment and Policy Pathways. (May), World Bank, Washington, DC. License: Creative Commons Attribution CC BY 3.0 IGO.

Translations-If you create a translation of this work, please add the following disclaimer along with the attribution: This translation was not created by The World Bank and should not be considered an official World Bank translation. The World Bank shall not be liable for any content or error in this translation.

Adaptations-If you create an adaptation of this work, please add the following disclaimer along with the attribution: This is an adaptation of an original work by The World Bank. Views and opinions expressed in the adaptation are the sole responsibility of the author or authors of the adaptation and are not endorsed by The World Bank.

Third-party content-The World Bank does not necessarily own each component of the content contained within the work. The World Bank therefore does not warrant that the use of any third-party-owned individual component or part contained in the work will not infringe on the rights of those third parties. The risk of claims resulting from such infringement rests solely with you. If you wish to re-use a component of the work, it is your responsibility to determine whether permission is needed for that re-use and to obtain permission from the copyright owner. Examples of components can include, but are not limited to, tables, figures, or images.

All queries on rights and licenses should be addressed to World Bank Publications, The World Bank Group, 1818 H Street NW, Washington, DC 20433, USA; e-mail: pubrights@worldbank.org.

Images: (C) World Bank

All images remain the sole property of their source and may not be used for any purpose without written permission from the source. 
"When the winds of change blow, some people build walls; others build windmills"

- Chinese proverb 


\section{CONTENTS}

ACKNOWLEDGMENTS

PREFACE

EXECUTIVE SUMMARY

Realities of Lebanon's Diesel-based Distributed Electricity Sector $\quad 8$

The Potential and Economics of Distributed Solar PV 8

Recommendations for an Efficient Transition Towards Renewables-Based Distributed Energy Market 9

\section{PART I:CONTEXT OF LEBANON'S ELECTRICITY SECTOR AND} DISTRIBUTED POWER GENERATION

1. Realities of Lebanon's Electricity Sector 12

2. Context of Diesel Generators' Operations 14

2.1 Evolution of government policies towards private generators 14

2.2 New rules, new challenges $\quad 15$

3. Distributed Renewable Energy Development 17

$\begin{array}{ll}3.1 & \text { Status and trends } \\ 3.2 & \text { Uses of distributed solar PV }\end{array}$

$\begin{array}{lll}3.2 & \text { Uses of distributed solar PV } & 18\end{array}$

3.3 Evolution of RE policies in Lebanon 19

PART II:THE DIESEL GENERATOR MARKET IN LEBANON 21

4. Value Chain and Market Size 22

4.1 Size of the commercial diesel generator market 22

4.2 Size of the generator sale and diesel fuel economy 24

5. The Business Model of Private Diesel Generators 28

5.1 Cost components 28

5.2 Revenue streams 30

5.3 Profits and profit margins 31

6. Ownership Models and Structures 33

7. Political Economy Considerations $\quad 34$

$\begin{array}{lll}7.1 & \text { Overview of political economy challenges } & 34\end{array}$

7.2 Actors, influences and interests 35

PART III:THE POTENTIAL AND ECONOMICS OF DISTRIBUTED SOLAR PV 37

8. Economics of Distributed Solar PV for Lebanon 38

8.1 Value propositions of distributed solar PV 38

$\begin{array}{lll}8.2 \text { Cost structure of distributed solar PV projects } & 40\end{array}$

8.3 Electricity production costs 41

8.4 Financial feasibility $\quad 42$

8.5 Costs outlook and the role of storage 43

8.6 Case Study: Beirut's Distributed Rooftop PV Potential 45

8.7 Can owners of diesel generators shift to a solar PV-based business model?

9. Ownership Models $\quad 51$

9.1 Ownership models 51

9.2 Third-party ownership model 52 
10. Technical Challenges and Solutions $\quad 54$

10.1 Challenges $\quad 54$

10.2 Solutions 55

11. Energy Security Considerations

11.1 Attacks on Lebanon's power sector 57

11.2 Energy security and distributed renewable energy 57

12. Environmental Impact 59

12.1 Diesel generator emissions $\quad 59$

12.2 Environmental impact of scaling-up distributed RE systems $\quad 61$

$\begin{array}{ll}\text { ANNEXES } & 62\end{array}$

APPENDIX A: CURRENT POLICY INSTRUMENTS 63

A.1 NEEREA Mechanism 63

A.2 Net-Metering $\quad 63$

A.3 Other Green Financing Mechanisms $\quad 64$

APPENDIX B: EVOLUTION OF GOVERNMENT'S POLICIES TOWARDS DISTRIBUTED POWER GENERATION $\quad 65$

B.1 Evolution of regulations and control over the operations of commercial diesel generator owners 65

B.2 Evolution of RE laws, regulations and government policies 66

B.3 Role of various ministries and public entities in dealing with distributed RE in Lebanon 66

APPENDIX C: ESTIMATE OF THE NUMBER OF DIESEL GENERATORS IN LEBANON $\quad 68$

$\begin{array}{ll}\text { APPENDIX D: METHODS } & 71\end{array}$

$\begin{array}{ll}\text { D.1 Levelized cost of electricity } & 71\end{array}$

D.2 Feasibility of rooftop solar PV systems $\quad 72$

$\begin{array}{ll}\text { APPENDIX E: DIESEL GENERATOR COSTS } & 74\end{array}$

$\begin{array}{ll}\text { E.1 Lifetime maintenance cost data of a typical diesel generator } & 74\end{array}$

E.2 Distribution infrastructure costs of a typical generator network $\quad 74$

E.3: Variable O\&M costs of the generator business $\quad 75$ 


\section{ACKNOWLEDGMENTS}

This paper was prepared by Ali Ahmad, consultant of the World Bank and an energy policy scholar at the American University of Beirut's Issam Fares Institute for Public Policy and International Affairs. The author would like to thank the World Bank Middle East and North Africa Energy team for commissioning and guiding this paper. The contributors to this paper include from the World Bank: Sameh Mobarek (Senior Energy and PPP Specialist), Tu Chi Nguyen (Energy Economist), and Rita Ghorayeb (Consultant); and from the International Finance Corporation (IFC): Jaikishin Asnani (Senior Investment Officer). The paper also benefited from the peer review of Marcel Rached (Country Officer, IFC) and Ashok Sarkar (Senior Energy Specialist, World Bank). The author is grateful to Paul Noumba Um (Regional Director, MENA Infrastructure, World Bank) and Erik Fernstrom (Practice Manager, MENA Energy, World Bank) who have given overall guidance on the paper.

The financial and technical support by the Energy Sector Management Assistance Program (ESMAP) is gratefully acknowledged. ESMAP_a global knowledge and technical assistance program administered by the World Bank-assists low- and middle-income countries to increase their know-how and institutional capacity to achieve environmentally sustainable energy solutions for poverty reduction and economic growth. ESMAP is funded by Australia, Austria, Canada, ClimateWorks Foundation, Denmark, the European Commission, Finland, France, Germany, Iceland, Italy, Japan, Lithuania, Luxemburg, the Netherlands, Norway, the Rockefeller Foundation, Sweden, Switzerland, the United Kingdom, and the World Bank. 
The electricity sector in Lebanon suffers from a chronic shortage of power supply which has been met by private diesel generators that have increased dramatically over the past two decades. The Government is embarking on a broadbased sector reform, elaborated in the Ministry of Energy and Water's "Policy Paper for the Electricity Sector" 2010 and updated in the "Updated Policy Paper for the Electricity Sector" of 2019. This reform aims to, among others, provide more stable power supply and reduce the high cost of the sector and the steep implicit subsidies required to keep the sector operating. If implemented, it is expected that demand for private diesel generation will subside. However, there remains a strong interest in maintaining and even increasing private sector participation through alternative retail solutions such as renewable energy and energy efficiency products and services.

This report describes the current state of play in the private diesel generation business and assesses how to invest in and create new markets for private sector participation within the green energy sector. The objective is not to provide precise numbers but rather to offer insights and inform reform plans aiming to help the power sector transition from the prevalence of private diesel generation toward renewable-based distributed electricity market (on-grid or off-grid) combined with more reliable grid-based electricity. Its initial sections focus on the private diesel generation business with respect to market size, value chain, cost of power generation, charged tariffs, profit margins, expected revenues, ownership and organizational structures, political economy aspects, and adverse health and environmental impacts. Given sizable market and employment shares of these businesses, their transformation will be challenging; however, they can play an important role in the transition toward clean energy, as aligned with the Government's objective of 30 percent renewables in electricity generation by 2030. In subsequent sections, the report discusses alternative markets which can replace or integrate private diesel generation, with a focus on distributed solar photovoltaic (PV). It provides techno-economic analysis of the potential market size, maps barriers to entry, and identifies the profitable ownership models and incentives for private sector participation.

This report relied on data from public and private sources as well as on information compiled in dozens of interviews. Data on energy supply and demand, peak capacity and distribution of outages were obtained from Électricité du Liban (EDL), the state-owned power company, and from the World Bank; while figures related to costs were gleaned from a study, also financed by ESMAP and commissioned by the World Bank, by Economic Consulting Associates (ECA) on Lebanon's cost-of-service and tariff design. Data on renewable energy capacity, costs, and modes of operation and ownership were obtained from various sources, including interviews with representatives of local renewable energy companies, the United Nations Development Program's Small Decentralized Renewable Energy Power Generation Project (DREG), the Lebanese Center for Energy Conservation (LCEC), and the Energy Policy and Security Program at the American University of Beirut. Information on the costs and business models of the diesel generator market was obtained via more than 30 interviews conducted with owners of diesel generator networks, importers of diesel generators, and municipalities. Data on the number of buildings in Beirut and their rooftop areas was provided by The National Council for Scientific Research (CNRS). Finally, the research relied on the 2019 Updated Policy Paper for the Electricity Sector for information on government plans and their timeline. Since the data collection, the sector and market conditions have evolved, including, but not limited to, diesel and renewable costs and the reform timeline, so numbers in this report will need to be updated accordingly. 


\section{EXECUTIVE SUMMARY}

\section{Realities of Lebanon's Diesel-based Distributed Electricity Sector}

Frequent power outages are part and parcel of the daily life of the Lebanese public. The percentage of electricity demand unmet by Électricité du Liban (EDL) has increased from $22 \%$ in 2008 to $37 \%$ in 2018 , totalling around 8.1 terawatt-hours (TWh). The gap between the power supplied by EDL and demand is covered by expensive, polluting and noisy diesel generators that are dispersed almost everywhere in the country. The owners of private generators took advantage of the gap between electricity supply and demand to expand their subscription-based businesses and thus created a complex informal economy that has been resistant to regulations and government oversight.

In 2018, the total commercial (subscription-based) generator market size is estimated at \$1.1 billion, serving 1.08 million customers whose electricity purchase is estimated at $4 \mathrm{TWh}$. At current average tariff level of approximately 9 US cents per kWh, compared with the tariff of private generator at around 30 US cents/kWh, the Lebanese public can achieve savings of around $\$ 800$ million per year if the diesel generators were phased out. Even if the EDL's tariff were doubled, savings would be around $\$ 400$ million. These are substantial savings that can be used as disposable income in a small economy like Lebanon's, with a GDP of around $\$ 57$ billion.

In total, the market composed of fuel imports and distribution, generator sales, and maintenance services is estimated at around $\$ 2$ billion, with fuel imports contributing $91 \%$, followed by maintenance services with $6 \%$, generator sales at 3\% and, lastly, fuel distribution at $1 \%$. The total size of the labour force linked to the operations of private diesel generators is estimated to be around 13,200 persons, of which 4,200 jobs are linked to diesel fuel importation and distribution, 2,000 jobs to generator sale and repair services, and 7,000 jobs to retail operations of private generator networks. Like other informal and cash-based sectors in Lebanon, the informal diesel generator electricity market likely does not pay taxes. Given the lengthy time span since the "generator economy" started operating, one can anticipate that the losses of the treasury due to forgone tax revenues are substantial. It should be noted, however, that this report does not address the impact of the informal diesel generator market on tax revenues or discuss its impact.

Lebanon's energy sector failings originate from deep-rooted political economy challenges. The biggest challenge that has spanned over the whole period since the early 1990s has been the diffused decision-making in which no single entity of power has been politically accountable for the mismanagement of the sector and its public institutions, chiefly EDL. Lebanese laws only grant EDL and licensed independent power producers the right to generate and sell electricity. The operations of the private diesel generators are therefore conducted outside the legally authorized mechanism. However, due to the inability of the consecutive governments to tackle the issue of power under-supply, Lebanese policy makers and law enforcement perceived the existence of private diesel generators as a necessity and, consequently, turned a blind eye to the sector for many years.

Diesel generators are estimated to have contributed around $39 \%$ of the total electricity Greenhouse Gases Inventory (GHI) in 2018, which is equivalent to $3400 \mathrm{Gg} \mathrm{CO2eq} \mathrm{or} 11.4 \%$ of Lebanon's total estimated GHI emissions. The content of emissions released by the combustion of the diesel oil used in private generators depends on the emission factors of the used diesel fuel and its chemical composition. Diesel generators were also shown to be contributing to the high levels of fine particulate matter (PM), which has also been linked to serious impacts on human health. Replacing all diesel generator capacity with the existing EDL mix of generation, however, yields around only $6 \%$ reduction in emissions. This is because private and EDL generation have similar emission factors. This is primarily because most of EDL power is generated with diesel and heavy fuel oil. For each MWp added to the distributed renewables generation in Lebanon, approximately 1000 tCO2eq is removed.

The wide reliance on diesel generators in Lebanon has been a "blessing in disguise" during forced or unplanned outages, especially during military attacks on power infrastructure. Energy facilities - be it power generation plants or transmission and distribution infrastructure - are generally one of the preferred targets during wars and armed conflicts, because disabling them promptly and deeply affects all aspects of life. Power generation in Lebanon has been one of the sectors most affected by armed conflicts, directly through external aggression by Israel and the civil war's infighting, which resulted in substantial destruction of EDL's generation, transmission and distribution assets.

\section{The Potential and Economics of Distributed Solar PV}

Distributed solar PV systems offer Lebanon serious benefits. From EDL's perspective, they can lower (or defer) investments in grid upgrades and reduce the need for installing expensive peaking capacity. From consumers' perspective, substantial cost savings could be achieved. However, the magnitude of these cost 
savings is highly dependent on project parameters. In addition to cost benefits, distributed solar PV can promote energy resilience, shorten the lead-time required to scale up RE, reduce emissions, and induce a positive cultural change.

At current market conditions, on-grid solar PV systems appear to be the least expensive deployment mode with a levelized cost of electricity (LCOE) of 8 US cents/kWh. Dual-mode solar PV systems with storage produce electricity at a cost around 37 US cents/kWh. However, with the projected reduction in storage costs, the economics of off-grid systems will likely improve over the next few years. As for diesel generators, the cost of electricity is heavily dependent on diesel fuel prices. At a price of US\$0.63/liter, the cost of electricity is around 24 US cents/kWh.

The National Energy Efficiency and Renewable Energy Action (NEEREA) mechanism is not a financially sustainable mechanism. It greatly influences the financial feasibility of distributed solar PV systems as it reduces discount rate from an $8 \%$ market-based to a subsidized $2.75 \%$ rate. This results in reducing LCOE from 8 to 5 US cents/kWh, at current market and technology conditions. NEEREA was designed to kick off the deployment of distributed renewables, especially solar PV systems; NEEREA could serve as an important bridging mechanism until learning has been established and costs decrease further. However, the economic impact of distributed renewables should be measured based on unsubsidized cost estimates that are reflective of their real cost on Lebanon's economy.

Beirut City has a potential of distributed rooftop solar PV capacity between $\mathbf{2 0 0}$ and $\mathbf{3 0 0} \mathbf{M W p}$. The average rooftop area is estimated at $185 \mathrm{~m}^{2}$, which translates into an average capacity of 12 to $17 \mathrm{kWp}$, depending on the rooftop occupancy factor. $31 \%$ of buildings have a surface area of less than $100 \mathrm{~m}^{2}, 70 \%$ with less than $200 \mathrm{~m}^{2}$, and $85 \%$ with less than $300 \mathrm{~m}^{2}$.

Adding solar PV systems to the existing commercial diesel generator network, when possible, in the hybrid model seems to offer a compelling financial case. The financial impact of incorporating solar PV systems is maximized when diesel prices are high, since the displaced fuel generates bigger savings. While it is hard to predict how prices will change in the future, including solar PV systems in the operations of commercial diesel generators can help to mitigate the risks of price volatility. Their economic value will also be improved with reductions in technology costs and increased learning.

The industrial and commercial sectors have several advantages compared to the residential sector when it comes to their ability to deploy solar PV systems: first, availability of space through the utilization of the rooftops of factories and warehouses to install higher capacities of solar PV modules; second, higher ability - and incentive, given their higher consumption - to finance such projects, especially in the presence of supportive financing mechanisms such as NEEREA. Third, industrial and commercial users are often more aware of the impact of their energy consumption on their costs and the overall profitability of their businesses, leading them to better assess the value of investing in installing solar PV systems.

Distributed solar PV systems pose some serious technical challenges that are dependent on the penetration level of these systems, their capacity and point of contact with electricity grid. However, the type and magnitude of technical challenges depend on the deployment model. In the short term, the biggest challenge that is related to Lebanon's power sector is the "islanding" effect, which requires on-grid renewable sources to immediately disconnect from the grid once the central electricity supply is disrupted. The islanding effect is prominent in Lebanon, given the high frequency of power outages, which leads to an economic challenge due to wasted energy (in the absence of storage), but this could be resolved as grid supply improves.

Storage solutions are solar PV's biggest support. Incorporating storage, for on-grid systems operating on a "dual-mode" could reduce power waste due to the islanding effect that is common in Lebanon given the frequent outages. However, energy storage remains a costly option despite the dramatic cost reductions in recent years. In terms of short-term solutions that can be deployed to deal with the islanding effect, EDL could start by implementing a smart rationing system, in which it would prioritize its supply hours to the areas with a solar generation above a certain threshold that would make a difference to its operations.

Utilizing big data analytics can be a powerful tool to transition Lebanon into the next phase of its energy planning and strategy. With the increased adoption of smart meters, EDL would be able to collect consumption data on a much more refined time scale than now. This could help EDL and other beneficiaries study consumption patterns and other variables that could then be used to optimize operations and test various policy instruments.

\section{Recommendations for an Efficient Transition Towards Renewables-Based Distributed Energy Market}

Government's reform program is aiming to transition Lebanon's electricity sector to a more sustainable pathway, with more reliable grid supply and higher penetration of renewable sources. The Ministry of Energy and Water's 2010 "Policy Paper for the Electricity Sector" and its 2019 update (referred hereinafter as the "Updated Policy Paper for the Electricity Sector") aim to achieve 24-hour grid supply at lower cost in the near future. In addition, the Government aims 
to reach $30 \%$ of renewable energy (RE) in electricity generation by 2030 . To reach these objectives, it is imperative to phase out the diesel generators through the promotion of an alternative distributed market that is based on RE sources and expansion of a utility-scale generation base using both natural gas and renewable energy-based technologies. The phase out of the diesel generator market will be challenging, not least because they have been an essential segment of the electricity sector for a long time, with established supply chains and vested interests. Such transformation, nevertheless, is necessary since the high cost and tremendous negative environmental and health impacts of diesel generation are unsustainable. As noted above, the economics of incorporating solar PV systems into the operations of commercial diesel generator owners yields a strong financial case for such transformation. Commercial owners of diesel generators can utilize their customer network and shift to providing electricity from distributed renewable energy generation. Workers can be retrained and retooled to install and maintain solar PV systems. Such transformation would require overcoming significant cultural, information, legal, and regulatory barriers, and some suggestions towards that end are further detailed below.

Distributed generation policies that target the promotion of renewables should incorporate market-based interventions and aim to achieve economic efficiency. This means encouraging self-consumption, lowering or removing any forms of subsidies, and minimizing the overall system costs of energy generation. A primary issue for the time being is the need to design a business model that incentivizes self-consumption. Tariff structure, credit rollover, minimum and maximum capacity thresholds, and other considerations should feed into utilizing generated energy where it is produced rather than exporting it to EDL's grid.

The following steps are recommended to initiate and speed up the launch of an alternative, RE-based, distributed energy market in Lebanon.

- In the short-term, leverage the existing distributed diesel generator capacity to promote a hybrid generation model, where applicable, that incorporates solar PV systems. This can be an effective entry point towards establishing an alternative green energy market. The main advantages of such a hybrid model are (1) reduction of diesel fuel costs and overall system costs, (2) development of an indigenous know-how that will be required in a market transition towards higher penetration of renewable energy generation, and (3) lowering air pollution, especially in dense urban areas.

- Develop a set of tools that would help owners of diesel generators assess the technical and economic feasibility of integrating solar PV systems into their operations and business models. Examples of such tools include technical and financial tools that can inform owners of diesel generators on the design, sizing and costing of solar PV systems. These tools can help match the existing conditions (space available, shading, load profile, etc.) with the expected performance of installed PV systems.

- Identify and implement pilot projects and focus on "low hanging fruit". Priority should be given to water utilities, community/municipal projects, industrial and commercial consumers who have a suitable load profile and access to space with no or little shading. Ideally, these projects should be initiated with customers who are connected to the medium-voltage grid to avoid losses on the distribution grid level. Additionally, from EDL's perspective, implementing pilot projects can be an effective means to examine the technical and administrative challenges that emerge from having distributed solar PV systems connected to EDL's grid and how these challenges would evolve with the increased penetration of the connected distributed capacity.

- Offer incentives for diesel generator owners to evolve their business model to shift into a third-party ownership model. This model can be based on leasing rooftops and other available and suitable space to install solar PV systems and sell electricity to customers. This should include creating the legal framework to allow peer-to-peer energy sale of electricity generated wholly or partly by renewable energy. Additionally, a differentiated tax system can be applied where owners of hybridized generator networks are offered tax relief.

- Conduct technical awareness workshops that target owners of diesel generators to highlight the technical challenges and issues encountered upon integrating solar PV systems with a diesel generator network. Examples of important technical issues include overcurrent and overvoltage protection, reactive power compensation and shortcircuit considerations. Dealing with these technical issues will improve the safety and quality of the PV-generator hybrid system.

- Examine the possibility of establishing a green fund to finance distributed energy projects that aspire to shift from diesel-based to renewables. International financial institutions and donor countries can support this fund. Funded projects must be technically and economically sound.

- Create simple, yet dynamic distributed generation polices. The importance of simple interventions cannot be overstated. Where human and technical capacity may be limited, simple policies that can be tracked and assessed go a long way toward ensuring policy effectiveness. 


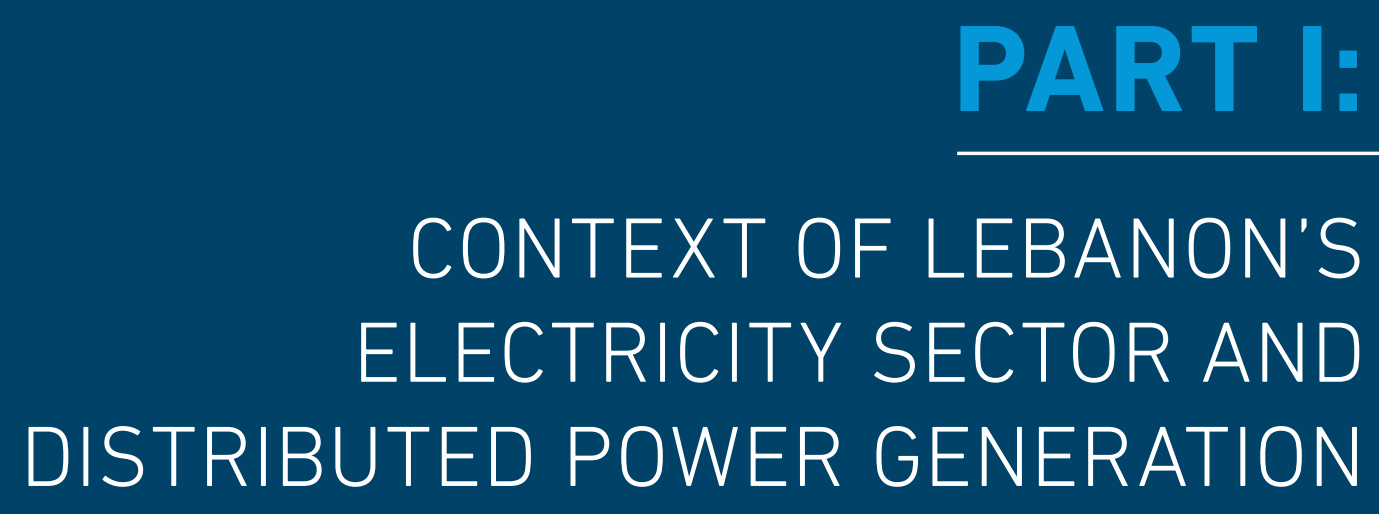




\section{Realities of Lebanon's Electricity Sector}

Frequent power outages are part and parcel of the daily life of the Lebanese public. These outages reflect the persistent challenges facing the power sector in the country, particularly the increasing deficit between supply and demand and the high levels of technical (transmission and distribution) losses. ${ }^{1}$ The failings of the Lebanese power sector trace back to the days of the civil war between 1975 and 1990, which resulted in substantial destruction of the state-owned power utility Electricité du Liban's (EDL) generation, transmission and distribution assets. ${ }^{2}$ The post-conflict reconstruction era did bring in new investments, especially in generation, with the addition of $900 \mathrm{MW}$ of capacity between 1990 and 1998. However, the post-war governments dedicated little attention to the problems and inefficiencies related to the transmission and distribution network or to EDL's financial losses.

Figure 1: Lebanon's electricity supply and demand balance (Sources: data was obtained from EDL, Projections are based on team's analysis)

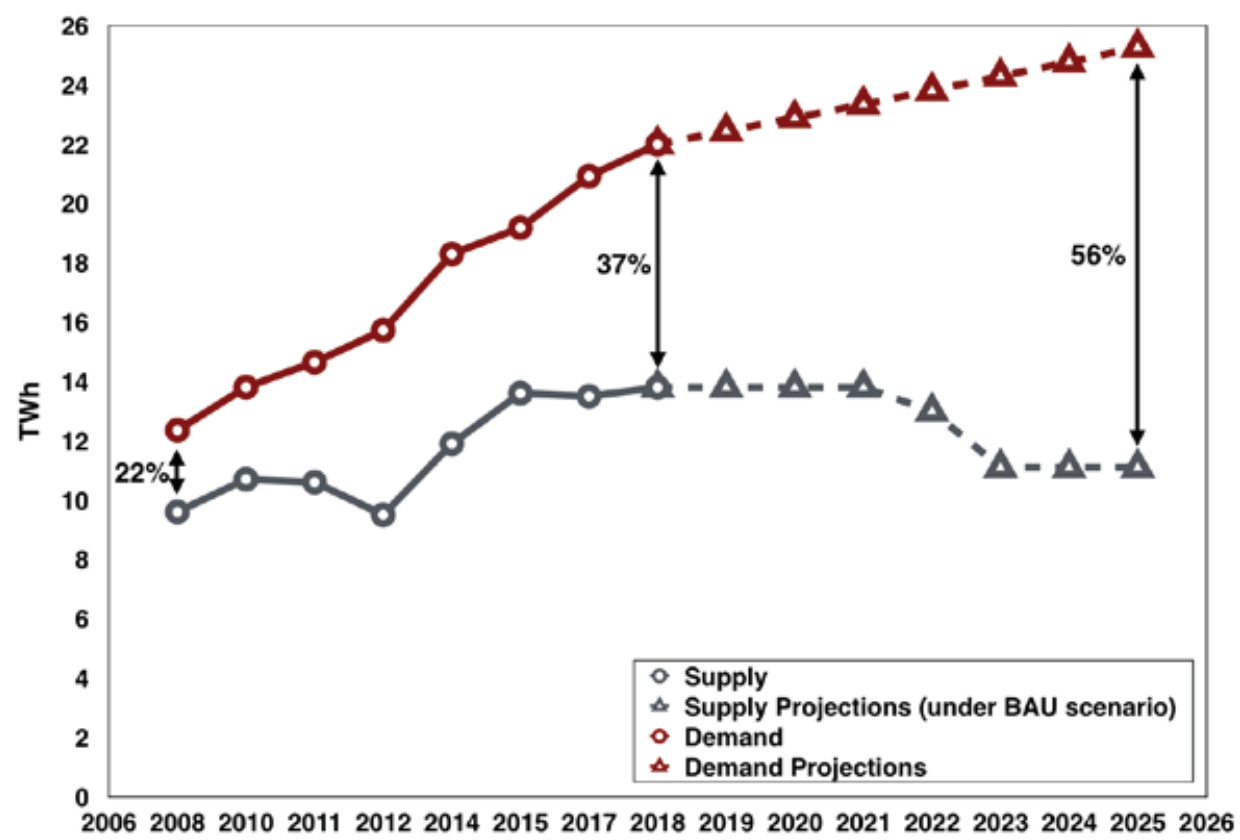

As shown in Figure 1 the percentage of electricity demand unmet by EDL in Lebanon has increased from $22 \%$ in 2008 to $37 \%$ in 2018. In a "Business-As-Usual" scenario, in which demand would continue to grow and no generation capacity would be added and in which the Jiyeh and Zouk power generation units would be retired in 2022, ${ }^{3}$ the supply-demand deficit is expected to grow to $56 \%$ by 2025 .

The frequency and length of power cuts is not uniform across Lebanon; it differs between different cities and parts of the country. Figure 2 shows the geographical variation in the average daily hours of power outages based on data obtained from EDL. ${ }^{4}$ The city of Beirut enjoys the best electricity coverage, with only 2.8 hours of outages per day, followed by Mount Lebanon, with an average of 5.6 hours. Inland regions are most affected by EDL's lack of service delivery, particularly the Baalbak-Hermel and Akkar districts, which endure outages of more than 10 hours per day, on average. The length and frequency of power cuts also vary temporally, as they increase in the summer and winter seasons due to the demand for cooling and heating. This peak demand often strains the distribution network, leading to failures and, consequently, to unplanned (or forced) outages.

1 EDL currently estimates transmission and distribution losses at around 19\%

2 Lebanon's power plants and their auxiliary facilities have also been targeted by Israeli airstrikes multiple times. See https:// www.latimes.com/archives/la-xpm-1999-jun-25-mn-50004-story.html

3 Based on the updated electricity policy paper of 2019

4 The data shown in Figure 2 is the average outages of EDL feeders in all the districts in Lebanon. Often, different feeders within the same district have different number of hours of outages. 


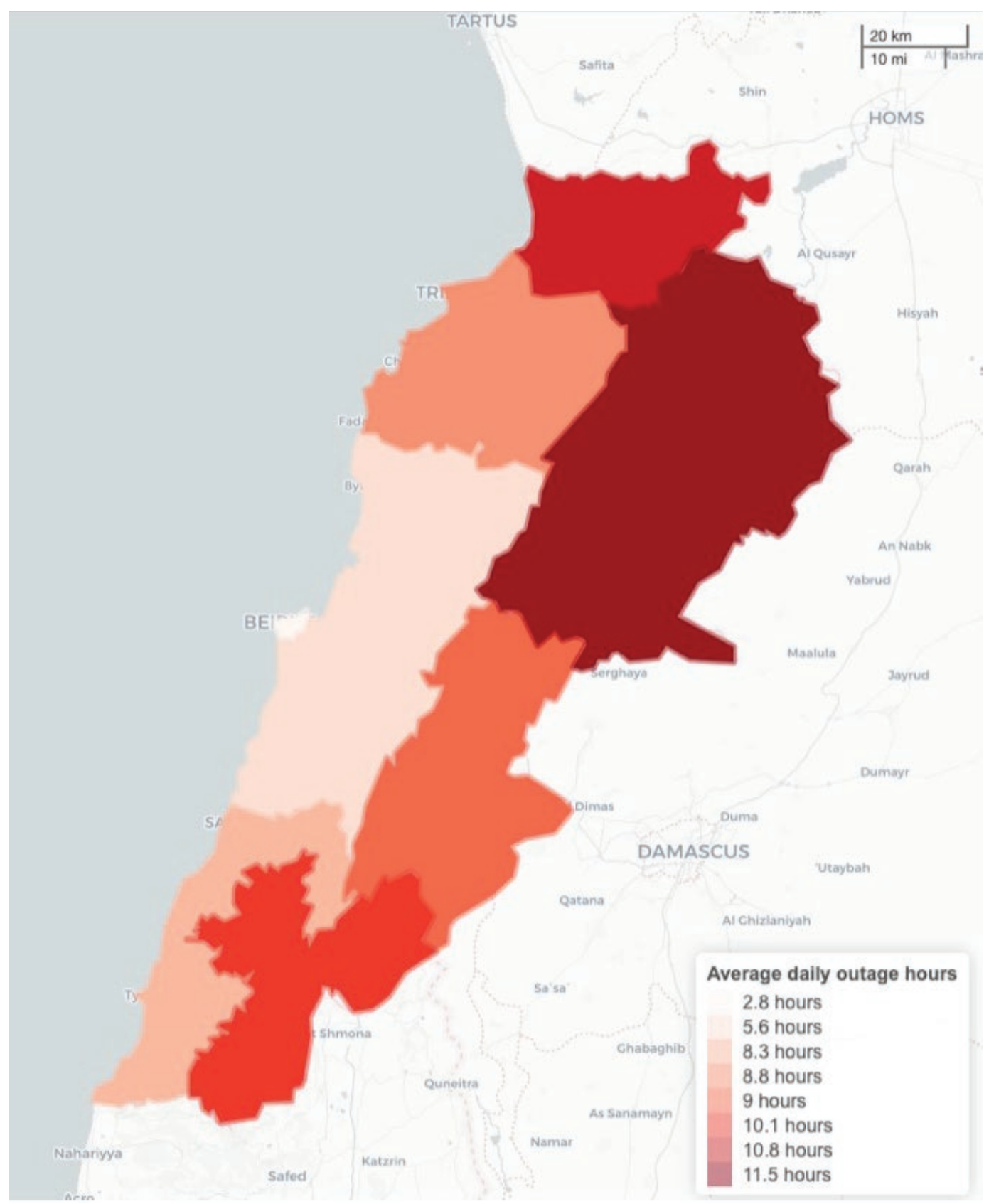

The gap between the power supplied by EDL and demand is covered by expensive, polluting and noisy diesel generators that are dispersed almost everywhere in the country. These generators are often located in the basements of buildings, parking lots and alleyways near residential units. Because of their typically short stack and low maintenance frequency, these generators' emissions are negatively impacting public health. ${ }^{5}$

In 2018, the power deficit covered by diesel generators totalled around 8.1 terawatt hours (TWh) (see Table 1). Such a substantial reliance has translated into a proliferation of diesel generators owners who operate at various scales, from 50 to thousands of kilo-volt-amperes (KVA). ${ }^{6}$ These owners took advantage of the gap between electricity supply and demand to expand their subscription-based businesses and thus created a complex informal economy that has been resistant to regulations and government oversight.

5 Effect of distributed electric power generation on household exposure to airborne carcinogens in Beirut. http://www.aub. edu.lb/ifi/Documents/publications/research_reports/2012-2013/20130207ifi_rsr_cc_effect\%20Diesel.pdf

6 Kilo-volt-ampere is the unit of power capacity in diesel generators. It can be converted to kW by multiplying it by a generatorspecific power factor (usually PF= 0.8) 


\begin{tabular}{lll} 
& Unit & Value \\
\hline Lebanon's peak capacity & MW & 3,456 \\
Load factor & $\%$ & $73 \%$ \\
Average capacity & MW & 2,529 \\
Total demand & TWh & 22 \\
Capacity: EDL plants & MW & 1,884 \\
Capacity: Purchased - Barges & MW & 388 \\
Capacity: Purchased - Imported & MW & 240 \\
Total generation capacity & MW & 2,512 \\
Average (generation) Load Factor & $\%$ & $75 \%$ \\
Total generation & TWh & 17 \\
Total technical losses & $\%$ & $15 \%$ \\
Generation delivered & TWh & 14.0 \\
\hline Deficit covered by diesel generators & TWh & $\mathbf{8 . 1}$ \\
\hline Percentage deficit covered by DGs & $\%$ & $\mathbf{3 7} \%$ \\
\hline
\end{tabular}

\section{Context of Diesel Generators' Operations}

Until recently, the diesel generator businesses in Lebanon were largely unregulated and not monitored. However, with the increasing discontent among the public due to the high flat tariffs imposed by the owners of private generators and their uncontrolled economy, the government, through the concerned ministries, ${ }^{7}$ began taking steps to regulate the sector. Government intervention included forcing the owners of diesel generators to install a metering system for all subscribers and ensuring compliance with the tariff structure published monthly by the Ministry of Energy and Water (MOEW). ${ }^{8}$

\subsection{Evolution of government policies towards private generators}

Today, as shown in Table 1, about 37\% of the unmet demand is covered by private generators. While Decree 16878 of 1964 grants EDL a monopoly on the generation and sale of electricity, Law 462 of 2002 opens the door to generating power from independent power producers (IPPs), who should acquire the necessary approvals and permissions. ${ }^{9}$ Since all the operations of the private diesel generators are conducted outside the legally authorized mechanism, the existence of generator businesses and their activities are illegal. However, due to the inability of the consecutive governments to tackle the issue of power under-supply, Lebanese policy makers and law enforcement perceived the existence of private diesel generators as a necessity and, consequently, turned a blind eye to the sector for many years. ${ }^{10}$

However, and since 2011, the government began to its efforts to regulate and control the private generator market, though little action was taken until mid-2018. Table B.2 (see Appendix B) highlights the evolution of the government's regulations and control measures over the operations of commercial and privately-owned diesel generators since 2011 . when the Council of Ministers (COM) issued a decree to permit the MOEW and Ministry of Economy and Trade (MOET) to regulate the sector.

7 The concerned ministries are listed in Table B.3 in Appendix B

8 Except in situations where the subscribers themselves signed a waiver choosing not to install meters.

9 Under Law 462, self-generation does not require authorization if its capacity is below $1.5 \mathrm{MW}$

10 In an interview with an official at the MOET, he elaborated that in their current dealings with owners of diesel generators, the question is not if they are legal or not, but rather if they are "acceptable" or not. By acceptable, he referred to owners who have installed meters and following the monthly tariff published by the Ministry of Energy and Water Resources. 
Prior to 2018, consumers often paid flat monthly tariffs based on the number of cut-off hours, which depends on the electricity supply and varies between regions, as shown in Figure 2. ${ }^{11}$ The tariffs imposed by the owners of generators were often inflated, which provided them with a substantial and consistent flow of cash. Increasing levels of frustration and discontent among the Lebanese public have pushed the government, since 2011, to issue a monthly pricing table that is sensitive to diesel prices and based on either the "per kilowatt hour" consumption or the electricity cut-off hours through the MOEW. ${ }^{12}$ Currently, the MOEW publishes a monthly tariff chart that includes a variable, per kWh, component and a fixed component that depends on the number of amperes offered to the customer..

In 2013, the Ministry of Environment (MOE) issued a circular specifying the acceptable emissions limits and air pollutants levels that may result from the operations of diesel generators. ${ }^{13}$ Despite these efforts, compliance by the owners of diesel generators remained limited, as they benefitted from the lack monitoring capacity within the MOE and the political infighting within the government over the electricity plan's implementation, which resulted in significant delays in the government's response to the country's energy crisis.

In June 2018, the MOET announced its plan to set a compulsory requirement to install metering systems for all subscribers connected to private diesel generators as of October 2018. The plan aimed to enforce a tariff that is based on electricity consumption and prices that are based on the MOEW's monthly tariff structure. Strict monitoring measures by the MOET, the MOEW as well as the Ministry of Interior and Municipalities (MOIM) followed to implement the plan, with the support of security forces. The enforcement phase included field inspection visits, the issuance of hundreds of fines for not installing meters, confiscation of several generators and even the arrests of some owners who were not implementing the required measures. As of March 2019, the MOET claims that $60 \%$ of all subscribers in Lebanon have installed meters, and that subscribers' invoices have almost been reduced by half. ${ }^{14}$

As for the role of municipalities, until the recent wave of regulations and enforcement, it was left to the municipal authorities to decide how they wanted to deal with generator networks within their jurisdictions. Prior to 2018, some municipalities either requested owners of generators to implement the monthly tariff published by the MOEW or issued their own tariff tables. Currently, all municipalities are being asked to implement the central tariff and metering regulations. Additionally, municipalities often register the monthly electricity cutoffs in their region to estimate an average monthly tariff for customers who choose not to install meters. In cases where generators have been confiscated, municipalities have stepped in to manage the operations of the generator's network until the owner obtains a legal clearance.

\subsection{New rules, new challenges}

The recently implemented metering regulations came with a set of technical and institutional challenges. The MOET, which is responsible for overseeing the implementation of the plan and making sure that consumer protection measures are respected, does so through a small monitoring team relative to the large number of generators and their spread across the country. More importantly, the MOET team seems to lack the technical expertise required to make sure the installed meters are functioning properly and that owners have not tampered with them, as has been reported in some cases. During a site inspection, the inspection team has to check the following:

- if the owner/operator has installed meters for all subscribers ${ }^{15}$

- if the installed meters fulfill the technical specifications set by the MOET

- if the invoicing system is well followed based on the new tariff and plan.

On the consumer side, metering has played a role in changing the behavior of consumers: given that both EDL's and private generator's electricity are now metered, with EDL being the cheaper one, consumers are likely to shift their energy consumption pattern to rely more on EDL's power, when available, to avoid the more expensive electricity delivered by private generators. Before the metering era, consumers preferred to use the generators' supply hours for tasks such as washing and water heating because they used to pay a flat rate regardless of their consumption. This behavior differential is expected to increase demands on EDL's service provision in the summer and winter, when demand picks up. This will likely affect EDL's transmission and place further strain on its distribution grid, potentially resulting in more unplanned outages, higher maintenance costs, and consequently increasing the share of power delivered by private generators

11 Some owners of diesel generators, especially municipalities, have installed meters even before the government push for them in 2018.

12 Based on a decree issued by the Council of Ministers on 14/12/2011.

13 Circular 11-1/2013. It specifies emissions' limit values and monitoring requirements of air pollutants and other conditions such as the minimal length of the exhaust stack.

14 This is based on an interview with MOET staff at the Ministry.

15 This is an issue that could not be easily verified since some subscribers either have agreed to continue paying the old flat rates, or were forced by owners to sign a paper that allows them to continue with the old tariff regime. 


\section{Box 1: Global Overview of Diesel Generators' Deployment}

Diesel generators are used in many countries and for different applications. The main driver for their use, however, is the lack of energy access and unreliability of supply. As in the case of Lebanon, the lack of energy access follows from a chronic under-supply of electricity that exposes the public to long hours of power outages. The gap between supply and demand of electricity, which resulted in the spread of informal and decentralized power systems that are based on diesel generators, often stemmed from under-investments in generation capacity and high losses in transmission and distribution.

According to a recent report by the International Finance Corporation (IFC) titled "The Dirty Footprint of the Broken Grid", 16 the total capacity of diesel generators in 167 developing countries (excluding China) is estimated between 350 to $500 \mathrm{GW}$, a massive capacity that is equivalent to around 1000 of large coal power plants. In some countries, electric capacity from diesel generators exceeded that provided by the national grid. The countries with the highest capacity of generators are Nigeria, India, Iraq, Pakistan, Venezuela, and Bangladesh. Together, these six countries account for over 50 percent of the electricity generated by back-up generators in the studied countries.

According to the IFC report, the operations of back-up generators come at high financial and environmental costs. In much of sub-Saharan Africa, spending on generators' fuel exceeded that on the maintenance and management of the national grid itself. For instance, Nigeria spends three times as much on back-up generator electricity as compared to the grid, and the Republic of Congo spends an astonishing nine times the amount. The financial impact and cost inefficiency become a more pressing issue when it involves government fuel subsidies as in the case of Iraq.

On the environmental front, the global annual emissions of back-up generators in the modeled countries mount to 100 megatons of $\mathrm{CO} 2$, which is around 20 percent of the emissions of the transport sector. The type of emissions released by generators are like those emitted by cars and trucks, however, the spread of generators in dense urban areas magnify their public health impact. Moreover, the smoke released by generators is a major contributor to air pollution in some parts of the world. The exposure to the particulate matter from all sources, including diesel generators, in low and middle-income countries is responsible for 2.5 million premature deaths annually. ${ }^{17}$

Beyond being a stopgap electricity access solution, back-up generators have been a conventional off-grid power solution, thanks to their relatively low upfront capital costs. In rural or remote areas where electricity grid extensions are not possible or very expensive, diesel generators have been deployed to provide an immediate access to electricity. However, the difficulty and cost of transporting the fossil fuel to those hard-to-reach areas pose a major challenge, let alone the intrinsic volatility of the fuel price.

The global experience in phasing out diesel generators revolve around two main actions: First, investing in energy capacity and transmission infrastructure. This action, coupled with implementing specific energy reforms, aims to improve the reliability and coverage of electricity supply. For example, in Iraq, current interventions aim to reinforce the transmission network to meet electricity demand and improve reliability of supply which would ultimately diminish the capacity provided by diesel generators in the targeted regions. ${ }^{18}$

The second action takes advantage of the lowering costs of renewable energy sources, particularly solar PV and electricity storage systems, to create an alternative market that uses distributed renewable energy to displace diesel generators or, in a transitional stage, save fuel through incorporating renewables in the operations of diesel generators through hybrid systems. Despite the promising future of distributed renewables to displace generators completely, market dynamics, especially in the developing countries, still require targeted interventions and financing that accelerate shifts to adopting renewables and storage solutions. The target, according to the IFC report mentioned above, are the first mover companies that have the capacity to benefit from market-based interventions to de-risk investments and to innovate products and business models.

16 International Finance Corporation. 2019. The Dirty Footprint of the Broken Grid The Impacts of Fossil Fuel Back-up Generators in Developing Countries. https://www.ifc.org/wps/wcm/connect/2cd3d83d-4f00-4d42-9bdc-4afdc2f5dbc7/20190919-FullReport-The-Dirty-Footprint-of-the-Broken-Grid.pdf?MOD=AJPERES\&CVID=mR9UpXC

17 Global Burden of Disease Study 2017. Global Burden of Disease Study 2017 (GBD 2017) Results. Seattle, United States: Institute for Health Metrics and Evaluation (IHME), 2017.

18 World Bank. 2019. Iraq - Electricity Services Reconstruction and Enhancement Project (English). Washington, D.C.: World Bank Group. http://documents.worldbank.org/curated/en/504001557108087756/Iraq-Electricity-Services-Reconstruction-andEnhancement-Project 


\section{Distributed Renewable Energy Development}

\subsection{Status and trends}

The growth of renewable energy (RE) for electricity generation in Lebanon is concentrated in the deployment of solar photovoltaic (PV), which accounts for almost all of the total non-hydro RE installed capacity. There are several reasons for this dominance by solar PV technologies. First, solar PV systems are modular, and therefore, can be installed at variable capacities, depending on space availability and budget. Second, PV systems have witnessed dramatic cost reductions in recent years. Turnkey costs of solar PV projects in Lebanon have plummeted from around $\$ 7,000$ per $\mathrm{kWp}$ in 2011 to around $\$ 800$ in $2018,{ }^{19}$ an $88 \%$ cost reduction in just eight years. Third, there is the country's climatic suitability. Lebanon benefits from around 300 sunny days in a year with 8 to 9 hours of sunshine during the day. ${ }^{20}$ Additionally, solar insolation levels are high across the country and range between 1,800 and $2,200 \mathrm{kWh} / \mathrm{m}^{2}$, where specific yield ranges between 1,400 and 2,000 kWh/kWp. ${ }^{21}$

Installed capacity of solar PV grew from almost zero in 2011 to around $47 \mathrm{MWp}$ in 2018. Subtracting the capacities of the Beirut River Solar Snake and the Zahrani Oil Installations projects, which account for 1.08 and 1.09 MWp, respectively, the remaining 44.8 MWp are all installed as decentralized systems. ${ }^{22}$

In terms of electricity generation, solar PV projects generated around $53 \mathrm{GWh}$, which is equivalent to $0.25 \%$ of Lebanon's total demand and $0.4 \%$ of EDL's total production. Despite this being a very modest contribution, it does highlight the rapid growth of the solar PV market in the country. However, the triple digit growth in installed capacity that had been reported in the years prior to 2017 has slowed down recently (a 50\% decrease year-on-year in 2017) due to the gradual increase of interest rates on the loans provided under the NEEREA mechanism, supported by BDL. ${ }^{23} 24$ In 2019 and 2020 , growth in solar PV projects is expected to stagnate as a result of the economic crisis. On the other hand, customs taxes were lifted on imported solar PV panels in March 2018, which could partly offset any growth slowdown.

Up to 2017, a total of 1,417 solar PV projects had been implemented in Lebanon. Most of these projects, in numbers and capacity, are of relatively small size. Almost $90 \%$ of projects are of a capacity below $50 \mathrm{kWp}$ and account for $27 \%$ of the total installed capacity. ${ }^{25}$ The sectoral distribution of the installed capacity in 2017 is shown in Figure 3. About 30\% of capacity, $12 \mathrm{MWp}$, is deployed by the industrial sector, followed by the commercial sector with $19 \%$ and the residential sector with $17 \%$.

It is not surprising that the industrial and commercial sectors are taking the lead in deploying solar PV systems. This is because of multiple factors: (1) both sectors often have more space available to install solar modules compared to residential buildings; (2) both sectors have access to capital and/or financing; and (3) they rely heavily on diesel generators for back-up power during EDL outages and installing solar PV could lower their total electricity bills substantially. ${ }^{26}$

19 The 2011 value is obtained from the "2017 SOLAR PV STATUS REPORT FOR LEBANON", while the 2018 value has been obtained from an interview with Elie Maalouf of EcoSys, one of Lebanon's largest solar PV companies.

20 Source: UNDP-CEDRO, 2013. Solar photovoltaic: Electricity for your house.

21 Variable sources but mainly interviews with solar companies.

22 Source: UNDP-DREG, 2017, LCEC, 2018

23 Rates have increased from zero to $2.75 \%$ now.

24 In 2017, 64\% of projects, by capacity, were funded by BDL's NEERA mechanism

25 Source: UNDP-DREG, 2017

26 An additional incentive, particularly for the commercial sector, is that operations are mostly conducted during the day and therefore, load profile is aligned with the availability of solar power, unlike the residential sector, which has its peak in demand in the evening hours. 


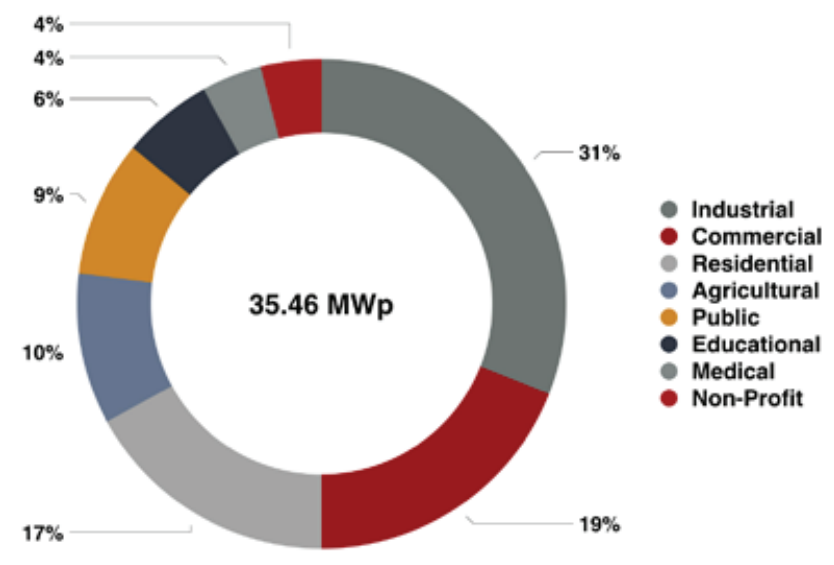

\subsection{Uses of distributed solar PV}

In terms of the split between different uses of the generated electricity, the majority of the distributed solar PV capacity $(63 \%)$ is deployed in an "on-grid" or "grid-tied" mode, meaning that it is connected to and dependent on EDL's grid. Gridtied systems offer the advantage of benefiting from the existing net-metering arrangement to lower electricity bills, as well as lowering installation costs. Currently, around $10 \%$ of projects deploy batteries, allowing them to function even if EDL's grid is not connected. This makes the installed solar system more flexible and captures more benefits from it; however, it also increases the costs due to the need to install added equipment and batteries. As the cost of storage continues to decrease and this mode of operation becomes more economically viable, its share is expected to increase.

Around $10 \%$ of the solar PV installed capacity in Lebanon is dedicated to water pumping. This highlights the potential coupling between renewable energy and resolving water access issues. This can directly benefit and be linked to the operations of water utilities and establishments, which are usually paying high costs for energy. ${ }^{27}$ Additionally, integration of renewables, especially solar PV, can help to mitigate disruptions of water services provision due to EDL power outages. On a smaller scale, solar water pumping can also be an effective tool implemented by municipal authorities and farmers to increase the energy efficiency in their water requirements. One advantage of such an arrangement is that unlike electricity, pumped water can be stored cheaply, offering an added layer of flexibility.

Based on the data collected by the UNDP-DREG project in $2017,9 \%$ of the installed capacity is deployed as "off-grid" or "off-grid with generator back up." These systems include batteries and therefore can function in an autonomous way. On the other hand, $8 \%$ of the installed capacity of solar PV is deployed in a "hybrid" mode where the PV modules are connected to a diesel generator network that is independent of EDL's grid. This mode is particularly valuable to entities that already rely completely on diesel generators for their power consumption. ${ }^{28}$ The primary incentive of this mode is fuel cost savings, which are higher than the savings, per kWh, generated by the net-metering arrangement if these systems were connected to EDL's grid, due to the vast cost differential between EDL's tariff and the cost of diesel generator electricity.

According to the UNDP-DREG 2017 data, in terms of geographical distribution, most projects (39\%) are in Mount Lebanon governorate, followed by Beqaa (19\%) and South Lebanon (14\%). It is interesting to observe that those regions, with the exception of Beqaa, are not as optimal in terms of topography (large areas are south facing) and solar insolation compared to regions such as Baalbak-Hermel. ${ }^{29}$ This shows the untapped potential for further deployment of distributed solar PV projects in inland regions. The current installed capacity is concentrated in Mount Lebanon mainly due to the strong presence of the industrial sector, which as shown in Figure 3, constitutes around a third of the 2017 deployed capacity.

27 In Lebanon, energy costs range between $30 \%$ to $50 \%$ of the total costs of water utilities. (Source: ongoing AUB study)

28 In interviews with dealers and agents of diesel generators in Lebanon, they mention that some of their clients, especially from industry, are competently reliant on diesel generators for their operations due to the high risk associated with unplanned interruptions of EDL's electricity.

29 According to interviewed solar companies, solar yield in Beqaa and Baalbak-Hermel is around 10\% higher than that in other regions. 


\subsection{Evolution of RE policies in Lebanon}

Over the past twenty years, Lebanon has initiated several laws and policies to promote the deployment of renewable energy. The evolution of these efforts is shown in Figure 4, and their description is given in Table B.2 (see Appendix B) below. In April 2019, the then newly formed government adopted an updated plan that is largely based on the 2010 Electricity Policy Paper. On the renewable energy side, the government plan committed to installing around $1 \mathrm{GW}$ of wind and solar electricity as follows:

- Wind: 220 MW by 2020 and 400 MW by 2023

- Solar PV: 180 MW by 2020 and 300 MW (with 210 MW of storage capacity) by 2022

- Distributed Solar PV: 45 MW by 2019

Figure 4: Major RE laws and government policies

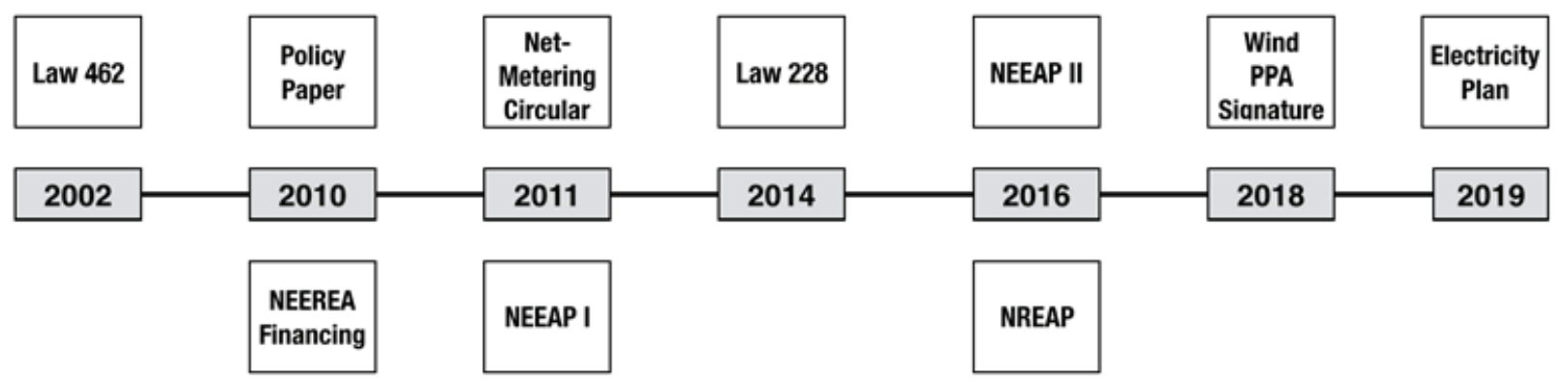

In parallel, the Lebanese Parliament extended Law 288 until April 2021 and amended Law 462 to provide a legal cover for projects to be tendered on Build, Operate \& Transfer (BOT) contract types. ${ }^{30}$ Prior to forming the government, Lebanese PM Hariri announced that $30 \%$ of Lebanon's energy mix will be covered by renewables by 2030 , without specifying how this goal will be reached. However, MOEW is already working on a plan to achieve this target with the support of the International Renewable Energy Agency (IRENA).

In 2002, Law 462 was ratified and provided the legal framework for privatization, liberalization and unbundling of the electricity sector. It built on Law 228 of 2000, which provided the governance structure for privatization operations, specifying its conditions and scope of implementation. Law 462 split the power sector into three components: production, transmission and distribution. While the transmission component was restricted to EDL, private production and distribution were allowed under the PPP terms of Law 228.

Law 462 also called for the establishment of a National Electricity Regulatory Authority (NERA), which is primarily mandated with licensing new power generation projects. Establishing NERA has been shelved for now with Law 288, the extension of which has given the MOEW and the MOF the ability to license independent power production for a two-year period until 2021. ${ }^{31}$ According to Law 462, self-generation of below $1.5 \mathrm{MW}$, be it from RE or other sources, is permitted. For IPPs with a generation capacity higher than $1.5 \mathrm{MW}$, the current arrangement is for their projects to be proposed by the MOEW (minister) and voted on by the COM. Consequently, the deployment of distributed energy generation such as rooftop solar PV systems, which are used for self-consumption, is legal as far as Law 462 is concerned.

In 2010, the COM adopted the Electricity Policy Paper, which was then ratified by Parliament through Law $181 / 2011$. The Policy Paper clearly stated the commitment to "launching, supporting, and reinforcing all public, private and individual initiatives to adopt the utilization of renewable energies to reach $12 \%$ of electric and thermal supply." This was soon followed by completing the wind atlas of Lebanon in 2011 and launching the IPP wind farm project, as well as studying the feasibility of establishing solar PV farms in the country. The Policy Paper also focused on the development of hydropower energy.

On the energy efficiency side, the 2010 Policy Paper committed to "the preparation and spreading of the culture for proper electricity use; adoption of national programs focused on demand side management as the basis for: effective energy use;

30 In 2014, the COM passed Law 288, giving the MOEW and the MOF the ability to license independent power production for a two-year period until the independent regulatory authority, defined in Electricity law 462/2002, is established. Furthermore, Parliament approved Law 54 in 2015, extending the duration of Law 288 until April 2018, which allowed the signing of the first Power Purchase Agreement (PPA) in this history of Lebanon with IPPs for a 200-MW wind farms in the northern governorate of Akkar.

31 Establishing NERA has in fact been one of the major sticking points in passing the recent 2019 Electricity Plan. The MOEW's argument for extending Law 288 is Lebanon's need to speed up its energy investments, and establishing NERA from scratch would cause major delays. 
peak shaving; load shifting; and demand growth control to save a minimum of 5\% of the total demand." This was reflected in launching initiatives related to the adoption of Solar Water Heaters (SWHs), Compact Fluorescent Lamps (CFL), and green financing mechanisms through the National Energy Efficiency and Renewable Energy Account (NEEREA). The currently implemented policy instruments are explained in Appendix A.

In 2015, at the $21^{\text {st }}$ United Nations Climate Change Conference in Paris, Lebanon signed the Paris Agreement, in which it pledged to reduce its national greenhouse gas (GHG) emissions through several non-conditional targets, in addition to targets conditioned on the provision of international support. Lebanon committed, unconditionally, to reduce its emissions by $15 \%$ and its power demand by $3 \%$ by 2030 . In 2016, the MOEW released the National Renewable Energy Action Plan (NREAP 2016-2020), which detailed the RE targets that are needed to reach the $12 \%$ RE share of by the year 2020.

Institutionally, there are many entities that deal with the deployment of RE in Lebanon, including several public institutions. Those institutions, and a brief description of their roles, are shown in Table B.3 (see Appendix B). 


\section{PART II: \\ THE DIESEL GENERATOR MARKET IN LEBANON}




\section{Value Chain and Market Size}

The total installed capacity of the diesel generator market in 2018 can be estimated by assuming that the entire power deficit, at peak demand, is covered by diesel generators; and that the growth rate of the market is the same as the growth rate of the gap between supplied and demanded electricity. Based on the data and assumptions in Table 2, the total installed capacity provided by diesel generators is 1,738 mega-volt amperes (MVA), covering around 1,320 MW of peak capacity. ${ }^{32}$

Table 2: Estimate of diesel generators' capacity in Lebanon (2018 data)

$\begin{array}{llc} & & \text { Value } \\ \text { Variable } & \text { Unit } & 3,456 \\ \text { Lebanon's Peak Capacity } & \text { MW } & 1,884 \\ \text { Production Capacity (EDL Plants) } & \text { MW } & 388 \\ \text { Production Capacity (Barges) } & \text { MW } & 240 \\ \text { Imported Capacity (Syria) } & \text { MW } & 2,512 \\ \text { Total Production Capacity } & \text { MW } & 377 \\ \text { Technical losses (15\%) } & \text { MW } & 2,135 \\ \text { Delivered Capacity } & \text { MW } & 1,321 \\ \text { Deficit Capacity } & \text { MW } & 5 \% \\ \text { DG distribution losses } & \% & 80 \% \\ \text { DG rated power factor } & \% & \mathbf{1 , 7 3 8}\end{array}$

\subsection{Size of the commercial diesel generator market}

The total installed capacity can be used to estimate the size of the diesel generator economy in Lebanon, which, as shown in Figure 5, can be divided into three main components: a commercial market where electricity is sold to consumers by operators who own diesel generators; a fuel economy that is mainly composed of diesel fuel importers and distributors; and a generator economy that consists of sales of generators and their spare parts and maintenance services.

Figure 5: Components of the diesel generators' economy

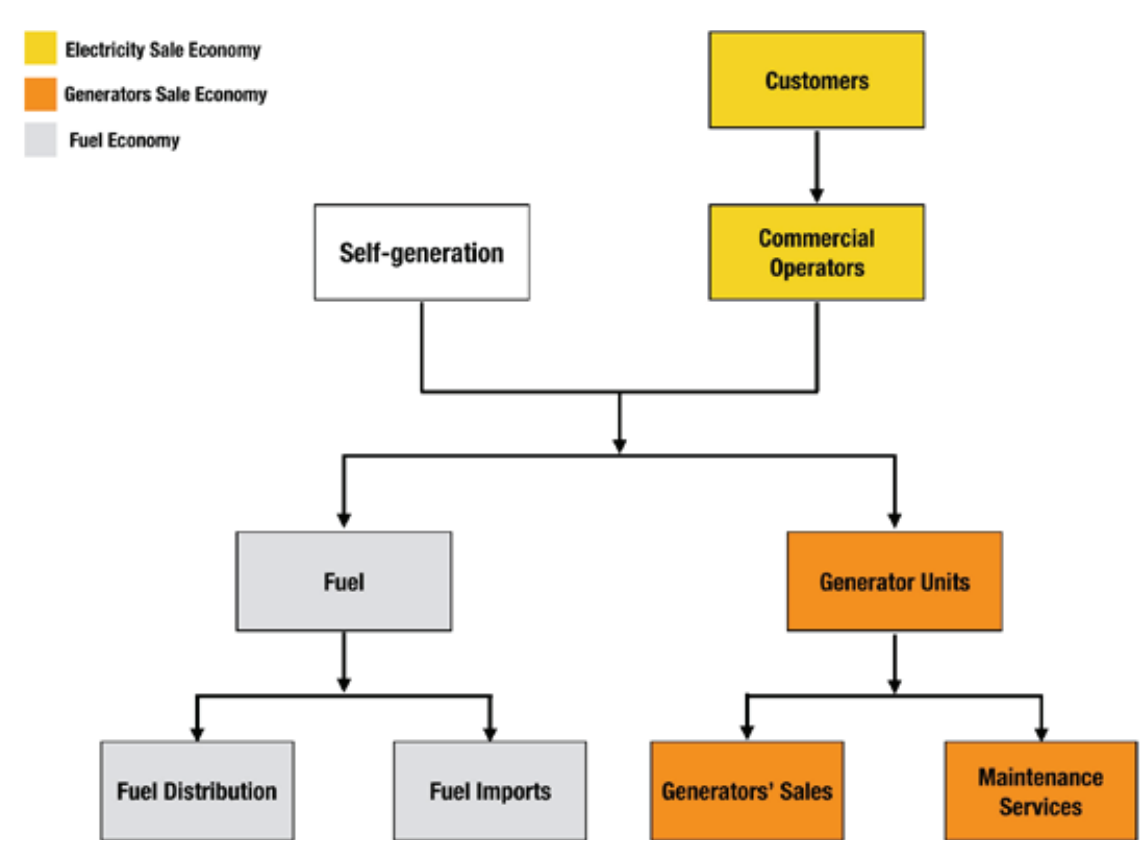

32 This total capacity includes both commercial and non-commercial generators. 
As shown in Table 1, diesel generators produced around 8.1 terawatt hours (TWh) of electricity in 2018. Assuming that commercial generators only provide electricity to residential and commercial customers, who are estimated to consume $66 \%$ of the total power supplied (same as the share of EDL's residential and commercial clients ${ }^{33}$ ); and assuming that $75 \%$ of the total residential and commercial customers rely on subscriptions to diesel generator networks (the rest rely on the self-generation model), ${ }^{34}$ the total purchased electricity by customers from commercial generators is estimated at 4 TWh.

Consequently, the variable income component of the commercial diesel generators market can be estimated by multiplying the MOEW's average monthly tariff in $2018(\$ 0.232 / \mathrm{kWh})$ by the total purchased electricity. This yields a value of $\$ 933$ million.

On the other hand, to estimate the fixed income component, one needs the number of customers subscribed to generator networks and their segmentation based on their number of amperes connected. Calculated based on the data and assumptions listed in Table 3, the estimated number of customers (subscribed households) is around 1.08 million. Consequently, the size of the fixed income component of the market is around $\$ 167$ million, giving a total commercial generator market size of $\$ 1.1$ billion (see Figure 6).

Figure 6: Diesel generators' retail market size and its breakdown

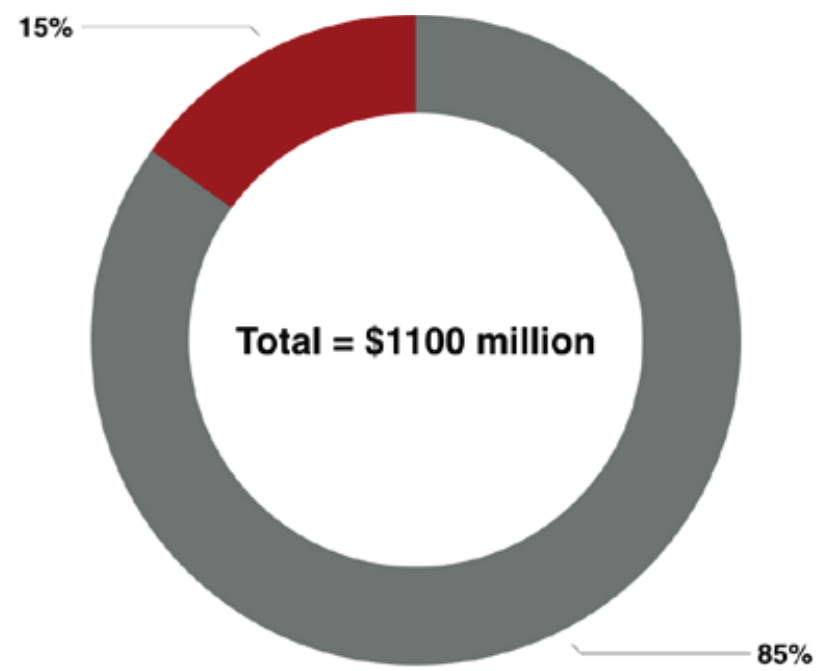

Variable Income

- Fixed Income

34 This assumption is based on insights gathered from interviews with owners of diesel generators and staff at the MOET. 
Table 3: Data and assumptions used to estimate the market size of commercial generator networks

\section{Variable}

Customer base (residential and commercial)

Residential and commercial segment

Percentage of residential and commercial customers relying on commercial generator networks

Power generated by commercial generators

Average tariff

Variable income

Capacity of a typical commercial generator

Residential load power factor

Generator rated power factor

Real power

Line to neutral voltage

Line to line voltage

Maximum potential current generation

Generator loading Level

Available current for delivery per phase

Standard unit

Maximum number of customers per phase

Total number of customers per 500 KVA

Estimated total number of customers

Assumed percentage of $5 \mathrm{~A}$ customers

Assumed percentage of 10A customers

Assumed percentage of $15 \mathrm{~A}$ customers

Monthly fixed fee for $5 \mathrm{~A}$

Monthly fixed fee for $10 \mathrm{~A}$

Monthly fixed fee for $15 \mathrm{~A}$

Fixed income

Total size of the commercial generator market

\section{Unit}

Value

$\%$

$\% \quad 66 \%$

$\% \quad 75 \%$

TWh 4

$\$ / \mathrm{kWh} \quad 0.232$

$\$ M$

933.6

KVA 500

A

611

0.85

519

A

5

104

312

\section{$1,082,720$}

$\% \quad 60 \%$

$\% \quad 25 \%$

$\% \quad 15 \%$

$\$ 10$

$\$$

$\$$

20

$\$ M$

167

$\$ M$

1,100

Based on these numbers, and assuming that consumers who own their own generators endure the same per kWh costs, one can quickly estimate the amount that could be saved by the public if EDL were to provide electricity around the clock. The current average tariff of electricity sold by EDL is around $\$ 0.09$ per $\mathrm{kWh}$. However, this tariff is below cost recovery and is likely to be increased as part of a broader reform program. Assuming the post-reform tariff is double the current one, i.e. at $\$ 0.18$ per $\mathrm{kWh}$, the tariff differential between EDL's and generators' electricity is $\$ 0.05$ per $\mathrm{kWh}$ and the savings can then mount to $\$ 404$ million per year. If the tariff differential doubles to $\$ 0.1$ per $\mathrm{kWh}$, the savings would reach $\$ 808$ million per year. These are substantial savings that can be used as a disposable income in a small economy like Lebanon's, with a GDP of around \$57 billion.

\subsection{Size of the generator sale and diesel fuel economy}

The commercial generator economy that is based on selling electricity to consumers is under the spotlight given the constant, often negative, interactions between the generator owners and customers on one hand, and between owners and the government and law enforcement institutions on the other hand. However, there are two other economic sectors 
that greatly benefit from the deployment of diesel generators in Lebanon: the fuel importers and distributors, as well as the manufacturers, agents and dealers who sell generator units, spare parts and maintenance services.

The fuel economy can be split into two main components: fuel imports and fuel distribution. The amount of diesel fuel imported and used to power diesel generators can be estimated based on the total electricity produced by generators ( 8.1 TWh), the average energy conversion rate ( $3.2 \mathrm{kWh} / \mathrm{L}$ ) and the price of diesel fuel (assumed at $\$ 0.66$ per liter)..$^{35}$ Therefore, the total value of generator-linked fuel imports in 2018 is estimated at $\$ 1.784$ billion (see Table 4).

\section{Table 4: Data and assumptions used to estimate fuel and generator sales economies}

\begin{tabular}{|c|c|c|}
\hline Variable & Unit & Value \\
\hline Deficit covered by diesel generators & TWh & 8.1 \\
\hline Generator network's T\&D losses & $\%$ & $5 \%$ \\
\hline Generation & TWh & 8.6 \\
\hline Average energy conversion rate & $\mathrm{kWh} / \mathrm{L}$ & 3.2 \\
\hline Estimated amount of diesel fuel & Liter & $2,674,249,342$ \\
\hline Price per Liter of fuel & $\$ / L$ & 0.667 \\
\hline Annual fuel costs & $\$ M$ & 1,784 \\
\hline Diesel fuel liter to ton conversion & L/ton & 1,177 \\
\hline Amount of diesel fuel in ton & Ton & $2,272,090$ \\
\hline Transport cost per ton & $\$ /$ ton & 10 \\
\hline Fuel transport costs & $\$ M$ & 22.7 \\
\hline DG lifetime & $\mathrm{H}$ & 15,000 \\
\hline Fuel consumption per hour & $\mathrm{L} / \mathrm{h}$ & 88 \\
\hline Energy generated over lifetime of a DG & $\mathrm{kWh}$ & $4,224,000$ \\
\hline $\begin{array}{l}\text { Total cost of maintenance services } \\
\text { (see Appendix E-1) }\end{array}$ & $\$$ & 54,138 \\
\hline Maintenance costs per kWh & $\$ / \mathrm{kWh}$ & 0.0128 \\
\hline Maintenance costs per year & M\$ & 109.7 \\
\hline Local generator sale market size & $\$ M$ & 49.4 \\
\hline
\end{tabular}

As for the fuel distribution economy, its size can be estimated using the total amount of diesel fuel distributed in metric ton and the cost of its transportation. Assuming a transportation cost of $\$ 10$ per $\mathrm{MT}^{36}$ the fuel transport economy is estimated at $\$ 22.7$ million.

The second component that is associated with the use of diesel generators in Lebanon is the sale of diesel generation units, their spare parts and maintenance contracts. The local market for generator sales in Lebanon is estimated by averaging the imports of generators over the last 10 years (2009-2018), which amounts to $\$ 98$ million per year, ${ }^{37}$ then multiplying this number by the percentage of domestic sales, which has been estimated at $50 \%$ based on data provided by generator's agents and dealers. Consequently, the generator sale market in Lebanon is estimated at $\$ 49$ million.

35 Diesel prices are issues weekly by MOEW based on the average last 4 weeks of Platts Med plus a premium to account for the cost of freight, insurance, etc.). It should be noted that the diesel prices are not affected by local supply and demand and are purely based on prices and variation of the international oil markets.

36 Source: interviews with owners of diesel generators

37 Based on data obtained from the Lebanese Customs Administration. 
Generator agents and dealers also provide spare parts and repair services. To estimate the market size of this segment, first the total lifetime maintenance cost of a typical 500 KVA generator ${ }^{38}$ has been calculated based on data obtained from owners of diesel generators (see Appendix E-1). The total cost is then divided by the total energy produced over the lifetime of the generator to obtain the average, per kWh, cost. The total value of the maintenance services market is calculated by multiplying the average per kWh cost by the total electricity generated (8.6 TWh, as calculated in Table 4). The estimated size of the auxiliary market of spare parts and maintenance services is around $\$ 110$ million per year.

In total, the market size composed of fuel imports and distribution, generator sales, and maintenance services is estimated at $\$ 1.964$ billion. Figure 7 shows the individual contribution of each segment with fuel imports contributing $91 \%$, followed by maintenance services with $6 \%$, generators' sale at $3 \%$ and, lastly, fuel distribution at $1 \%$.

Figure 7: Market size of diesel generators' supporting sectors ${ }^{39}$

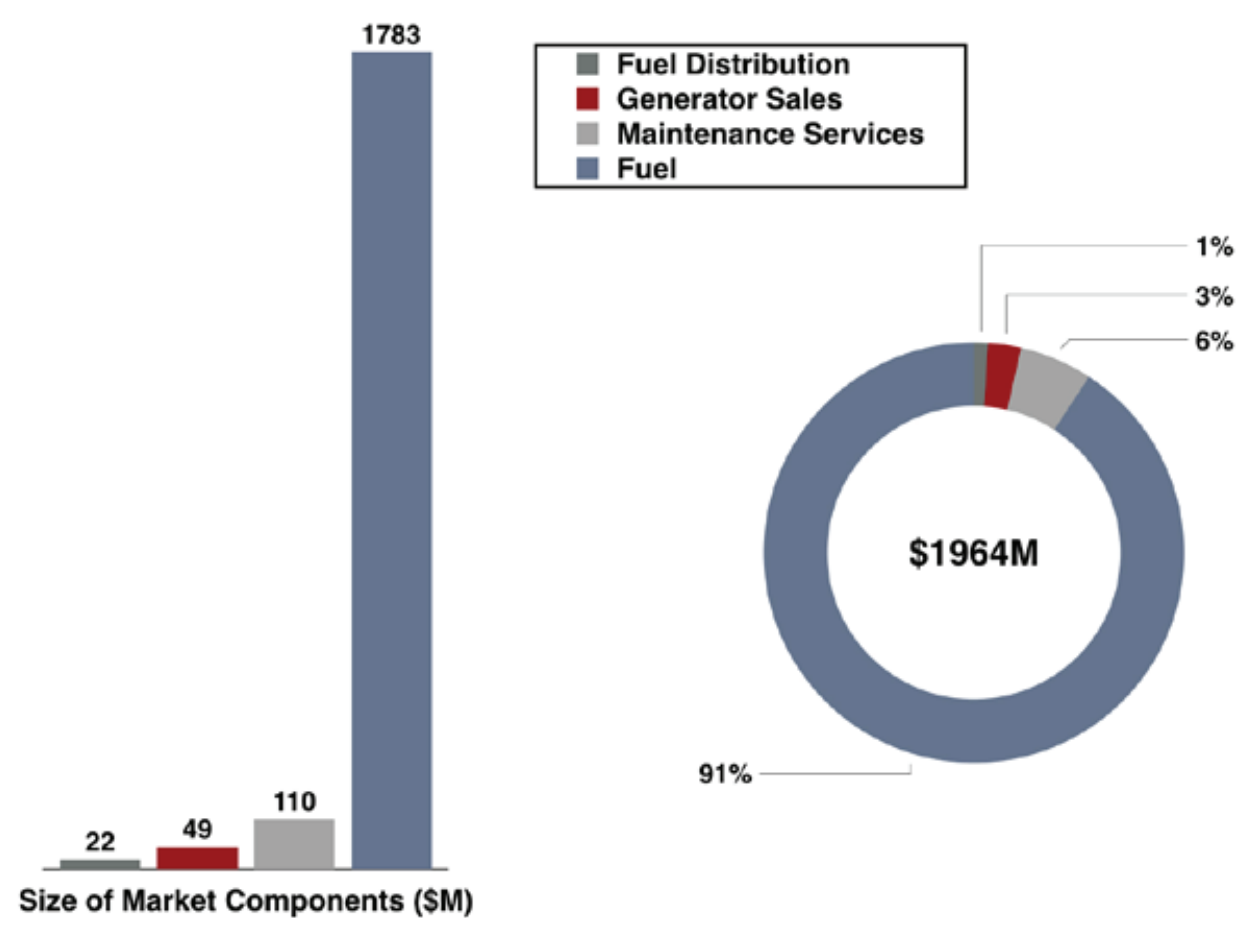

38 Typical DG is a 500 KVA, Volvo (more than $70 \%$ of DGs in Lebanon), located in a city setting.

39 It should be noted that this number is for the entire diesel generator sector in Lebanon, including privately and government owned generators (for all use and commercial purposes). 


\section{Box 2: Size of the labor force of Lebanon's diesel generators economy}

To estimate the size of the labor force in the generator economy in Lebanon, one needs to look again at the value chain and add up the size of each component. Figure 8 shows an estimate of the size of the labor force in each component of the value chain. For fuel importation, the total labor force is about 14,000 employees. ${ }^{40}$ Diesel imports (excluding public sector procurement) comprise about $30 \%$ of the total volume of petroleum products. Assuming a linear correlation between volume of imports and number of employees, the size of the fuel labor force is estimated at 4,200 .

Figure 8: Distribution of the labor force within the generators' economy in Lebanon

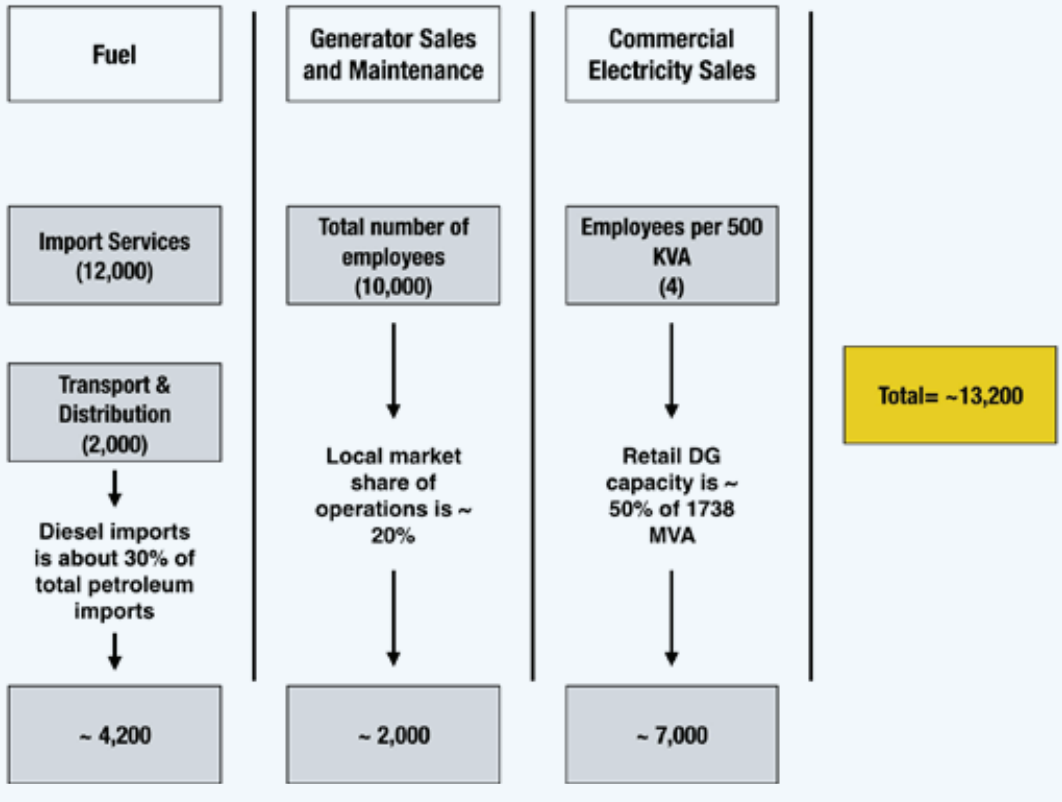

For dealers and agents, a large part of their operations involves assembling generators, a portion of which are shipped outside the country. The total industry workforce is estimated at 10,000 by information extracted from interviews with agents and dealers. ${ }^{41}$ The average percentage of local market share in the operations of agents and dealers is estimated at $20 \%$, again obtained from interviews, leading to an estimate of 2,000 employees directly connected to the domestic market.

As for the commercial operations, as discussed above, they contribute almost $50 \%$ of the total electricity produced by diesel generators in Lebanon. In terms of capacity, this translates into around 870 MVA. Based on interviews with generator owners, each 500 KVA generator requires three full time employees (two fee collectors/customer services staff and one technician). Adding the owner themselves, the number of employees becomes 4 . Dividing the 870 MVA by 500 KVA and then multiplying it by 4 gives us an estimate of the work force on the commercial side of around 7,000. Adding up the numbers of fuel, sales and maintenance, and commercial operations, the total size of labour force is estimated to be around 13,200 persons.

40 Source: Association of Petroleum Importing Companies (Lebanon), 2015

41 Jubaili Bros has 1500 employees and has around 15\% market share. Consequently, the total market labor force is estimated at 10000 . 


\section{The Business Model of Private Diesel Generators}

\subsection{Cost components}

The costs of the diesel generator business can be divided into three components: fixed capital costs, fixed operations and maintenance (O\&M) costs and variable $0 \& M$ costs. Clearly, these costs vary with location and generator capacity, as well as other factors such as the average load factor at which the generator is operating. However, in this analysis, cost assumptions are based on a 500 KVA generator located in an urban area. Discussion of the effects of variations from this baseline case is included below. ${ }^{42}$

The fixed capital costs of the commercial diesel generator business are listed in Table 5. The costs are aggregated into a single estimate of a fixed monthly payment. The monthly payment for each cost line has been calculated using the following formula:

$$
\text { Payment }=\frac{P V(\text { cost }- \text { salvage value }) r}{1-(1+r)^{-n}}
$$

Where $r$ is the discount rate (assumed at 10\%) and $n$ is the number of interest periods in months. Based on Table 5 , the highest contributors to fixed capital costs are that of the distribution infrastructure and the generator, respectively. The detailed cost breakdown of the distribution infrastructure is listed in Appendix E-2.

Table 5: Fixed capital costs of the commercial diesel generator business (500 KVA)

\begin{tabular}{|c|c|c|c|c|}
\hline Item & Cost (USD) & Lifetime (months) & Salvage Value & Monthly Payment \\
\hline $\begin{array}{l}\text { Generator Procurement and } \\
\text { Installation }\end{array}$ & 37,500 & 60 & 7,500 & 637 \\
\hline Earthing and Protection System & 2,500 & 240 & 500 & 19 \\
\hline $\begin{array}{l}\text { Ready to Use Office Procurement } \\
\text { and Installation }\end{array}$ & 6,500 & 240 & 1,300 & 50 \\
\hline $\begin{array}{l}\text { Fuel Tanks procurement } \\
\text { Infrastructure and Installation }\end{array}$ & 3,000 & 240 & 600 & 23 \\
\hline Generator Exhaust & 3,080 & 66 & 616 & 49 \\
\hline Complete Electrical Board & 5,000 & 120 & 1,000 & 53 \\
\hline Electrical Distribution Infrastructure & 47,374 & 240 & $9,474.8$ & 366 \\
\hline Transportation Motorcycle & 750 & 66 & 150 & 12 \\
\hline
\end{tabular}

The other fixed monthly set of payments paid by the owners of commercial generators is the fixed O\&M costs. Those costs are listed in Table 6. Again, the costs in Table 6 are representative of the typical, 500 KVA generator, case chosen, and they may vary in other cases. For example, in some cases generator owners may have to pay for rent or pay more than the assigned cost. The total of the fixed $0 \& M$ costs is about $\$ 1,900$ which is roughly split between land rental and staffing costs. Any economies of scale benefits in the generator business are likely to be captured in these cost components.

42 The cost assumptions and methodology adopted in this analysis is largely based on the legal study done by Eng. Marwan Ghantous that was submitted to Judge Roula Chamoun. However, some cost assumptions and methodology components have been modified based on information collected from generator owners, dealers and agents. 
Table 6: Fixed monthly 0\&M costs of the commercial diesel generator business

Item

Full-time staff for fees collection and customer Service

Part-time technician

Land rental cost

Various office fees

Electricity and water utility fees

Fuel for transportation motorcycle

Phone charges

Insurance for staff

Insurance for generator

Total Cost (USD/month)

\section{Total Cost (USD/month)}

400

400

750

100

50

50

75

25

66

$\sim 1900$

Summing the fixed capital and O\&M costs, they add up to $\$ 3,125$ per month. As estimated above, a 500 KVA generator can deliver electricity to around 312 customers with $5 \mathrm{~A}$ lines. Consequently, the fixed cost, per customer, is about $\$ 10$, which is exactly the fixed cost specified by the MOEW.

As for the variable, per kWh, costs, those are shown in Table 7. The numbers are based on a generator's lifetime of 15,000 hours. The details of each cost line are listed in Appendix E-3. Approximately, $94 \%$ of the variable costs are attributed to the cost of fuel. For a diesel fuel price of $\$ 0.67$ per liter, the total variable cost is $\$ 0.22$ per $\mathrm{kWh}$. If the price of diesel decreases or increases by 5,000 Lebanese pounds (LBP) per 20L, which is the equivalent of a decrease or an increase of $\$ 0.167$ per liter, the variable cost range would be between $\$ 0.17$ and $\$ 0.27$ per $\mathrm{kWh}$, respectively. The percentage breakdown of the fixed and variable costs is shown in Figure 9.

Table 7: Variable 0\&M costs of the commercial diesel generator business

\begin{tabular}{ll} 
Variable Costs & Value (USD) \\
\hline Total non-fuel costs & 59,139 \\
Cost of fuel & 884,400 \\
Energy generated over lifetime of a DG (kWh) & $4,224,000$ \\
Total Variable Cost (\$/kW) & $\mathbf{0 . 2 2}$
\end{tabular}

Figure 9: Breakdown of fixed and variable costs of the diesel generator business

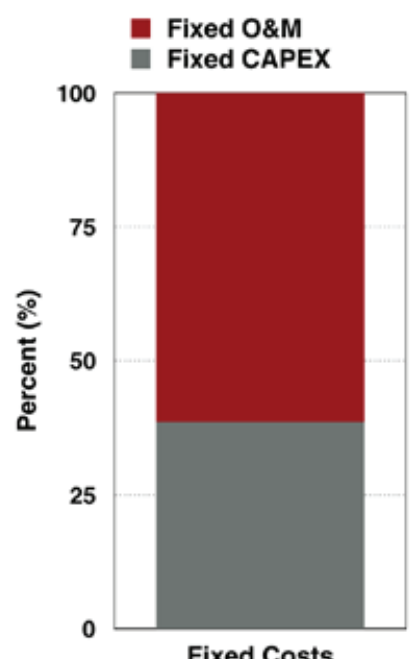

Fixed Costs

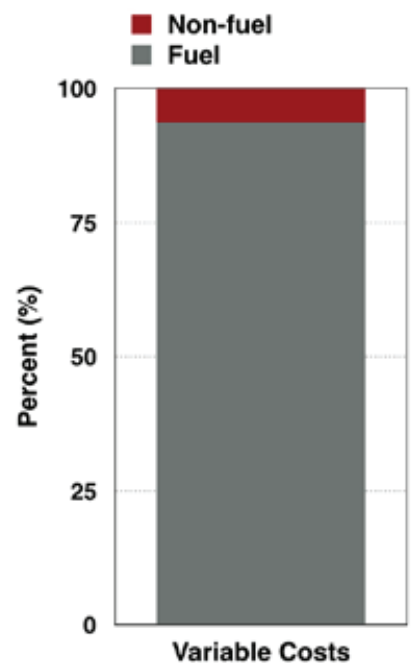




\subsection{Revenue streams}

The revenues of the generator business depend on the scale of the network, its capacity and the number of customers. The total revenue is equal to the sum of the fixed and variable revenues.

\section{Total Revenue $=$ Fixed Revenue + Variable Revenue}

The fixed revenue can be estimated by multiplying the number of customers in each fixed charge category, Si by the fixed charge of each category, Pi., where $i$ is the subscription category: 5A, 10A, 15A

$$
\text { Fixed Revenue }=\sum_{i} S i \times P i
$$

Based on interviews with owners of generator networks, an approximate split of their customer base is as follows: ${ }^{43}$

- 5A: $60 \%$ of customers

- 10A: $25 \%$ of customers

- 15A: $15 \%$ of customers

The fixed charge in each category is determined by the monthly tariff structure announced by the MOEW. The current fixed charges, $P i$, are 15,000, 23,000 and 30,000 LBP, for 5A, 10A and 15A, respectively. ${ }^{44}$ For the 500 KVA typical case we are considering in this analysis, the total number of customers is estimated at 312. Applying the above split percentages and fixed charges, the total fixed revenue is about $\$ 4,000$ (see Table 8 for detailed revenue breakdown).

On the other hand, the variable revenues can be estimated by multiplying the number of kilowatt-hours generated over a specific period by the average variable tariff set by the MOEW:

The total number of kWh generated over the lifetime of the generator (15,000 hours) is estimated at 4.224 million using the following formula: 45

Therefore, the monthly energy production is $70,400 \mathrm{kWh} .{ }^{46}$ Assuming that $5 \%$ of the generated power is unbilled, the monthly billed energy generated is $66,880 \mathrm{kWh}$. The monthly revenues collected by selling electricity are then estimated at around $\$ 18,000$. Similarly, the revenues of owners of generator networks of other capacities can be estimated. The breakdown of revenues in 100, 500 and 5000 KVA cases, representing three type of generator owners, is shown in Figure $10 .{ }^{47}$ The disparity in monthly income between small, medium and large generator owners is staggering. As expected, the higher the capacity of the network, the higher the share of the variable revenue component, benefiting from economies of scale and lower fixed costs per KVA installed.

Table 8: Revenues of a 500 KVA diesel generator

\begin{tabular}{lll} 
Variable & Unit & Value (500 KVA) \\
\hline Energy generated over lifetime of a DG & $\mathrm{kWh}$ & $4,224,000$ \\
DG lifetime & $\mathrm{H}$ & 15,000 \\
Unbilled electricity & $\%$ & $5 \%$ \\
Billed electricity & $\mathrm{kWh}$ & $4,012,800$ \\
Monthly billed electricity & $\mathrm{kWh}$ & 66,880 \\
Number of customers & $\% 12$ \\
Assumed percentage of 5A customers & $\%$ & $30 \%$ \\
Assumed percentage of 10A customers & $\%$ & $25 \%$
\end{tabular}

43 The split of the DG network customers' base is highly dependent on their type (residential vs commercial) as well as on how affluent the area is. In affluent areas, customers often require 15A, or more to power their bigger houses and appliances.

44 Currently, the tariff structure adds 5,000 LBP for each additional 5A beyond 15A.

45 For 500 KVA generator, the fuel consumption rate is 88 liters per hour at $85 \%$ load and the energy conversion rate is 3.2 $\mathrm{kWh} /$ liter.

46 This assumes no depreciation occurs.

47100 KVA represents the capacity of a small size generator business, 500 KVA represents the medium size and the 5,000 KVA represents the large generator business. 
Assumed percentage of 15A customers

Monthly fixed fee for $5 \mathrm{~A}$

Monthly fixed fee for $10 \mathrm{~A}$

Monthly fixed fee for $15 \mathrm{~A}$

Monthly fixed income from 5A

Monthly fixed income from 10A

Monthly fixed income from 15A

$\$ 934$

Total monthly fixed income
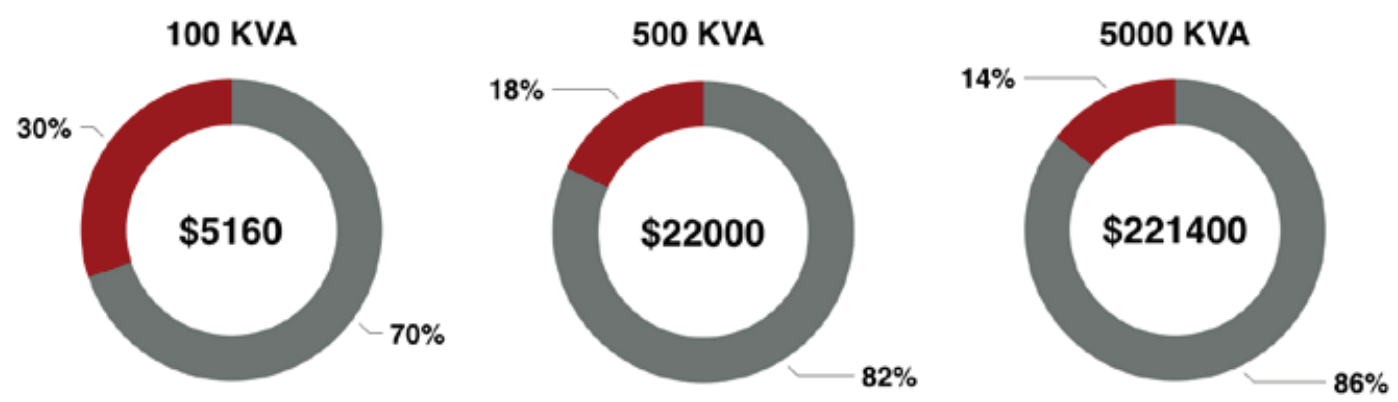

Variable Revenue

Fixed Revenue

\subsection{Profits and profit margins}

Similar to the cost and revenue parts above, the profit margins earned by the owners of diesel generator networks can be split into two components: a fixed, per-customer component, and a variable, per kWh, component. Table 9 shows the estimate of the fixed earnings, around $\$ 2.80$ per customer, based on the 500 KVA case. If the scale of operations is smaller, this number is expected to be lower. Conversely, if the scale of operations is higher, the fixed, per customer, earnings are expected to increase.

Table 9: Fixed earnings per customer (based on 500 KVA DG)

\begin{tabular}{lll} 
Item & Unit & Value \\
\hline Number of customers & & 312 \\
Total monthly fixed income & & $3,997.4$ \\
Fixed O\&M costs & $\$$ & $1,916.0$ \\
Fixed capital costs & $\$$ & $1,209.2$ \\
Fixed profit per customer & $\mathbf{\$}$ & $\mathbf{2 . 8 0}$
\end{tabular}


As for the variable component, the profits can be estimated by multiplying the difference between the breakeven cost ( $\$ 0.22$ per $\mathrm{kWh}$ ) and tariff set by the MOEW by the number of $\mathrm{kWh}$ produced in a specific period. As discussed above, the monthly billed generation of a $500 \mathrm{KVA}$ generator is estimated at $66,880 \mathrm{kWh}$. Based on the latest tariff of $405 \mathrm{LBP}$ (March 2019), which is equivalent to $\$ 0.27$, the average variable profits per 500 KVA can be estimated at $\$ 3,344$ per month. Adding up the fixed and variable profits, the monthly income from a single $500 \mathrm{KVA}$ generator is around $\$ 4,218$ per month, or $\$ 50,611$ per year, a number that is almost four times the annual household median income. ${ }^{48} 49$

Clearly, the earnings of owners increase with the increase of their installed capacity. This is not only due to the increased number of customers and electricity sold, but also due to lower fixed costs, benefiting from economies of scale. Figure 11 shows the difference in the scale of revenues and profits as the owner's installed capacity increases. While the income of the owner of a small generator of $100 \mathrm{KVA}$ capacity is between $\$ 4,000$ and $\$ 5,000$ per month, depending on the average load factor during that month, the income of a mega owner with a capacity of 5,000 KVA is between $\$ 211,000$ and $\$ 160,000$ per month.

Figure 11: Revenues before and after implementing the new metering system
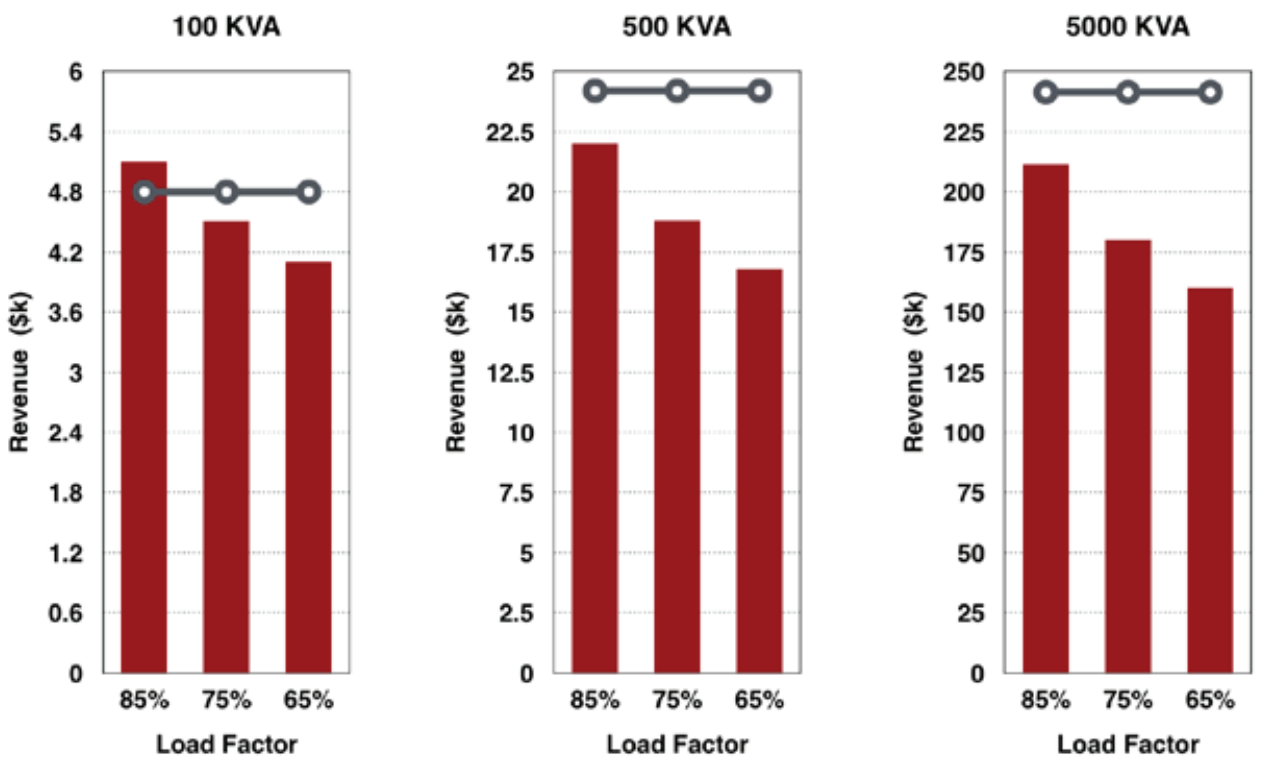

- Flat charge

- New variable charge

Figure 11 also shows the impact of the newly implemented tariff system on the profitability of generator owners. For owners with relatively small capacities such as $100 \mathrm{KVA}$, the difference is minor. However, as the capacity increases, the metering system substantially reduces the profits of generator owners. For example, for the owners of 500 KVA, their profits were reduced by $9 \%$ at an average generator load of $85 \%$ and by $32 \%$ at a load of $65 \%$. Clearly, on the old flat fee system, generator owners made substantial profits when operating their generators at lower loads (lower fuel costs). Their profits would have been boosted further should fuel prices have plummeted. In the case of mega owners, the new tariff structure would have the same impact in terms of percentages, but their losses are much more substantial in absolute value. For the owner of 5,000 KVA, their profits would have been reduced by about $\$ 80,000$ a month.

In the new metering system, lower load factors mean lower profits, since profits are linked to the number of kWh generated. This disparity between the old and new tariff systems explains why generator owners were very frustrated and dismayed by the government decision to enforce metering and the adoption of the MOEW tariff structure.

In addition to the clear effects of load factors and fuel prices, there are other factors that also affect profits but with lower impacts. One such factor is the socio-economic status of the customer base. In areas with higher average income, customers' willingness to pay is higher and consequently they are likely to consume more. Additionally, the geographic location of the generator network also affects profits through its impact on costs. For example, the distribution infrastructure costs in rural regions are expected to be higher than those in urban setting due to the need to cover areas with more a dispersed and less dense population.

48 In 2014, the annual household median income was estimated at \$13,000. See: https://www.byblosbank.com/library/ assets/Gallery/Publications/LebanonThisWeek/Lebanon\%20This\%20Week_339(1).pdf

49 On the other hand, supporting staff such as fee collectors and technicians earn $\$ 4,800$ and $\$ 8,000$ per year, respectively. 


\section{Ownership Models and Structures}

Initially, to substitute for EDL's electricity during outages, people relied on small electric generators placed on balconies, sidewalks, and in front of street shops. As these caused high levels of noise and tension in populated areas, some forms of organized private generator networks started to emerge. Medium to large-sized generators were introduced by street-smart individuals who had the necessary experience and knowledge to deal with the potential difficulties and dangers of an urban environment. The sector has rapidly grown across the country as its potential profitability became clear. Consequently, diesel generators can now be found almost everywhere: basements, parking lots, alleyways, next to residential and institutional buildings, etc.

Historically, three models of commercial generator networks ownership were formed: (1) a private "entrepreneurship" model that is largely composed of street-savvy owners; (2) a cooperative model by which a number of residents, who often live in the same building, decide to buy and operate their own diesel generator and share the corresponding costs; and (3) a municipal model where local authorities such as municipalities either started owning DGs as soon as a need for them arose or bought the generator network from an existing private owner and start providing electricity as a municipal service.

The comparison of these three models is summarized in Table $10 .{ }^{50}$ For private owners, they often operate on a relatively large scale (between 60 and 5,000 KVA of capacity) and provide power subscription service to hundreds or thousands of customers. Because of the private model's business-oriented approach, the relative cost to customers, compared to the other ownership models, is high and its social acceptability is low. ${ }^{51}$ The cooperative model operates on a lower scale that is often based on the need of a single building or a subset of a neighborhood. As such, the fees paid by subscribers are usually cost recovery fees, which ultimately translates into a better perception of the service provided. As for the municipal model, it falls somewhere in the middle between the private and cooperative models in terms of relative costs and acceptability. The scale of municipal operations is relatively large and can cover hundreds, if not thousands of customers.

Table 10: Characteristics of the different DG ownership models

\begin{tabular}{llll} 
Ownership Model & Private & Cooperative & Municipal \\
\hline Relative scale & Large & Small & Large \\
Relative cost to customers & High & Low & Medium \\
Relative acceptability & Low & High & High \\
\hline
\end{tabular}

In most cases, a neighborhood or a town is shared among multiple generator owners who have an implicit agreement on the limits of their respective "territories." The origin of such limits is mainly economical: to lower transmission losses and infrastructure costs, private generator owners often locate their generators within a proximity of $500 \mathrm{~m}$ to their customers. Sometimes, these limits are set by sectarian and demographic boundaries. ${ }^{52}$

In other cases, generator owners have expanded their networks to the extent of owning hundreds of generators and delivering electricity to thousands of customers. Based on interviews with generator owners, those "mega" owners have managed to expand their networks to such a scale via three main methods: (1) forging strong connections with local law enforcement and municipal authorities; ${ }^{53}$ (2) expanding within a relatively homogenous area demographically; and (3) being able to gradually benefit from economies of scale that provided them with substantial cost savings and allowed them to invest in expanding their networks. ${ }^{54}$

50 Private large commercial and industrial ownership is not included

51 "Relative social acceptability" in this context refers to the perception of the end-users of the entity that owns the generator network in the three models examined.

52 For example, in the Municipality of Hadath in Mount Lebanon, the geographical coverage of generator networks is split between different operators who belong to the same sectarian distribution.

53 Owners of generators often provided powerful connections such as army and police officers, municipal streets as well as churches and mosques, with free electricity. Now, with meters installed, owners have voiced their discontent with such arrangements, which led many of them to stop offering such free services.

54 For example, some of the big owners procure and import their own diesel fuel in huge quantities. 


\section{Box 3: Union Arrangements}

As the private generators' sector expanded, owners established their own support and coordination channels. This included the formation of a syndicate-like body (تجمع أمحاب المولدات), which played a prominent role in galvanizing owners in the face of the recent government crackdown on non-metered generation. ${ }^{55}$ This body, formed in August 2017, added a formal layer of cooperation among generator owners. In the past, coordination was mainly about delineating boundaries of territories within which they sell their subscriptions.

Currently, out of the total of 3,000 diesel generator owners ${ }^{56}$, around $50 \%$ of them are members in the syndicate. However, some enlisted owners have left the syndicate for various reasons, such as disagreements over tactics, approaches and conflicting interests. For example, not all members agreed to cut off power in protesting the government's measures. An interesting observation is that most of the group's members are considered "smallscale" operators. ${ }^{57}$ "Mega" operators, with tens of generators and thousands of subscribers have their own channels of exerting influence and voicing their interests.

\section{Political Economy Considerations}

Throughout the years, the coalition of the generator owners' networks and their tight coordination have created a complex business-power structure that has been resistant to regulations and reforms. Built on mutual interests, this structure greatly benefited from prolonged periods of policy inaction and strengthened its hold by building robust relationships with politicians, security forces, judiciary power, municipal officials, and fuel importers. The expansion of the private generator networks indeed created some job opportunities, especially in the repair services and fuel distribution sectors, including for technicians, engineers, part-time collectors, night guards, etc. However, the economic movement the sector created was informal and outside the government taxing system and official banking route. ${ }^{58}$

\subsection{Overview of political economy challenges}

Although the challenges of Lebanon's energy sector can be expressed in technical terms and quantified in numbers, they originate from deep-rooted political economy challenges. These challenges, shown in Figure 12, are reflected in the sector's poor governance and management since the beginning of the post-war reconstruction efforts. Ultimately, the biggest challenge that spans over the whole period since early 1990s until today has been the diffused decisionmaking in which no single entity of power has been politically accountable for the sector's failings. Even the responsible consecutive ministers often cited external factors that limited their ability to make a change. The effects of such a confessional and diffused political system cannot be overstated and have resulted in two major shortcomings: (1) lack of reforms, especially with respect to increasing tariff levels to close EDL's cost-recovery gap; and (2) failure to address EDL's challenges on the technical, human capacity and management levels.

Figure 12: Political economy challenges of Lebanon's energy sector

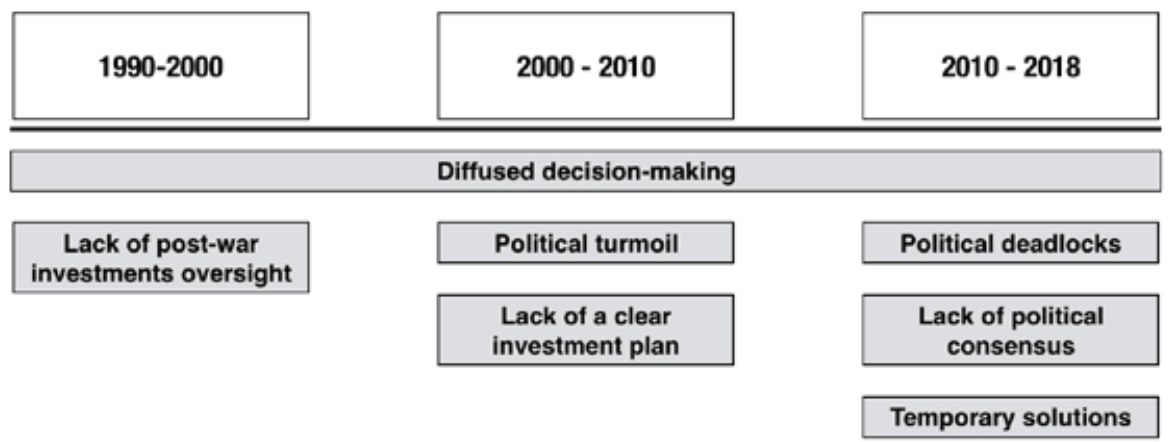

55 Although the group of owners of diesel generators functions within itself as a syndicate, they cannot be legally recognized as a "syndicate" since members are parties in an illegal sector. As far as the government is concerned, the group is an "illegal entity" (كيان غير قانوني).

56 This number has been provided by the group that represents DG owners and has not been verified.

57 In this context, small-scale refers to having 200 or less subscribers.

58 However, the treasury earns indirect income through taxes collected on imports of fuel, generators, spare parts, etc. 
Compounding the effects of the lack of political accountability, there have been other challenges that have also contributed to the current dire state of the country's energy sector. In 1990s, the influx of capital into the sector was ineffective in building a modern energy utility and generation fleet. Additionally, early investments were not followed through on, resulting in an incomplete transmission network.

Between 2000 and 2010, the energy sector was affected by the political turmoil that engulfed Lebanon - the assassination of Prime Minister Rafic Hariri and Israel-Lebanon war, and political instability, notably in 2007. In this period, there was a lack of a clear investment plan to keep up with increased demand and deal with EDL's losses.

In 2010, the energy sector policy plan was endorsed by the government and did provide some generic pathways to invest in the sector while tackling the thorny issue of reforms.

However, from the time of the parliamentary elections in 2009 up to 2018, Lebanon faced several political deadlocks. ${ }^{59}$ These deadlocks exacerbated the challenges faced by the energy sector, especially in dealing with EDL's spiralling costs. Even when a new president was elected and governments were formed, lack of consensus and political bickering were instrumental in deepening the energy crisis. Additionally, the introduction of temporary solutions (power ships) did affect the dynamics as they were perceived as comfortable way to partly fill the power deficit at a lower price than that of EDL. ${ }^{60}$ This has resulted in shifting these power ships from a short-term to a long-term solution.

Consequently, the political economy aspects of the commercial and wider diesel generator market and its connections with the fuel importation and distribution market are directly related to the holistic political economy of the energy sector in Lebanon, especially to that of EDL. The answer to the question of why generator networks exist lies in the failings of the governance of the wider energy sector in Lebanon, particularly in dealing with EDL and its persistent challenges. After all, generator networks are filling a gap that has been created by poor governance and management of the sector, as well as by the lack of much needed reforms.

\subsection{Actors, influences and interests}

Despite the overshadowing political economy of the larger energy sector in Lebanon, there are existing political economy dynamics that go beyond EDL and its pitfalls. Table 11 lists the main actors who are involved in the existence of generator networks in Lebanon, their type and perceived influence and visibility. ${ }^{61}$

It is interesting to note that the private sector actors who benefit the most from the existence of diesel generators - fuel importers and dealers and agents, who together account for around $\$ 2$ billion of revenue per year (see Figure 7) - are the least visible actors. ${ }^{62}$ In the public discourse, the owners of generator networks were often in the spotlight and therefore received high attention by the media.

Table 11: Main actors, their type and perceived influence and visibility

$\begin{array}{llll}\text { Actor } & \text { Type } & \text { Influence } & \text { Visibility } \\ \text { DG owners } & \text { Private sector } & \text { Variable (local) } & \text { High } \\ \text { Fuel importers and distributors } & \text { Private sector } & \text { High (national) } & \text { Low } \\ \text { DG dealers and agents } & \text { Private sector } & \text { Low (national) } & \text { Low } \\ \text { Key Ministries (MOEW, MOET, MOE) } & \text { Public sector } & \text { High (national) } & \text { High } \\ \text { Local authorities } & \text { Public sector } & \text { High (local) } & \text { High } \\ \text { Political Parties } & \text { Political entities } & \text { High (local and national) } & \text { High }\end{array}$

59 These deadlocks included staying two years and a half without a President between May 2014 and October 2016, and almost a year without a government following the election of President Aoun in October 2016.

60 In 2018, the average cost of EDL's electricity was around 16 cent per kWh, while purchased power from barges was at 12 cents per kWh.

61 The perceived influence and visibility are based on the author's interviews with all stakeholders for this study as well as the public discourse around the issue of diesel generators in Lebanon reflected in media articles and interviews.

62 In fact, arranging for interviews with fuel importers and generator agents and dealers has been much more challenging compared to other actors. 
In terms of influence, fuel importers exert a high influence on the national level. Their influence is based on two main factors: (1) these companies and the fuel that they import form a substantial and direct source of income to the government's treasury through customs, income and VAT taxes; (2) the overlap between the shareholders of these companies and the political establishment in the country. While this overlap is most visible when a politician or a political affiliate owns shares in these companies, directly or indirectly, there is a less pronounced overlap that is channeled through donations to political and religious institutions, philanthropy work and nepotism. The list of the importing companies and their market share is shown in Table 12.

The owners of commercial generator networks exert high influence, but mostly on the local level. As mentioned above, the influence of generator owners is forged though building strong connections with local authorities and law enforcement officers. In some cases, the mayor or a member of a municipal council owns the generator network. ${ }^{63}$

When it comes to mapping the interests of each of the main actors, the situation becomes a bit more complex. While generator owners, fuel importers and generators' dealers and agents have a clear interest in continuing with the status quo, the real interests of the other actors are less clear. This is mainly because of the possibility of a conflict of interest between the institutions and the individuals they are run by (ministers, mayors, law enforcement officers, etc.). Sometimes, this conflict of interest emerges from the political oversight of a party leader or a close crony affiliate.

Table 12: Diesel fuel importers and their market share (2018 data)

$\begin{array}{lll}\text { Importer } & \text { Share } & \text { Capacity (MT) } \\ \text { Uniterminals } & 22.40 \% & 393,232 \\ \text { Liquigas } & 14.10 \% & 247,525.5 \\ \text { Cogico } & 12.30 \% & 215,926.5 \\ \text { Coral Oil } & 10.60 \% & 186,083 \\ \text { Medco } & 9.80 \% & 172,039 \\ \text { Total Liban } & 6.90 \% & 121,129.5 \\ \text { IPT } & 6.00 \% & 105,330 \\ \text { Gefco } & 5.30 \% & 93,041.5 \\ \text { Wardieh } & 4.40 \% & 77,242 \\ \text { Mediterranean Petr.Co. } & 3.80 \% & 66,709 \\ \text { Apec } & 3.30 \% & 57,931.5 \\ \text { Universal Gas } & 1.10 \% & 19,310.5\end{array}$

On the flip side, changing the status quo by implementing a tariff structure that is fair to the consumer, installing meters or even providing EDL's electricity around the clock, is perceived by the political elite as an important move that could return substantial political gains, particularly to the concerned ministries such as the MOEW.

Given the negative perception of the owners of generator networks within the public as well as their dispersed and local influence, it is unlikely that the owners of generator networks will receive political support. Indeed, no political party is voicing support for the owners inside or outside of policy making rooms.

63 In an interview with staff at the Ministry of Economy and Trade, they stated that the municipalities that have not been cooperating with the Ministry's implementation of the regulation to install meters in diesel generator networks are often those with mayors who either own the generator network or close to those who own it. 


\section{PART III:}

THE POTENTIAL AND ECONOMICS OF DISTRIBUTED SOLAR PV 


\section{Economics of Distributed Solar PV for Lebanon}

\subsection{Value propositions of distributed solar PV}

Globally, distributed (or decentralized) energy systems, which do not require connection to high-voltage transmission lines, bring in a set of value propositions, which differ in scope and magnitude in different contexts and markets. In Lebanon, there is already some reliance on distributed power generation due to the wide use of diesel generators that cover the deficit between supply and demand. However, as explained earlier, there are a number of serious issues associated with the use of diesel generators such as their high costs, polluting and noisy operations, and the informal economy that has sprung up around them and has been resistant to regulations and reforms.

Table 13 summarizes the potential benefits that can be achieved through scaling-up distributed solar PV systems in Lebanon. Distributed systems can lower (or defer) investments in expensive grid upgrades. Additionally, they can reduce the need for installing expensive peaking capacity, which only runs during periods of peak demand. Figure 13 plots the yearly (normalized) variations of solar irradiation and electricity consumption, based on real data collected on 2200 buildings in Beirut City. Both profiles overlap nicely with maximum demand in summer months coincides with maximum irradiation in the same period. ${ }^{64}$

Table 13: Potential added values of distributed renewable energy systems

\section{Added Value}

Lower generation and transmission investments

Net costs savings

Reduce exposure to fuel price volatility

Improved energy security

Short lead-time

Lowering air pollution and noise

Change in social attitude towards RE

New business opportunities

\section{Major Beneficiary}

Treasury/EDL

Consumers

Treasury/Consumers

Consumers

Consumers

Consumers

Society at large

Private sector

Figure 13: Yearly profiles of solar irradiation and consumption (normalized)

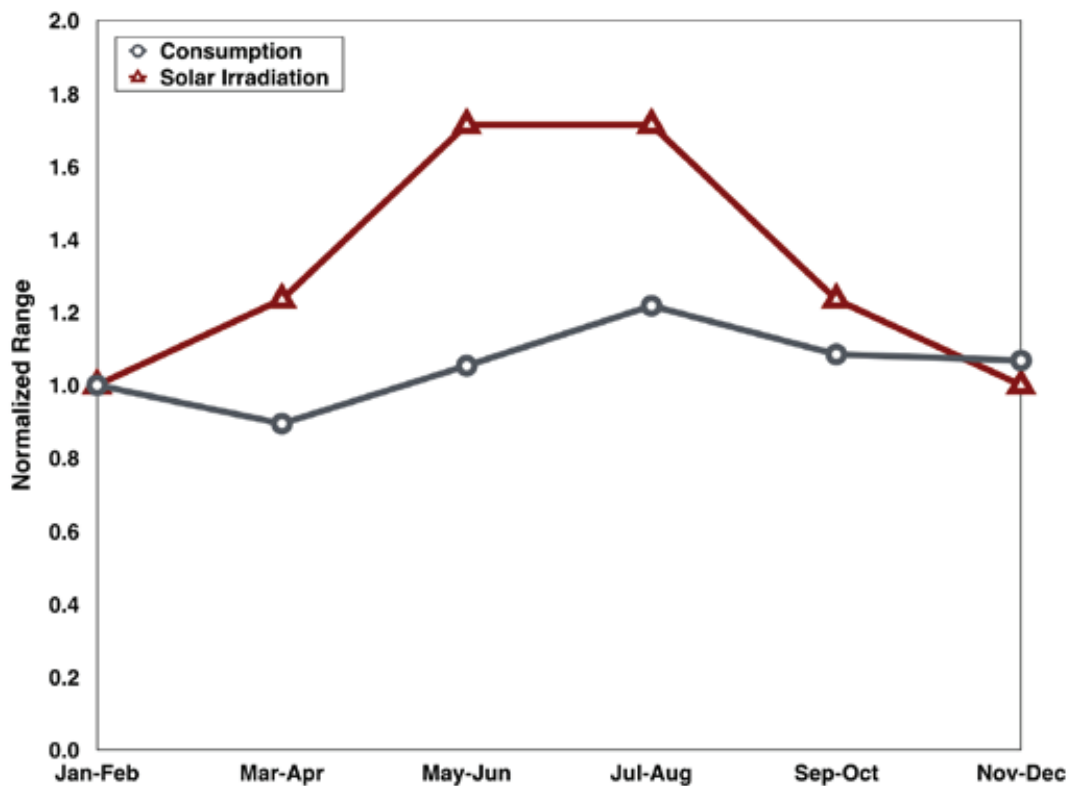

64 On the daily level, there are two demand peaks, one around mid-day and another one in the early evening. While solar PV alone can indeed help dealing with the mid-day peak, its potential to "shave" the yearly peak is more prominent given the higher climatic certainty during the summer months. 
From the perspective of Lebanese consumers, installing distributed solar systems can bring several benefits. First, from an economic perspective, serious cost savings could be achieved. However, the magnitude of these cost savings is highly dependent on project parameters such as location, mounting structure required, capacity, etc. Figure 14 shows the current ranges of per-kWh costs of electricity generated by EDL, private diesel generators and distributed solar PV systems. EDL tariffs currently range between 2.3 cents/kWh for the lowest consumption tier (below $100 \mathrm{kWh}$ per month) and 13.3 cents/ kWh for consumption above $500 \mathrm{kWh} .{ }^{65}$ Commercial consumers, in particular, are likely to pay the high-end tariff given their elevated consumptions. Moreover, EDL's low tariff is likely to be increased as part of a reform program to fix the financial and technical performance of the company. For now, the tariff increase is assumed to be double the current tariff.

As for the cost range of diesel generators, the high and low values were obtained as the minimum and maximum variable tariff published by the MOEW over the last 12 months, with the lowest being 17.5 cents/kWh in April 2018 and highest being around 30 cents $/ \mathrm{kWh}$ in October $2018 .{ }^{66}$ Clearly, the tariff of private diesel generators is dependent on international market prices of diesel oil; however, the provided range does seem representative of potential tariff swings.

Figure 14: Current cost ranges of EDL, diesel generator and distributed solar PV in Lebanon

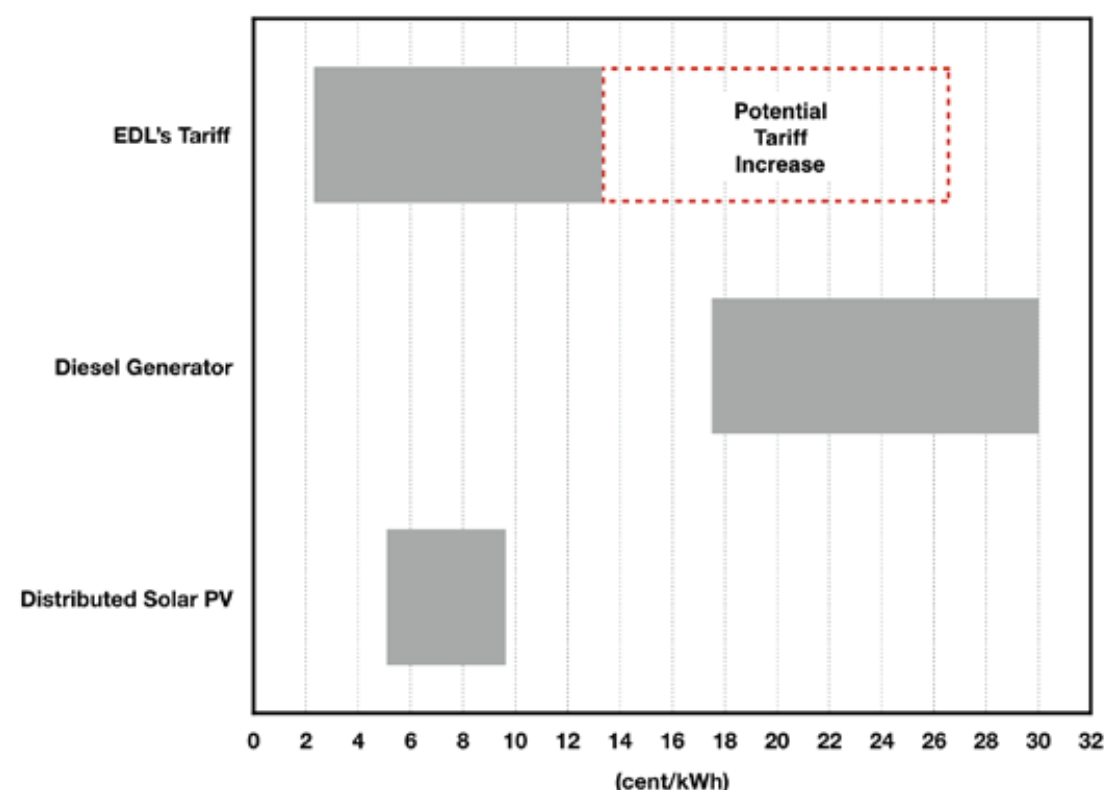

On the other hand, the cost range of distributed solar PV has been estimated using the financial simulation tool, based on a discounted cashflow methodology. The financial modeling methodology is presented in Appendix D in more details. Based on the assumed values of solar PV projects in Lebanon, which have been extracted from interviews with leading solar PV companies in the country, the range of cost of installed solar PV modules ranges between $\$ 800$ to $\$ 1,200$ per $\mathrm{kWp}$ at two distinct discount rates $8 \%$ (unsubsidized) and 2.25\% (subsidized), leading to a levelized cost, discounted over the 25 year project lifetime, of between 5 and 9.6 cents/kWh.

As discussed below, the financial viability of installing solar PV modules, given that the technical criteria are met, depends on the average (effective) amount paid by the consumer for their EDL and diesel generator tariffs. ${ }^{67}$

In addition to cost savings, distributed power generation from solar PV systems offer some other benefits, which may not be easily measured quantitatively. For example, there is the role distributed systems play in improving energy security. Around the world, even in countries where there are no or rare power outages, the energy security argument is pushing governments and consumers alike to adopt distributed power generation models. ${ }^{68}$ Recent natural disasters such as the one in Puerto Ricco in 2018, have demonstrated the effectiveness of distributed power generation in responding to unplanned power disruptions. ${ }^{69}$

65 See: http://www.edl.gov.lb/page.php?pid=39\&lang=en\#1

66 See: https://energyandwater.gov.lb/ar/prices?type=2

67 It should be noted that the costs of the "self-generation" model are different than those of commercial private diesel generators. The economic assessment of distributed solar PV vis-à-vis different ownership models will be discussed in detail later in Section 8.7 and Chapter 9 below.

68 See https://phys.org/news/2018-09-energy.html

69 For example, recent disasters such as the one in Puerto Rico demonstrated the impact and need of distributed renewable energy sources. See https://www.wsj.com/articles/weary-of-power-outages-puerto-ricans-find-solace-insolar-1537531200 
Linked directly to Lebanon's lengthy bureaucratic (and often political) delays associated with utility-scale projects that require government intervention, the decentralized implementation and short lead time required for small-scale distributed systems to be installed and operate is a major incentive. This is primarily due to the lower levels of decisionmaking processes associated with individuals, firms, and municipal authorities.

The impact of renewable energy deployment in general, and distributed generation in particular, on the environment and public health will be examined closely in the upcoming Part III of this project. However, it is evident, given the high levels of air pollution generated by burning diesel oil), that the proliferation of distributed solar PV systems and their potential to reduce the operational time of diesel generators, will ultimately contribute to lower carbon and other toxic emissions.

The very premise of decentralized/distributed energy systems is to challenge the traditional way of generating and transmitting electricity. In countries like Lebanon, where electricity is perceived as a public service that should be provided by the government, a major challenge facing the scaling up of distributed renewable electricity, is the social acceptability of such a paradigm shift. Additionally, lack of awareness of the role such systems can play in promoting cost-effective and sustainable energy solutions could prove to be a major hurdle in getting buy-in from businesses and the society at large. On the flip side, and given Lebanon's existing energy crisis, the public is thirsty for affordable solutions that can fill in the supply-demand gap. ${ }^{70}$

For efforts to scale up distributed renewable energy in Lebanon to be successful, a smart communication strategy with a focus on generating awareness is needed to inform and engage the public. Such a strategy could drive a positive change in social attitudes in support of more unfamiliar, communally-based electricity provision.

\subsection{Cost structure of distributed solar PV projects}

The cost structure of distributed solar PV projects differs widely depending on several factors, such as location, structural requirements, capacity, type of PV modules, whether storage is included or not, etc. Table 14 lists the major cost components of a typical on-grid solar PV project: PV panels, inverters, mounting structure, electrical components and vendor services. PV modules and inverters comprise $53 \%$ and $21 \%$ of the total capital costs, respectively.

Table 14: Cost components of a typical $500 \mathrm{kWp}$ on-grid solar PV system (Source: EcoSys, April 2019)

\begin{tabular}{|c|c|c|c|}
\hline Component & Description & Quantity & Cost Breakdown \\
\hline PV Panels & 405W Mono & 1,204 & $212,500(53 \%)$ \\
\hline Inverters & 15,20 and $50 \mathrm{KVA}$ & 11 & $82,800(21 \%)$ \\
\hline PV Mountings & & & $54,700(13.6 \%)$ \\
\hline Electrical Components & $\begin{array}{l}\text { - Electrical Panels } \\
\text { - Protection Devices } \\
\text { - Monitoring and Data Logging System } \\
\text { - Energy Management System and Fuel Save } \\
\text { - DC Cables } \\
\text { - AC Cables } \\
\text { - Connectors } \\
\text { - Cable trays } \\
\text { - LCD Screen } \\
\text { - Other }\end{array}$ & & $32,500(8.1 \%)$ \\
\hline Professional Services & $\begin{array}{l}\text { - Protection Management } \\
\text { - Installation Works } \\
\text { - Project Design } \\
\text { - Drawings } \\
\text { - Logistics (Cranes, Transportation...) } \\
\text { - Testing and Commissioning } \\
\text { - } 10 \text { years Full Support }\end{array}$ & & $17,500(4.3 \%)$ \\
\hline Total Investment (\$) & & & 400,000 \\
\hline Total Power (kWp) & & & 488 \\
\hline Capital cost (\$/kWp) & & & 820 \\
\hline
\end{tabular}

70 In an interview with Ismail Hijazi, the Mayor of Kabrikha, a village in South Lebanon where the first community solar PV project was commissioned with the support of United Nations Development Program (UNDP), he mentioned that one major achievement of the project so far has been raising awareness about the possibility of community solar PV projects in neighboring villages. 
Based on data shown in Section 3.1 above, almost 90\% of the solar PV projects in Lebanon are of a capacity below $50 \mathrm{kWp}$. It is expected that as the project size decreases its capacity cost (per-kWp) will increase, as some of the cost components shown in Table 14, such as electrical components and professional services, would not necessarily decrease proportionally. Interviewed companies working in the Lebanese market have specified an economics of scale multiplier on project costs between 1.3 to 1.4 , which means an increase in capital costs between 30 to $40 \%$ when shifting from projects of size of $500 \mathrm{kWp}$ to ones below $50 \mathrm{kWp}$.

For projects with the same installed capacity, there are still a number of cost differentiators. First, there is the type of solar panels: mono vs poly. Monocrystalline panels are more expensive since they have higher efficiency and thus provide more yield or less land space requirement. Although most Lebanese clients prefer poly, recently, more clients have been choosing mono panels due to a decrease in their prices. Another important cost differentiator is the type of mounting structure required (rooftop vs ground). It should be noted that tracking is only considered for utility-scale projects, which increases capital costs but it also increases the energy output of the plant.

\subsection{Electricity production costs}

Based on the levelized cost methodology presented in Appendix D, one can estimate the costs of different distributed energy systems and their breakdown into capital, O\&M and fueling costs. Table 15 lists the cost assumptions and their corresponding levelized, per-kWh.

Figure 15 shows the levelized cost and its components for on-grid solar PV and diesel generator systems. Based on current market prices and conditions, on-grid solar PV systems appear to have a significantly lower per-kWh cost, with a levelized cost of 8 cents $/ \mathrm{kWh}$. As for diesel generators, the cost of electricity is heavily dependent on diesel fuel prices. At a price of $\$ 0.63 /$ Liter (19000 L.L / 20 Liter), the cost of electricity generated by a diesel generator is around 24 cents/kWh.

As shown in Figure 15, the cost structure of solar systems is capital intensive where capital costs for PV comprise around $80 \%$. On the other hand, the fueling costs comprise $82 \%$ of the levelized cost of diesel generators. Because of this different cost structure, one can plot a cost differential chart between these two sources while varying prices of diesel fuel.

As shown in Figure 16, on-grid solar PV systems yields a positive cost differential at any diesel price between $\$ 0.5$ and $\$ 1$ per liter. Clearly, this cost differential analysis is based on today's cost assumptions. Further cost reductions in prices of PV modules will shift the histograms in Figure 16 upward. This effect will be examined in the Section on costs outlook below.

Table 15: Technical and economic assumptions used in estimating the levelized cost of energy

\begin{tabular}{lll} 
Parameter & On-grid Solar PV & Diesel Generator \\
\hline Project Capacity (kWp) & 500 & 400 \\
Unit Capital Cost $(\$ / \mathrm{kW})$ & $\$ 1,000$ & $\$ 181$ \\
Upfront Capital $(\$)$ & $\$ 500,000$ & $\$ 72,400$ \\
O\&M cost ratio & $2.00 \%$ & $31.70 \%$ \\
Fixed O\&M (\$/kW-y) & $\$ 20.00$ & $\$ 57.38$ \\
Variable O\&M (\$/kWh) & 0 & 0.0140 \\
Energy Conversion Rate (L/kWh) & & 0.3125 \\
Diesel Price (\$/L) & & 0.62 \\
Fueling costs (\$/kWh) & 0 & $\$ 0.19$ \\
Economic life & 25 & 5 \\
Capacity Factor & $16.0 \%$ & $40.0 \%$ \\
Specific Yield (kWh/year/kWp) & 1401.6 & 3504 \\
Discount Rate & $8.00 \%$ & $8.00 \%$ \\
Annual Energy Production (kWh) & 700800 & 1401600 \\
Total levelized cost (cent/kWh) & $\mathbf{8 . 0 0}$ & $\mathbf{2 3 . 7 0}$
\end{tabular}




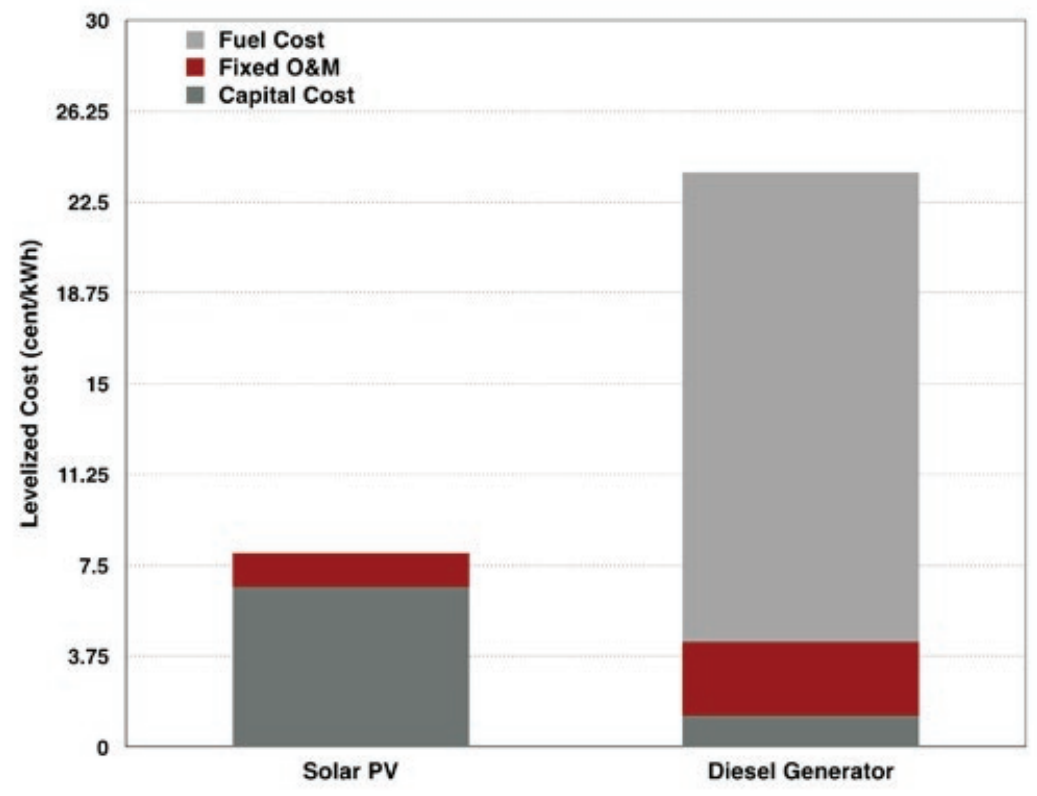

Figure 16: Variation of cost differential between diesel generator levelized cost and that of solar PV

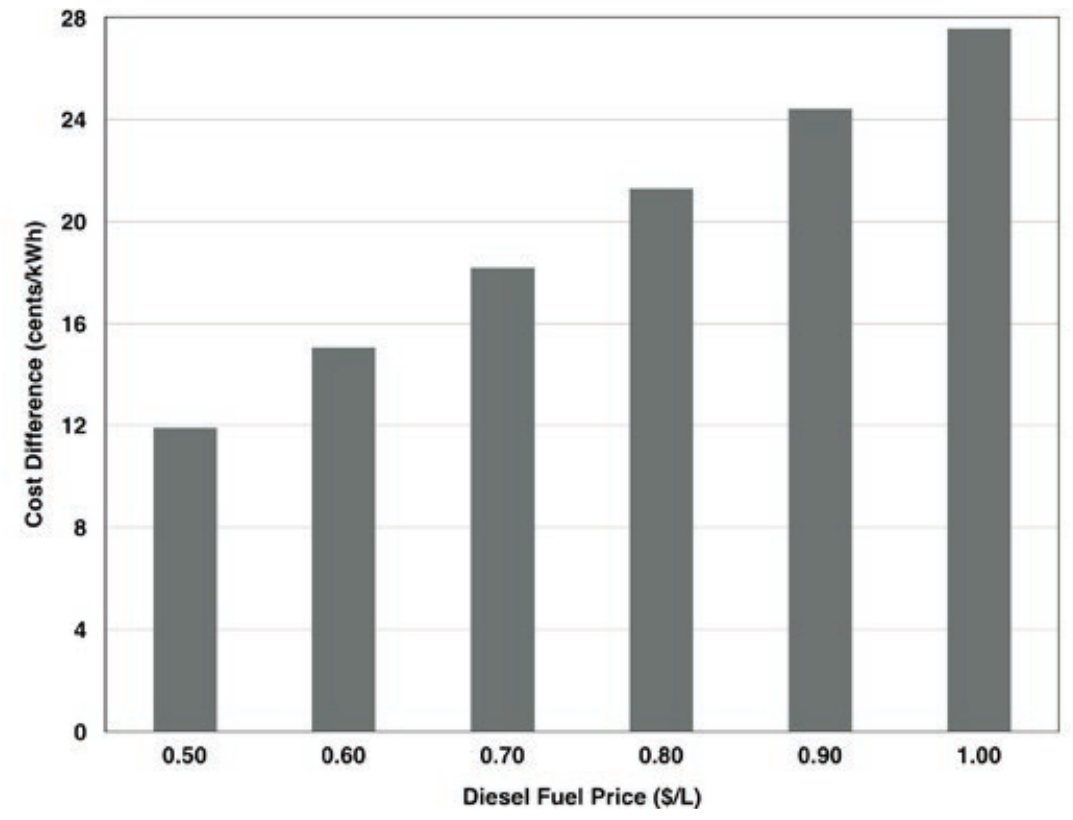

According to data obtained from the interviewed solar companies, solar yield in the inland Beqaa region is $10 \%$ higher than that obtained in projects based in Beirut. This increases the specific yield assumed from 1,400 to 1,540 kWh/Year/ kWp. Factoring in such a substantial increase lowers the levelized cost of solar further to 7.3 cents/kWh, respectively.

\subsection{Financial feasibility}

The financial feasibility of on-grid solar PV is conducted through a net present value analysis (NPV). The net present value is the net balance between cash inflows and outflows over the lifetime of the project. Essentially, the net present value of a project reflects the profitability of investments.

One major parameter in the NPV analysis is the assumed discount rate. Two values of discount rate have been used in this work: an $8 \%$ rate that reflects the weighted average cost of capital (WACC) based on input by Lebanese bankers and 
financiers, reflecting an unsubsidized investment costs; and a 2.25\% discount rate for projects supported by the NEEREA financing mechanism that is initiated by BDL (refer to Appendix A-1 for more details on NEEREA). Under the NEEREA scenario, the capital is assumed to be paid through a NEEREA loan that would be repaid over a period of 10 years. ${ }^{71}$

With a discount rate of $8 \%$, the payback period, which is equal to the time required for the produced electricity to create cash inflows (savings) for the initial project investment to break-even, is around eight years. Given that solar projects are capital intensive, reducing the payback period is of high importance to create higher incentives for adopting such solutions. With a NEEREA $2.25 \%$ discount rate, the payback period can be reduced to 4.4 years.

Another important factor that could lower the payback period is the effective tariff that is being replaced by solar electricity. If, for example, the current effective tariff is increased from 17 to 25 cents/kWh, the payback period under non-NEEREA and NEERA financing will decrease to 4.2 and 3.6 years, respectively. The variation of the payback period with different discount rate, capital cost and effective tariff assumptions are shown in Table 16.

\section{Table 16: Payback periods under different discount rates and effective tariff (at capital cost $=\$ 800 / \mathrm{kWp}$ )}

Effective Tariff $=17$ cents $/ \mathbf{k W h}$

Discount Rate

\section{Payback period (years)} 5.4 4.4

Effective Tariff $=25$ cents $/ \mathrm{kWh}$

Payback period (years)

Discount Rate

\begin{tabular}{ll}
$8 \%$ & 5.4 \\
\hline $2.25 \%$ & 4.4
\end{tabular}

$2.25 \%$

Indeed, the value of the assumed effective tariff in the financial simulation affect significantly the financial feasibility and profitability. As the effective tariff increases, installing on-grid solar PV systems make more economic sense.

\subsection{Costs outlook and the role of storage}

The estimates of how fast solar PV costs have fallen are striking. Between 2008 and 2018, the average cost of utility-scale solar PV has fallen by $88 \%$, reaching 4.3 cents/kWh in 2018, based on numbers published by Lazard, a financial advisory firm. ${ }^{72}$ Figure 17 shows the reduction in turnkey capital costs of solar PV and solar PV + storage systems in Lebanon. The 2016 and 2017 values were obtained from the UNDP DREG annual report; 2019 numbers were obtained from interviews with solar companies in Lebanon. 2025 cost projections were assumed to be reached with an annual average reduction rate of $8 \%$. This value was taken from Lazard's estimates of cost reductions over the next five years. ${ }^{73}$

Currently, and as shown in Table 14, the cost of the panels constitutes about $50 \%$ of the total capital costs. This means that, unlike before where the capital cost was dominating by the cost of the PV module, any potential reduction in the cost of PV panels will have a smaller impact on the overall capital cost of a project. In fact, interviewed industry leaders in Lebanon believe that the "Balance-of-System" costs (BoS) are now becoming a more important factor in costing projects. ${ }^{74}$ Unlike PV panels, where there might be a room for further cost reduction with increased efficiency, the potential to substantially reduce BoS costs remains limited, but possible with further system optimization. Clearly, BoS costs are more sensitive to economies of scale, especially when comparing residential (below $50 \mathrm{kWp}$ ) to industrial and commercial applications (usually between 50 and $1000 \mathrm{kWp}$ ). Due to some of its cost components such as labor and mounting structures, which can be either manufactured locally or imported at a higher cost, BoS costs also differ from one country to another.

71 In the financial simulation, no grace period is assumed. However, in current NEEREA projects, clients could benefit from a two-year grace period.

72 It should be noted that Lazard's estimates are based on US market. Global averages are likely to be lower. See https://www. lazard.com/media/450784/lazards-levelized-cost-of-energy-version-120-vfinal.pdf

73 Given the dramatic decline of solar PV and storage costs in recent years, an $8 \%$ reduction rate might seem a bit conservative.

74 The BoS costs refer to all capital costs except that of the PV modules. These costs include inverters, mounting structures, cables, bolts, labor, contract costs, grid connection, etc. 


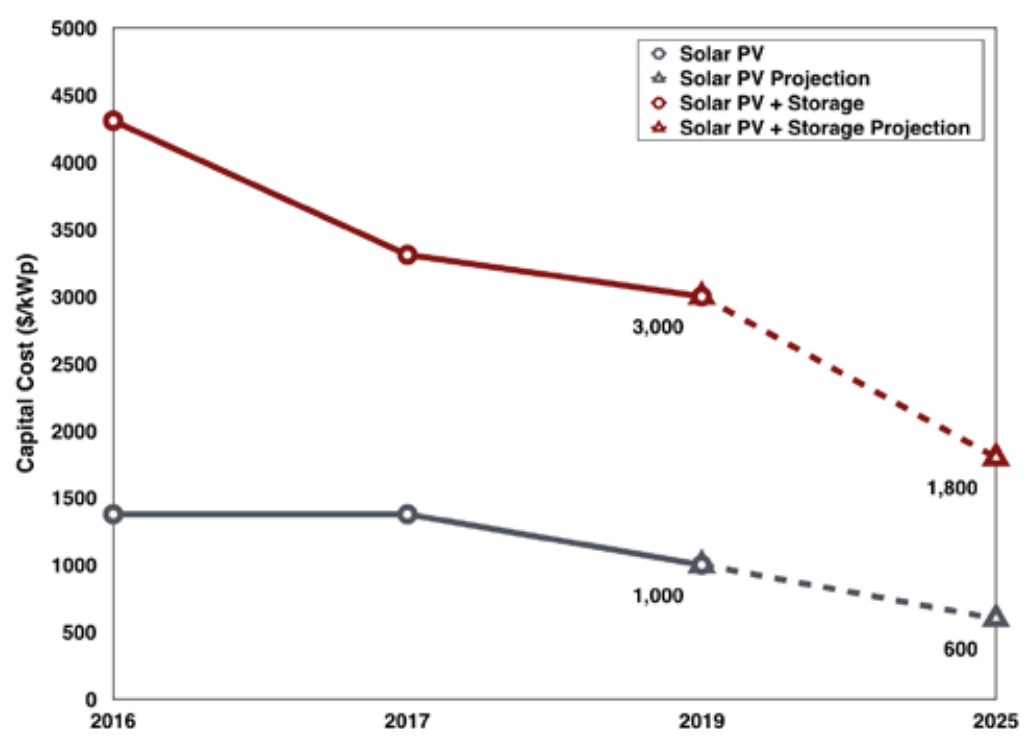

Plugging in the 2025 capital cost projections, i.e. $\$ 600 / \mathrm{kWp}$ and $\$ 1800 / \mathrm{kWp}$ for solar PV and solar PV + storage systems, respectively. At a NEEREA discount rate of $2.25 \%$, the levelized cost of on-grid solar PV reaching 3 cents $/ \mathrm{kWh}$. As for solar PV + storage systems, their NPV turns positive at an effective tariff of 27 and 35 cents per kWh at discount rates $2.25 \%$ and $8 \%$ respectively, as shown in Figure 18. These favorable economics of PV + storage systems would go a long way to promote distributed off-grid systems, where focus is on self-consumption. As storage costs continue to decline, the effective tariff threshold below which storage becomes economically competitive will also reduce. At this stage, however, it is premature to project beyond 2025, as the energy sector is very dynamic, and between now and then new technologies and concepts might dramatically change the global energy landscape.

Figure 18: NPV sensitivity versus effective tariff for PV + Storage systems

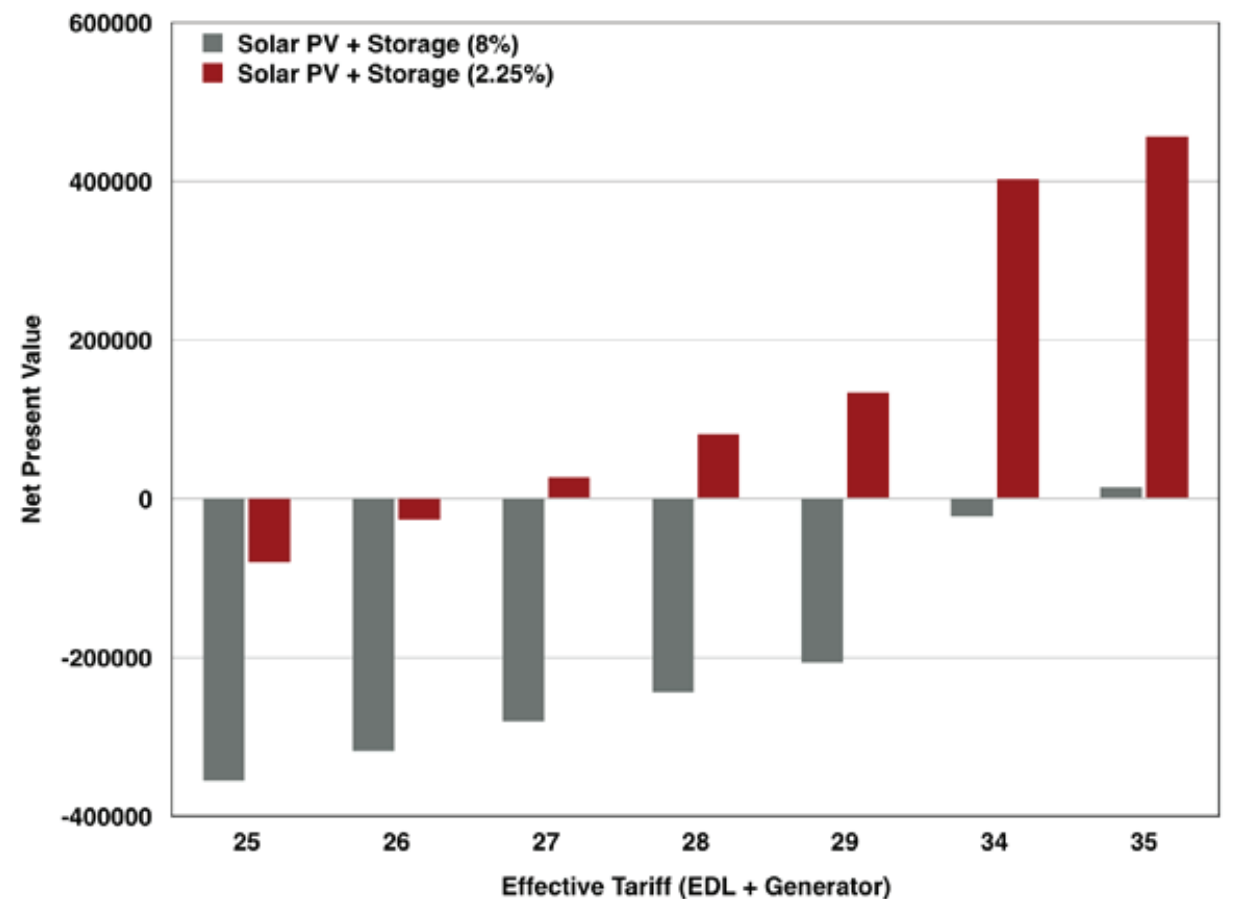


This section examines the real potential of a city-wide deployment model of rooftop solar PV systems and its economic features. It underlines the mapping between the solar resources available based on rooftop spaces, the amount of solar insolation they receive, and the financial case based on available data.

The examined sample consists of 13,000 buildings in Beirut City, which is around two-thirds of the total number of buildings in the city. Those building were chosen due to the availability of data on their rooftop area, the distribution of which is shown in Figure 19. The data shows that $31 \%$ of buildings have a surface area of less than $100 \mathrm{~m}^{2}, 70 \%$ with less than $200 \mathrm{~m}^{2}$, and $85 \%$ with less than $300 \mathrm{~m}^{2}$.

\section{Figure 19: Distribution of rooftop surface area in a sample of 2200 buildings in Beirut}

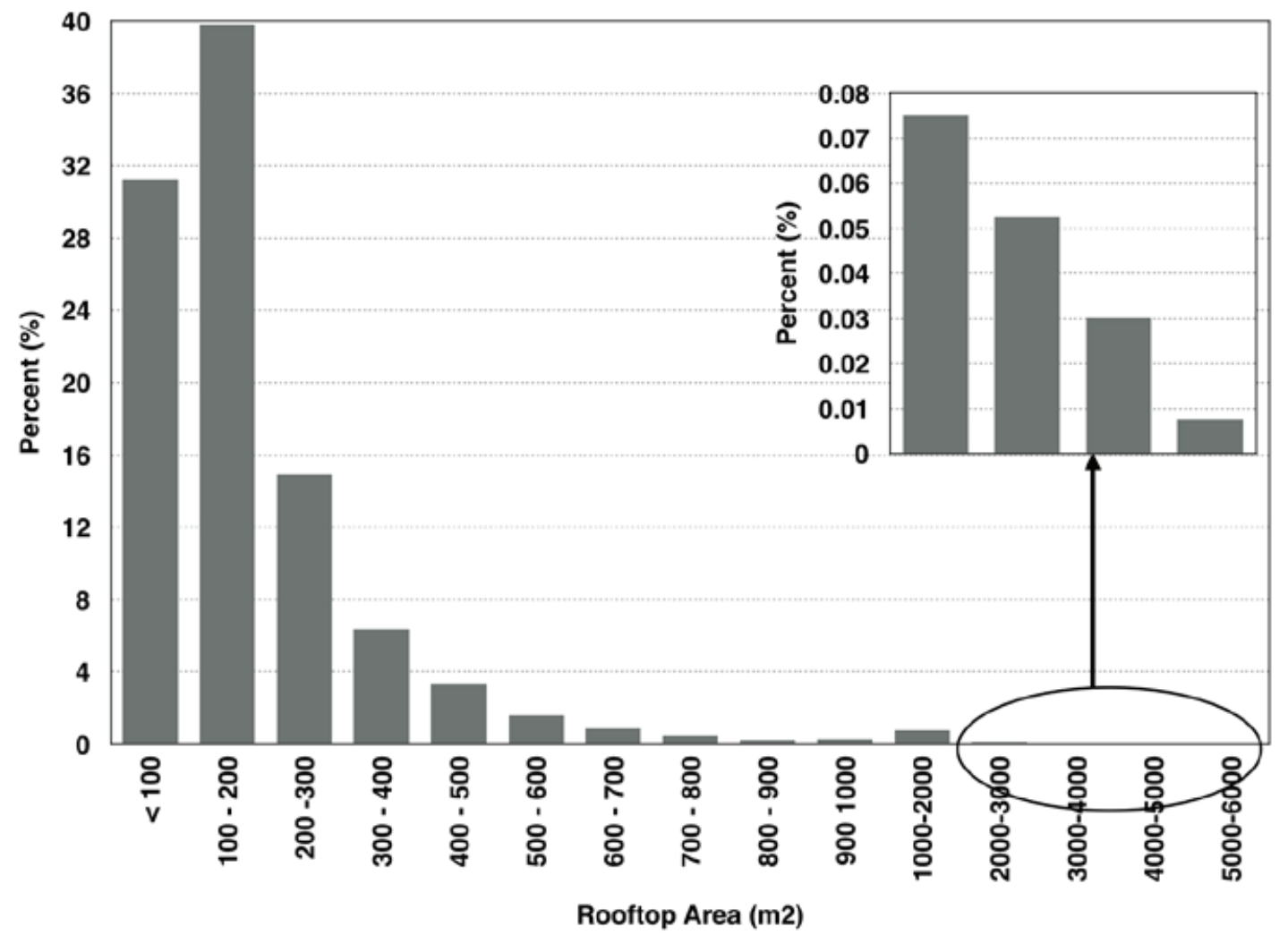

One important parameter in assessing the potential of rooftop solar PV is the occupancy factor. In this analysis, two cases have been considered: a low case with an occupancy factor of $50 \%$ and a high case with $75 \%$. Of course, some buildings would have occupancy factors either below $50 \%$ or higher than $75 \%$, but in general this range can be safely assumed for this assessment.

Assuming that the area required per $1 \mathrm{kWp}$ is $8 \mathrm{~m}^{2}$, the distribution shown in Figure 19 can be converted to a solar PV capacity distribution as shown in Table 8. The data in Table 17 shows the minimum and maximum range of installed capacity in each rooftop area category. For example, $40 \%$ of buildings in Beirut can install a capacity between 13 and $19 \mathrm{kWp}$. The average rooftop area is estimated at $185 \mathrm{~m}^{2}$, which translates into an average capacity of 12 to $17 \mathrm{kWp}$, depending on the rooftop occupancy factor. 
Table 17: Distribution of maximum installed capacity $(\mathrm{kWp})$ in the studied sample

\begin{tabular}{llll} 
Area & Percent & Theoretical Capacity $(\mathbf{k W p})-$ Low & Theoretical Capacity $(\mathbf{k W p})$ - High \\
\hline$<100$ & $31.24 \%$ & 6 & 9 \\
$100-200$ & $39.78 \%$ & 13 & 19 \\
$200-300$ & $14.91 \%$ & 19 & 28 \\
$300-400$ & $6.33 \%$ & 25 & 38 \\
$400-500$ & $3.33 \%$ & 31 & 47 \\
$500-600$ & $1.59 \%$ & 38 & 56 \\
$600-700$ & $0.85 \%$ & 44 & 66 \\
$700-800$ & $0.50 \%$ & 50 & 75 \\
$800-900$ & $0.26 \%$ & 56 & 84 \\
9001000 & $0.26 \%$ & 63 & 94 \\
$1000-2000$ & $0.77 \%$ & 125 & 188 \\
$2000-3000$ & $0.08 \%$ & 188 & 281 \\
$3000-4000$ & $0.05 \%$ & 250 & 375 \\
$4000-5000$ & $0.03 \%$ & 313 & 469 \\
$5000-6000$ & $0.01 \%$ & 375 & 563 \\
\hline
\end{tabular}

Figure 20 shows a projection to the full city level of the distribution of the buildings in the studied sample in terms of their type (commercial \& industrial, residential and mixed) and corresponding theoretical capacity. This is done assuming that the ratios of building types and average theoretical capacity would remain the same when extrapolating to all of Beirut. Details of the results shown in Figure 20 and their type breakdown are listed in Table 18. The results show that Beirut City alone has a potential of distributed rooftop solar PV that is roughly between 200 and $300 \mathrm{MWp}$, corresponding to an occupancy factor of $50 \%$ and $75 \%$, respectively.

Figure 20: Distribution of commercial \& industrial, residential and mixed buildings in the studied sample in terms of their number and theoretical solar PV capacity

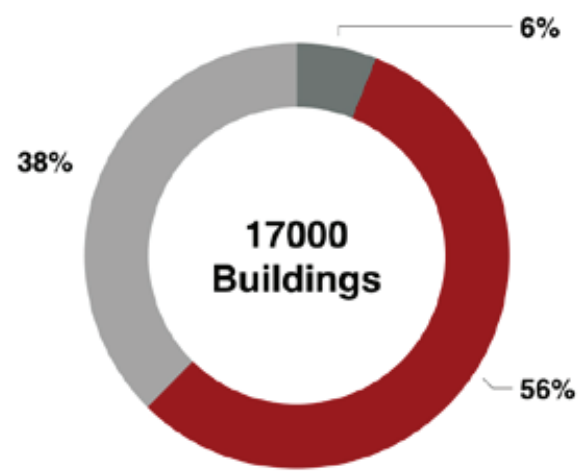

- Commercial \& Industrial

- Residential

Mixed

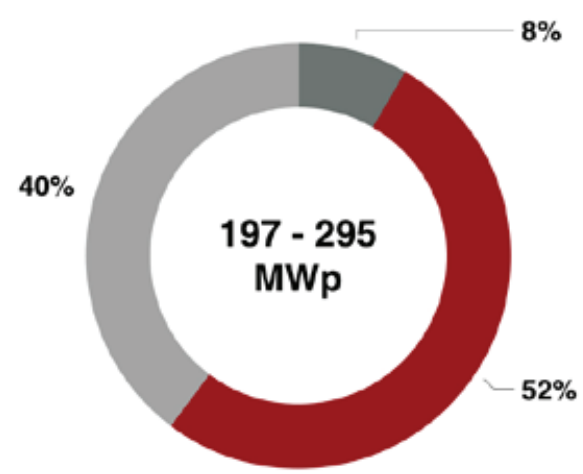

- Commercial \& Industrial

- Residential

Mixed

One can extrapolate the above analysis to all of Lebanon's buildings, but the results would be somewhat conservative. In rural regions, houses and buildings tend to have a bigger rooftop area compared to those in cities like Beirut. As such, one would expect those buildings to have a higher average theoretical capacity of solar PV systems that could be installed on them. 
Table 18: Estimate of Beirut City Solar PV rooftop potential

\begin{tabular}{llllll}
$\begin{array}{l}\text { Type of } \\
\text { Building }\end{array}$ & $\begin{array}{l}\text { Average } \\
\text { Area }(\mathbf{m} \mathbf{2})\end{array}$ & $\begin{array}{l}\text { Theoretical } \\
\text { Capacity - Low }\end{array}$ & $\begin{array}{l}\text { City Potential - } \\
\text { Low (MWp) }\end{array}$ & $\begin{array}{l}\text { Theoretical } \\
\text { Capacity - High }\end{array}$ & $\begin{array}{l}\text { City Potential - } \\
\text { High (MWp) }\end{array}$ \\
\hline Commercial & 300.0 & 18.8 & 19.3 & 28.1 & 29.0 \\
Residential & 160.0 & 10.0 & 95.7 & 15.0 & 143.6 \\
Mixed & 205.0 & 12.8 & 82.0 & 19.2 & 122.9 \\
Total & & & $\mathbf{1 9 7 . 0}$ & & $\mathbf{2 9 5 . 5}$
\end{tabular}

As shown in Table 18, commercial and industrial buildings have the highest average theoretical capacity, between 19 and $28 \mathrm{kWp}$. In fact, in the studied dataset many commercial and industrial buildings have a rooftop area of more than $1,000 \mathrm{~m}^{2}$. The maximum surface area found was around $5,900 \mathrm{~m}^{2}$, which would be potentially capable of installing around $550 \mathrm{kWp}$ at an occupancy factor of $75 \%$. It should be noted that the higher the surface area of a building, the higher its occupancy factor is expected to be, especially in the commercial and industrial sector. As such, for buildings with a surface area of $1,000 \mathrm{~m}^{2}$ and higher, the occupancy factor is likely to exceed the $75 \%$ upper range limit studied.

The financial feasibility of installing a rooftop solar PV system on each building in the studied sample has been assessed based on the methodology in Appendix D-2. Since each building is a "decision unit," the net present value (NPV) has been calculated for every building in the sample. The variations of the NPV are dependent on the set of technical and financial parameters assumed, and they are examined based on the developed rooftop feasibility simulation too. The variables examined are:

- Occupancy factor: $50 \%$ and $75 \%$

- Effective tariff paid by the consumer

- Discount rate: $8 \%$ and NEEREA's $2.25 \%$

- Capital cost: $\$ 1,000 / \mathrm{kWp}(2019)$ and $\$ 600 / \mathrm{kWp}$ (2025 projection)

To account for the impact of the project size on the overall NPV, i.e. the effect of the economies of scale (EoS), the capital cost assigned for each building is multiplied by an EoS multiplier as shown in Table 19. The values of these multipliers were based on data extracted from interviews with solar companies in Lebanon. For projects with a capacity of $400 \mathrm{kWp}$ and higher, the EoS multiplier is 1, and it increases linearly as the capacity of the project decreases, reaching 1.5 for projects of capacity below $50 \mathrm{kWp}$.

Table 19: Variation of economies of scale (EoS) multiplier with projects' capacity range

\begin{tabular}{ll} 
Capacity Range & EoS Multiplier \\
$<50$ & 1.5 \\
$50-100$ & 1.4 \\
$100-200$ & 1.3 \\
$200-300$ & 1.2 \\
$300-400$ & 1.1 \\
$400-500$ & 1 \\
$>500$ & 1 \\
\hline
\end{tabular}

A baseline financial case is established with the parameters and assumptions listed in Table 20. According to this analysis, only $7.4 \%$ of the total potential capacity of rooftop solar PV in Lebanon (16.7 MWp) yields a positive net present value. This low percentage is due to several factors, mainly: (1) the $8 \%$ discount rate assumed, which doesn't fare well with high upfront cash outflows; (2) diseconomies of scale, as will be shown later; and (3) relatively low effective tariffs. 
Total number of buildings in Beirut

Occupancy factor

Area required for $1 \mathrm{kWp}$

Capital cost (@ 500kWp)

Specific Yield

Discount rate

Lifetime

LCOE

Effective Tariff (EDL+Generator)

$\begin{array}{ll} & 17,000 \\ \mathrm{~m} 2 & 50 \% \\ \$ / \mathrm{kWp} & 8 \\ \mathrm{kWh} / \mathrm{kWp} & 1,000 \\ & 1,400 \\ \text { Years } & 8 \% \\ \text { cents/kWh } & 25 \\ \text { cents/kWh } & 8 \\ & 17\end{array}$

The results of varying the assumptions of the baseline case are shown in Figure 21. Raising the occupancy factor from the low estimate of $50 \%$ to the high one of $75 \%$ yields only a 9.8 percentage point increase in the financially viable capacity. On the other hand, the results are highly sensitive to increases of the effective tariff and decreases of the discount rate. Increasing the effective tariff by just 1 cent per $\mathrm{kWh}$ renders all projects financially viable. Similarly, a decrease of the discount rate from $8 \%$ to $7 \%$ does the same. This shows that the economic conditions for rooftop solar PV systems are almost there, if the viability line has not been crossed already. This is primarily due to the continuing cost reductions in the technology, which boost the economies of small projects, despite diseconomies of scale effects.

Figure 21: Percentage of on-grid rooftop solar PV capacity of projects with a positive NPV as a function of occupancy factor, effective tariff and discount rate

\section{Capacity with positive NPV}
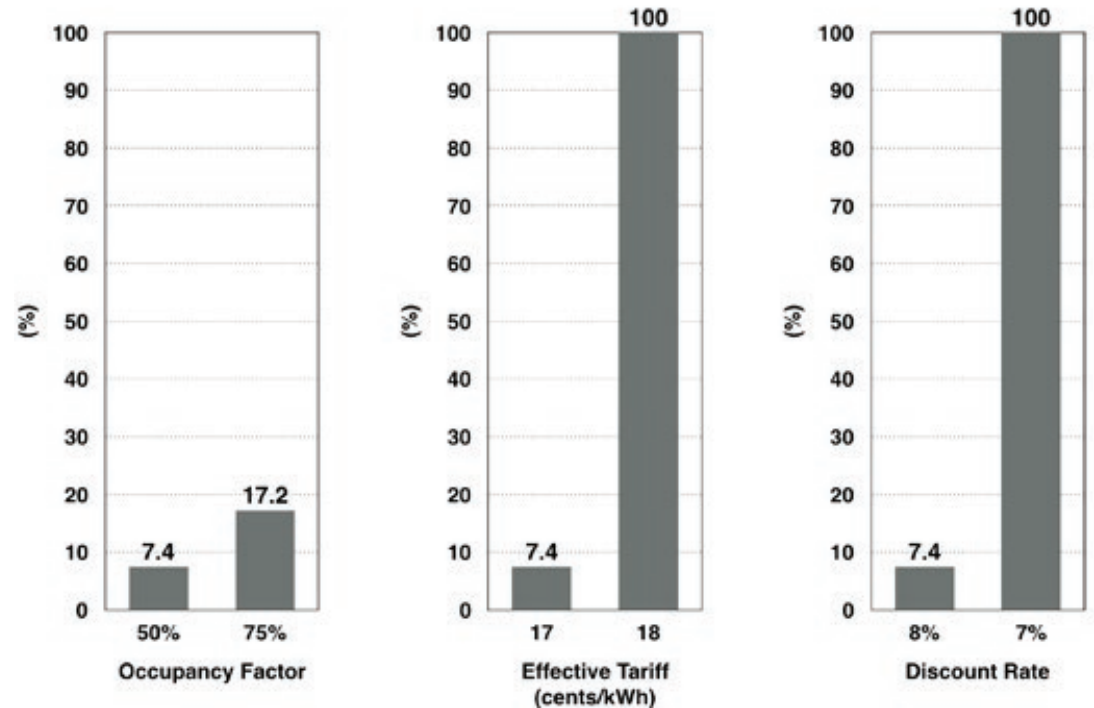

When the baseline case is examined more closely by looking at the projects that constitute the $7.4 \%$ of capacity with a positive NPV, they are all above a capacity threshold of $50 \mathrm{kWp}$, which is equivalent to having a rooftop space of around $800 \mathrm{~m}^{2}$

\subsection{Can owners of diesel generators shift to a solar PV-based business model?}

There are four major categories of impediments that limit the participation of diesel generator owners in launching an alternative distributed energy market that is either based on or incorporates solar PV system. These are: legal, technical, 
financial, and cultural. This section examines closely the financial issue, while the other challenges are discussed in more detail in Section 9.3 and Chapter 10.

Potentially, owners of commercial diesel generators can provide their services with three types of energy sources: (1) generator alone (as is the case now); (2) a hybrid system where solar PV systems are added to their grid; and (3) solar PV plus storage systems that eliminate the generator completely. As discussed above, PV + storage systems are not yet cost competitive in Lebanon. The financial parameters reflecting the other two options, based on the case of a $500 \mathrm{KVA}$ (400 kW) diesel generator, are listed in Table 21. Roughly speaking, 500 KVA generators provide electricity to about 300 customers.

Table 21: Financial parameters of potential energy source combinations that can be utilized by owners of diesel generators

\begin{tabular}{llll} 
Parameter & Solar PV & Diesel Generator & Hybrid (PV + Generator) \\
\hline Generator Capacity (kW) & 0 & 400 & 400 \\
PV Capacity (kWp) & 500 & 0 & 280 \\
Unit Capital Cost $(\$ / k W)$ & $\$ 1,000$ & $\$ 181$ & $\$ 518$ \\
Upfront Capital (\$) & $\$ 500,000$ & $\$ 72,400$ & $\$ 352,400$ \\
O\&M cost ratio & $2.00 \%$ & $31.70 \%$ & $8.1 \%$ \\
Fixed O\&M (\$/kW-y) & $\$ 20.00$ & $\$ 57.38$ & $\$ 41.99$ \\
Variable O\&M (\$/kWh) & 0 & 0.0140 & 0.0084 \\
Energy Conversion Rate (L/kWh) & & 0.3125 & 0.3125 \\
Diesel Price (\$/L) & & 0.62 & 0.62 \\
Fueling costs (\$/kWh) & 0 & $\$ 0.19$ & $\$ 0.12$ \\
Economic life & 25 & 5 & 25 \\
Capacity Factor & $16.0 \%$ & $40.0 \%$ & $40.0 \%$ \\
Specific Yield (kWh/year/kWp) & 1401.6 & 3504 & 3504 \\
Discount Rate & $8.00 \%$ & $8.00 \%$ & $8.00 \%$ \\
Annual Energy Production (kWh) & 700800 & 1401600 & 1401600 \\
LCoE (cents/kWh) & $\mathbf{8 . 0 3}$ & $\mathbf{2 3 . 7 1}$ & $\mathbf{1 6 . 3 2}$
\end{tabular}

In terms of solar PV installed capacity, the hybrid system requires $280 \mathrm{kWp}$, which is equivalent to $70 \%$ of the generator's maximum capacity, due to the need to avoid light-loading. ${ }^{75}$ In total, the capacity of the hybrid model is $680 \mathrm{~kW}$ and consists of $400 \mathrm{~kW}$ from the generator and $280 \mathrm{~kW}$ coming from the PV system. ${ }^{76}$ As for the solar PV plus storage model, the solar capacity required should be double that of the generator alone since the storage capacity would require its own solar PVarrays. ${ }^{77}$

Adding solar PV systems to the existing diesel generator network in the hybrid model seems to offer a compelling financial case. Table 22 shows the comparison between the generator and hybrid models, and the impact of incorporating solar PV into the existing model of commercial diesel generators in Lebanon. In terms of capital costs, adding a capacity of $280 \mathrm{kWp}$ would increase the capital costs by around 400\%; however, in return, the levelized cost decreases by $31 \%$, annual profits increase by $225 \%$ and the 25 -year NPV increases by $930 \%$.

75 Generally, operating below $30 \%$ of a generator's capacity is considered light-loading. Light-loading shortens the lifetime of the generator and makes it less efficient due to suboptimal operation regime.

76 One way to increase the penetration of solar PV is to have multiple generators with smaller capacities as opposed to large ones. Having multiple smaller generators allow for switching them off and on to follow load, while maximizing the solar input.

77 It should be noted that in this model, having a back-up diesel generator would still make sense, especially in case of prolonged outages or prolonged absence of sunshine in winter days. 
It should be noted that the relative economics of the hybrid model are strongly dependent on the price of diesel fuel oil and that the values presented in Table 22 are estimated at a diesel price of $\$ 0.62$ per liter. The impact of varying the diesel price on the LCOE, and thus on profitability, is shown in Figure 22. As expected, the financial impact of incorporating solar PV systems is maximized when diesel prices are high, since the displaced fuel generates bigger savings.

Table 22: Impact of incorporating solar PV into the existing business model of commercial diesel generators

\begin{tabular}{lll} 
Parameter & Generator & Hybrid (generator + PV panels) \\
\hline Solar PV capacity (kWp) & 0 & 280 \\
Capital costs (\$) & 72400 & 352400 \\
Area (m2) & & 2240 \\
Diesel fuel consumed per year (L) & 438000 & 315360 \\
Retail Price (cents/kWh) & 27 & 27 \\
LCOE (cents/kWh) & 23.7 & 16.32 \\
Annual profits (\$) & 46000 & 150000 \\
NPV (tariff = 27 cents/kWh) & 103636 & 1076000 \\
Payback period (years) & 1.6 & 2.4 \\
\hline
\end{tabular}

While it is hard to predict how prices will change in the future, including solar PV systems in the operations of commercial diesel generators can help to mitigate the risks of price volatility. Their economic value will also be improved with reductions in technology costs and increased learning. Based on this analysis, there is a case for a shift towards deploying solar PV panels in the commercial segment of Lebanon's distributed energy market. The real impediments seem to emerge from other factors, which are discussed in Section 9.3 and Chapter 10 below.

Figure 22: Variation of the LCOE with diesel fuel price in hybrid and generator only business models

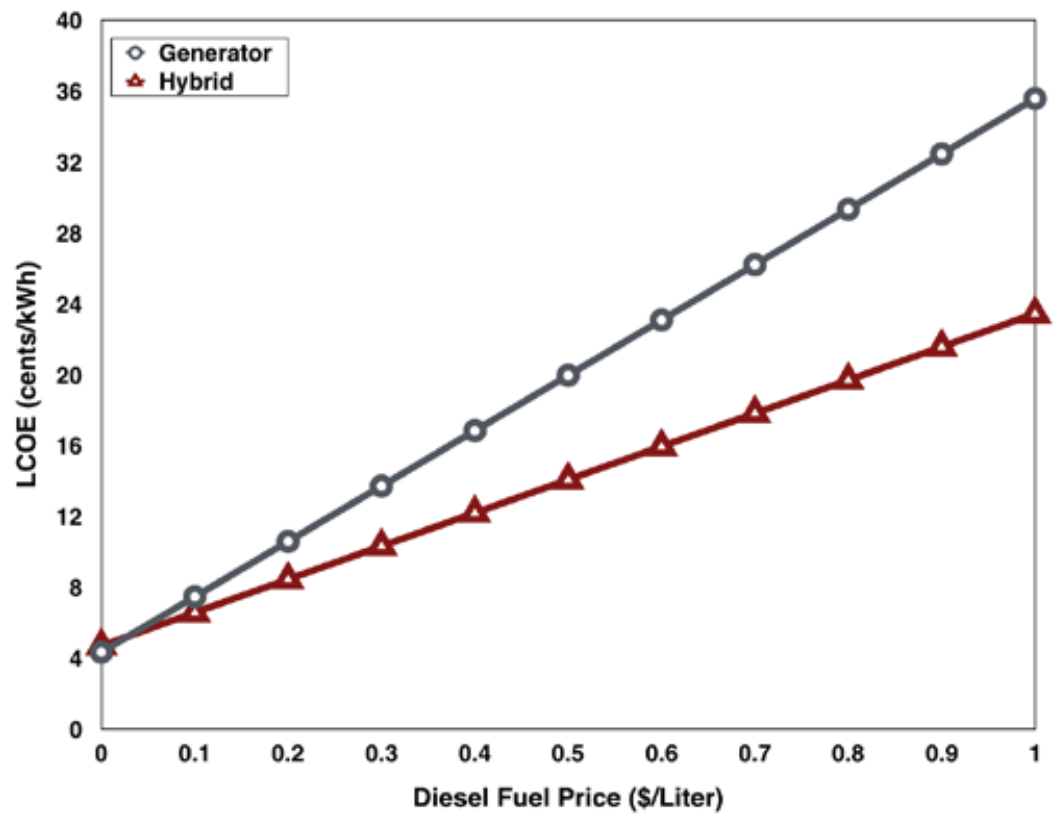




\section{Ownership Models}

\section{$9.1 \quad$ Ownership models}

Since this work ultimately aims to examine the potential of distributed solar PV systems to replace diesel generators in Lebanon, four ownership models that are aligned with owning a diesel generator are studied: (1) a private residential model by which the owner(s) of the house (or building) decides to install rooftop solar PV system ${ }^{78}$; (2) a private industrial and commercial model; (2) a community-shared model that includes service provision to a number of customers - as is the case with municipal projects ${ }^{79}$; and (4) a third-party, entrepreneurial, model that is equivalent to the existing model of owning a diesel generator and selling electricity to a number of subscribers.

Table 23 lists the relative scale of deployment of distributed solar PV systems in each ownership category and their corresponding main limitations. For the industrial and commercial sector, one major limitation is the misalignment between the load profile with the profile of solar power input. Equally important is the power quality limitation, especially in relation to power-sensitive industries and machinery, where low or inadequate power quality could prove very risky and costly. More details on the power quality issues that could arise from the integration of solar PV systems are discussed in Section 10.1 below.

For the residential category, the main challenge is the limited availability of space, especially in urban regions, where buildings include many residents, and consequently, their roofs are crowded with solar water heaters, satellite dishes, cables and wires.

\section{Table 23: Major limitations facing the utilization of solar PV systems in different ownership models}

\begin{tabular}{|c|c|c|}
\hline Ownership Model & Relative Scale & Major Limitations \\
\hline $\begin{array}{l}\text { Private - Industrial and } \\
\text { Commercial }\end{array}$ & Medium to large & $\begin{array}{l}\text { Misaligned load profile; Power quality issues; } \\
\text { High upfront capital costs }\end{array}$ \\
\hline Community (municipal) & Large & Space availability \\
\hline Third-party (entrepreneurial) & Medium to large & Absence of supportive legal and regulatory framework \\
\hline
\end{tabular}

Another main challenge facing the deployment of distributed solar PV systems on the residential level is the high upfront capital cost. As discussed above, interviewed companies working on the Lebanese market have specified a cost range between $\$ 1,000$ to $\$ 800$ per $\mathrm{kWp}$ for a project size of $500 \mathrm{kWp}$. Since the capacities that can be realistically installed on rooftops of buildings is much lower than this, the negative economics of scale multiplier discussed above is factored in and is estimated at an increase of $40 \%$ above the baseline range. Therefore, residential customers are expected to pay between $\$ 1,400$ and $\$ 1,120$ per $\mathrm{kWp}$ installed. For an average capacity of $22 \mathrm{kWp}$, the upfront capital cost required range between $\$ 30,800$ and $\$ 24,640 .{ }^{80}$

Community-shared ownership models such as projects implemented by local and municipal authorities are becoming more popular in Lebanon. ${ }^{81}$ In this ownership model, access to capital is somewhat easier, since municipalities have their own financial resources as well as resources given to them by the central government. Additionally, municipalities have been effective in attracting funding through grants from international donors. The main challenge for community-shared projects is land availability and technical suitability. Even though the lowering of capital costs experienced globally and in Lebanon may make a case for deploying solar PV even in "not-so-perfect" siting conditions (see Figure 23), the per$\mathrm{kWh}$ cost is sensitive to the solar yield received and will ultimately make a big difference in the economic feasibility of these projects.

78 This model also includes a "cooperative" model by which a number of co-owners within the same building decide to install a solar rooftop system.

79 Like the Kabrikha project, for example.

80 On the other hand, the capital cost of a 35 KVA diesel generator is $\$ 8,400$ (including TVA). Source: interview with Younes Bros staff

81 There are currently at least 17 municipality-led solar PV projects in Lebanon that are either implemented or in consideration. 


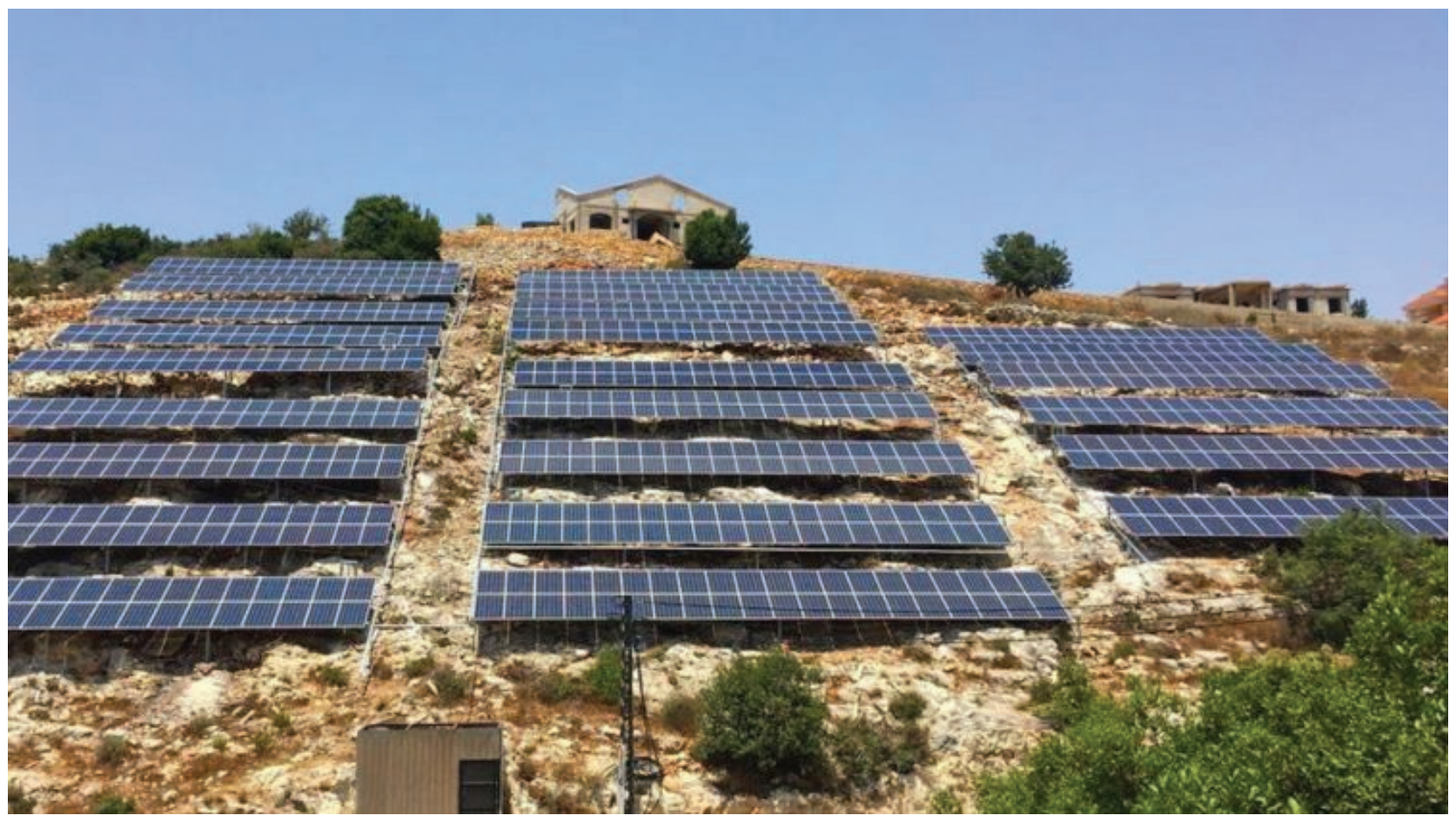

\subsection{Third-party ownership model}

The economics of incorporating solar PV systems into the operations of commercial diesel generator owners has been examined in Section 8.7 and yielded a strong financial case for such a transformation. In this section, other challenges to the third-party model are examined from legal, operational and cultural perspectives. Technical challenges are discussed separately in Section 10.1 below.

First, there is the legal challenge that results from the absence of a supportive legal and regulatory framework. Law 462 prohibits third-party developers from selling power, except those given a special concession by the Council of Ministers and the Parliament. ${ }^{82}$ As discussed in Section 2.3 above, existing laws prevent private "wheeling" wherein private producers sell electricity to private consumers. As such, distributed solar generation can only be exported to EDL's grid. Even if the owners of diesel generator networks started to shift towards deploying rooftop solar PV systems according to the hybrid model discussed above, their operations would still be considered illegal as far as existing laws and regulations are concerned.

Second, there are some serious technical challenges that could prevent diesel generator networks from including solar PV systems. Most prominent is the space requirement. Given that $8 \mathrm{~m}^{2}$ are needed for every $\mathrm{kWp}$, the area required to install $280 \mathrm{kWp}$, which is the maximum solar PV capacity that can be coupled to a $500 \mathrm{KVA}$ (400 kW) generator, would be $2240 \mathrm{~m}^{2}$ As shown in Section 8.6, the average rooftop area in urban Beirut is estimated at $220 \mathrm{~m}^{2}$. If one assumes a rather generous occupancy factor of $75 \%$, the rooftops of 14 buildings would be needed to install the required $280 \mathrm{kWp}$.

This is a huge challenge. First, it requires the owners of diesel generator owners to be granted access to rooftops. In interviews with generator owners they mentioned this as the biggest challenge as they would have to negotiate with buildings' owners, who may not approve at all or may demand to be compensated by being given free electricity. Interviewed diesel generators' owners also mentioned that in many buildings, the ownership of, and thus access to, the rooftop is not clear. In some cases, the rooftop is co-owned by multiple parties, which makes such negotiations even more complicated.

However, in some cases, owners of the diesel generator networks may have access to a large space nearby (such as a rooftop of an industrial or a commercial facility) that they can take advantage of in return for either renting the space or offering the owner an electricity bill discount. In such a case, the cost must be included in any feasibility analysis. For generator networks operating in rural areas where space limitations are less of an issue, there is a better chance of accessing the required space, which might be given for free as an incentive by the local municipal authority, for example.

82 Such as the case with EDZ 
Third, there are the behavioral and cultural barriers. Adopting or shifting to a new business model must start with an open mindset for change. There is also the "path dependence" effect, which is essentially the tendency to prefer existing means and operations that are well known over those that are less known. Many of the interviewed owners of diesel generators in Lebanon were not aware of the potential business opportunity associated with solar power or other renewable energy sources, although some did have some knowledge and seemed to have thought about solar as an alternative business model. Even for experts, the economic case for distributed solar is not that straightforward - especially when storage, load-management and other technicalities are included - let alone for owners of diesel generators. This may lead to a resistance to adopting new business pathways.

In conclusion, while increasing the penetration of distributed solar PV seems achievable and advisable, it is unlikely that the charge would be led by owners of diesel generator networks. Even for those with access to cash and space, cultural and information barriers are serious impediments. 


\section{Technical Challenges and Solutions}

\subsection{Challenges}

Regardless of the ownership model, distributed solar PV systems pose some serious technical challenges that are dependent on the penetration level of these systems, their capacity and point of contact with electricity grid. However, the type and magnitude of technical challenges do depend on the deployment model; for example, whether the system is connected to the grid or not. In this analysis, the focus is on grid-tied distributed systems that are generally below 500 $\mathrm{kWp}$. As such, the discussed technical challenges are more relevant to the distribution grid than to the transmission one.

Figure 24 shows the matrix of the technical challenges associated with the deployment of solar PV systems. The matrix is split by concerned party: end-user (household) and utility (EDL); and by short and long-term issues. Long term issues implicitly assume high enough penetration of distributed solar PV systems to make an impact on EDL's operations. In the short term, the biggest challenge that is related to Lebanon's power sector is the "islanding" effect, which requires on-grid renewable sources to immediately disconnect from the grid once the central electricity supply is disrupted. This requirement is mainly to protect the grid's infrastructure and for the safety of personnel who might be working during power cuts. The islanding effect is prominent in Lebanon, given the high frequency of power outages, which leads to an economic challenge due to wasted energy (in the absence of storage). In fact, this has been one of the main challenges of currently commissioned solar PV projects in Lebanon, based on the interviews conducted for this study.

Another technical challenge that would span over the short and long terms is power loss, but this will be more of an issue for the power utility, EDL. One of the main advantages of distributed systems is that they lower or eliminate transmission and distribution losses, since the energy they generate is produced very close to where it is consumed. However, when there is an excess of energy, it will be transported back to the grid. In Lebanon, this is expected to be a serious issue since the distribution grid is not of good quality, with already existing losses. Effectively, what this could mean for EDL is lost revenue, because according to the net-metering mechanism, power outflow is metered at the exporting end-user, but by the time it reaches the consuming end-user, a percentage would have been lost along the way.

Figure 24: Matrix of technical challenges of distributed solar PV systems

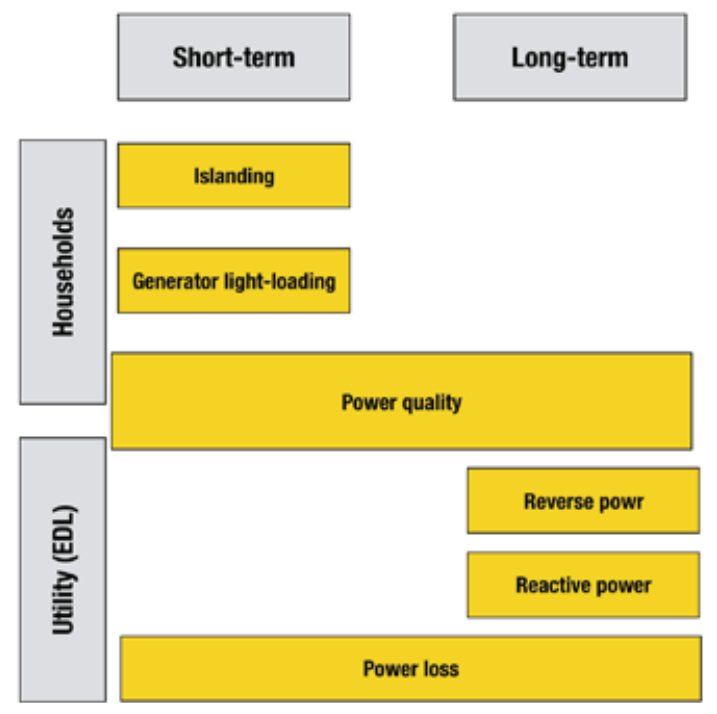

In the short term, power quality issues seem to be a common challenge for both households and EDL. The poor quality is mainly due to intermittency and voltage and current swings, as well as power harmonics created by the inverters. On the household level, this can negatively impact the performance and lifetime of electric appliances ${ }^{83}$ From the utility perspective, the issue of power quality is proportional to the capacity installed at the so-called "point of common coupling." In the case that high capacities are added (more than $500 \mathrm{kWp}$ ), a grid impact assessment might be required. This could well be an issue in the long term but might be addressed by the development of inexpensive storage solutions, which could be deployed in part to provide better power quality, as discussed in the solutions Section below. 
In the long term, increased penetration of distributed solar PV is also expected to induce reverse and reactive power issues. Reverse power occurs when the production on the distributed level (low voltage) exceeds the demand fed by local feeder, such as at noon on a spring day. This could overload distribution feeders and lead to malfunction in their operations.

Another challenge that is perhaps less technical is the soiling and accumulation of dust. The effect of dust is widely reported as reducing the efficiency of solar panels. ${ }^{84}$ In Lebanon, a recent study based on real collected data of a 300 $\mathrm{kWp}$ solar PV project showed that regular cleaning resulted in an improvement of around $32 \%$ in energy output. ${ }^{85} \mathrm{Clearly}$, cleaning increases the O\&M costs of solar PV projects, but with the existence of robotic solutions, these costs can be minimized.

\subsection{Solutions}

Higher penetration of distributed solar PV faces significant technical challenges, as discussed above. However, there are some existing and emerging solutions to these challenges. These solutions are primarily driven by the urgent need of countries around the world to scale up their renewable energy generation and the corresponding reaction from the solar industry and its auxiliary affiliates such as electricity storage and control applications. Table 24 lists the challenges discussed above and their corresponding solutions or potential solutions; as well as the requirements and limitations of these solutions in the Lebanese context.

It is evident by now that storage solutions are solar PV's biggest support. Incorporating storage, for on-grid systems operating on a "dual-mode" could reduce power waste due to the islanding effect that is common in Lebanon due to the frequent outages. In terms of short-term solutions that can be deployed to deal with the islanding effect, until storage solutions become cost competitive, EDL could start by implementing a smart rationing system, in which it would prioritize its supply hours to the areas with a solar generation above a certain threshold that would make a difference to its operations. Clearly, this strategy would also need to take into account the other factors that are currently (or in the future) used by EDL in deciding its power rationing policies.

Islanding does not only pose an economic issue due to wasted solar generation (in the absence of storage); it also poses a safety issue. As such, implementing active and passive grid connection detection techniques would be important, especially during unplanned EDL outages. ${ }^{86}$ In terms of resolving power quality issues, once again, storage solutions can be of great help. Battery storage coupled with a smart controller can be a good tool to smoothen frequency and voltage swings. However, again, these components would substantially increase system's total costs. ${ }^{87}$

It should also be noted that electricity provision in Lebanon, even without the introduction of intermittent renewables, is tainted with power quality issues. ${ }^{88}$ Some of the quality issues are due to the under-voltage created by heavy consumption at certain grid nodes. In that case, installing solar PV systems nearby could lead to an improvement in power quality.

Although the concept of big data might sound alien in the Lebanese context, given the existing challenges faced by the sector and EDL, utilizing big data analytics can be a powerful tool to transition Lebanon into the next phase of its energy planning and strategy. With the increased adoption of smart meters, EDL would be able to collect consumption data on a much more refined time scale than now. ${ }^{89}$ The large volume of data available to be collected and processed could help EDL and other beneficiaries study consumption patterns and other variables that could then be used to optimize operations and test various policy instruments.

84 For example, Muhammed Adinoyi and Sayed Sid found that accumulation of dust could reduce the performance solar modules by up to 50\%. See: https://www.sciencedirect.com/science/article/pii/S0960148113003078

85 See: https://www.sciencedirect.com/science/article/pii/S0038092X19303366

86 Broadly speaking, passive detection techniques rely on deviations in some parameters such as voltage and frequency at the point of common coupling. On the other hand, active techniques reply on the inverter continuously exchanging signals with the grid to test for connection.

87 At this stage, using batteries to deal with power quality issues is mainly practiced at utility-scale projects due to imposed codes and regulations.

88 Source: Extracted from an interview with Raymond Ghajar, advisor at the MOEW (Currently Minister of Energy and Water).

89 Currently, EDL issues consumption bills every two months. 


\begin{tabular}{|c|c|c|}
\hline Challenge & Solutions & Requirements/Limitations \\
\hline Islanding & $\begin{array}{l}\text { - Smart rationing system by EDL } \\
\text { - Storage } \\
\text { - Active and passive detection }\end{array}$ & $\begin{array}{l}\text { - Capacity building at EDL's level } \\
\text { - Cost } \\
\text { - Cost and technical capacity }\end{array}$ \\
\hline Power quality & $\begin{array}{l}\text { - Implementation of advanced control methods } \\
\text { - Storage } \\
\text { - Flexible appliances }\end{array}$ & $\begin{array}{l}\text { - Cost and technical capacity } \\
\text { - Cost }\end{array}$ \\
\hline $\begin{array}{l}\text { Reverse and Reactive } \\
\text { Power }\end{array}$ & $\begin{array}{l}\text { - Big data analytics } \\
\text { - Supply-demand management }\end{array}$ & $\begin{array}{l}\text { - Wide use of smart meters } \\
\text { - Smart inverters } \\
\text { - Power quality sensors } \\
\text { - Technical capacity }\end{array}$ \\
\hline Power loss & $\begin{array}{l}\text { - Connecting to the medium voltage grid } \\
\text { - Smart grid }\end{array}$ & $\begin{array}{l}\text { - Capacity threshold } \\
\text { - Cost (transformers) }\end{array}$ \\
\hline
\end{tabular}

Big data applications do not stop at the consumer level but also extend to the transmission and distribution operations with real data collection of the distributed generation units connected to the grid, such as solar rooftops systems. On the other hand, continuous collection of climatic data such as solar irradiation, temperature and wind data can be fed into a multi-supply model and optimized according to demand load and its variations to forecast generation from intermittent power sources. However, cleaning and processing such data would require a serious attempt by EDL to expand its technical capacity in data science and management. This would ultimately become part of transitioning EDL into a modern power utility.

As for dealing with the challenge of power loss in the case of a reverse flow of electricity from the distributed source back to the connecting utility grid, this could be mitigated by connecting the source directly to the medium voltage lines. This, however, would require installed capacity at the source to exceed a certain threshold, between 0.1 to $1 \mathrm{MWp} .^{90}$ The advantage of connecting to the medium voltage network is that it avoids the extra losses in the distribution grid. It should be noted, however, that while connecting distributed solar PV to the low-voltage grid can pose a capacity limit, voltage swings become a more prominent issue when those sources are connected to the medium-voltage lines. ${ }^{91}$ On the other hand, investing in a smart grid could optimize the linking between consumption and production centers. This would require live and active data monitoring as well as some reliance on machine learning in the future to input the effect of climatic changes such as temperature.

Due to EDL's high combined technical and non-technical losses, the self-consumption model remains preferable for the time being. Consequently, for any policy instrument that is based on feeding distributed renewables into EDL's grid to be successful, it must be preceded by lowering these losses to an acceptable level (usually below 10\%, combined). Simply put, not resolving grid losses would render distributed renewables unviable as it would increase the cost of delivery, which is already heavily subsidized. From EDL's perspective, if the absorbed quantities are priced equal to or higher than the average tariff (currently around 9 cents per kWh), feeding renewable electricity into its grid would be an additional downward pressure on the utility's finances.

\section{Energy Security Considerations}

"Energy security" was coined as a term and became a widely used concept following the so-called Arab oil embargo in the early 1970s. This led to the emergence of energy security policies, mainly in Western countries, that focused on ensuring an undisrupted supply of oil. In recent years, energy policies expanded the scope of energy security beyond the sole purpose of ensuring an uninterrupted supply of fuels to cover new components such as availability, accessibility, affordability and acceptability (known as the 4As). Now, with the current complexities of energy markets and policies, it would be fair to assume that energy security means different things to different countries or even to different stakeholders within the same country.

90 See: https://data2.unhcr.org/fr/documents/download/65011

91 This is primarily based on a review of the German experience. See: https://www.sciencedirect.com/science/article/pii/ S0960148117311461 
In Lebanon, where the chronic electricity deficit is reflected in prolonged power outages and their subsequent toll on the economy, the resulting quality-of-life concerns of the Lebanese public mean that the availability component has taken priority over other considerations. In this regard, diesel generators have enhanced Lebanon's energy security by allowing the country to continue to function when its power infrastructure was targeted (this is discussed in greater detail below). However, and as discussed in Chapter 12, environmental and public health considerations have gained more attention in recent years, with more studies showing the impacts of fossil fuel-fired power generation, especially from the widespread use of diesel generators.

\subsection{Attacks on Lebanon's power sector}

Energy facilities - be it power generation plants or transmission and distribution infrastructure -- are generally one of the preferred targets during wars and armed conflicts, because disabling them promptly and deeply affects all aspects of life. Power generation in Lebanon has been one of the sectors most affected by armed conflicts, directly through external aggression by Israel and the civil war's infighting, which resulted in substantial destruction of EDL's generation, transmission and distribution assets.

Clearly, some of the power sector's failings in Lebanon can be attributed to the accumulated impact of the frequent attacks on the sector's infrastructure. Figure 25 lists the major Israeli attacks on Lebanon's electricity generation and transmission assets. ${ }^{92}$ Those attacks on centralized power plants have ultimately contributed to the wide deployment of diesel generators. In the 2006 war, Israeli attacks forced EDL to zero its power output, and the whole country was mostly running on the distributed diesel generator units, mitigating what would have been otherwise a complete blackout.

Figure 25: Major attacks on Lebanon's power sector's infrastructure

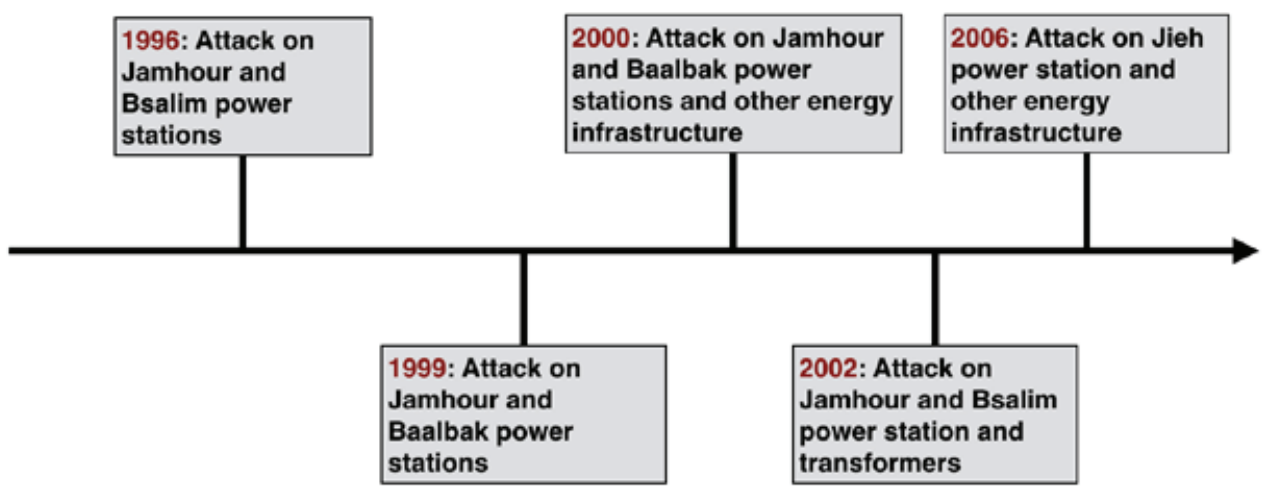

\subsection{Energy security and distributed renewable energy}

As discussed above, from an energy security perspective, the wide reliance on diesel generators in Lebanon has been a "blessing in disguise" during forced or unplanned outages, especially during military attacks on power infrastructure. However, the spread of diesel generators solves one problem: the vulnerability of central power generation. It does not eliminate the reliance on importing and transporting fuel, which can be also disrupted. In fact, disruption of petrol supply can be due to exogenous factors affecting the value chain of the oil and gas industry, such as regional wars, terrorist attacks on pipelines and terminals, and even natural disasters.

Moreover - and highlighting the expanded definition of energy security -- reliance on fossil fuels for power generation, be it in centralized or distributed systems, makes the system vulnerable to price volatility, which can ultimately affect the affordability of generating power. A disruption in the supply of petrol derivatives could result in a spike in the prices of oil and gas (and diesel).

Figure 26 provides an overview of five energy security vulnerabilities and how thermal and renewable energy generation rank at the utility-scale and distributed levels. These vulnerabilities are: fuel supply disruption, fuel price volatility, impact of disruptions (proportional to the number of customers supplied with power), social acceptability, and environmental impact.93

92 Many other attacks took place that targeted regional substations, transmission lines, etc.

93 Environmental impact in this context only refers to carbon and other greenhouse emissions. 
In terms of the impact of disruption, centralized, utility-scale, power plants have the highest vulnerability, regardless of whether they are thermal or renewables-based. This is an intrinsic weakness that is correlated with the capacity of the power plant. In other words, the larger the capacity, the higher the number of people who would be impacted by any disruptions of its operations. Distributed systems, on the other hand, provide power to a much smaller subset of customers and consequently have a much lower impact. ${ }^{94}$ The declining cost of solar PV modules has contributed to their wide deployment in conflict-affected regions such as in the Gaza strip ${ }^{95}$ and Yemen ${ }^{96}$, especially since large and centralized power stations were constantly targeted.

Figure 26: Vulnerabilities of thermal and renewables power generation at the utility-scale and distributed levels

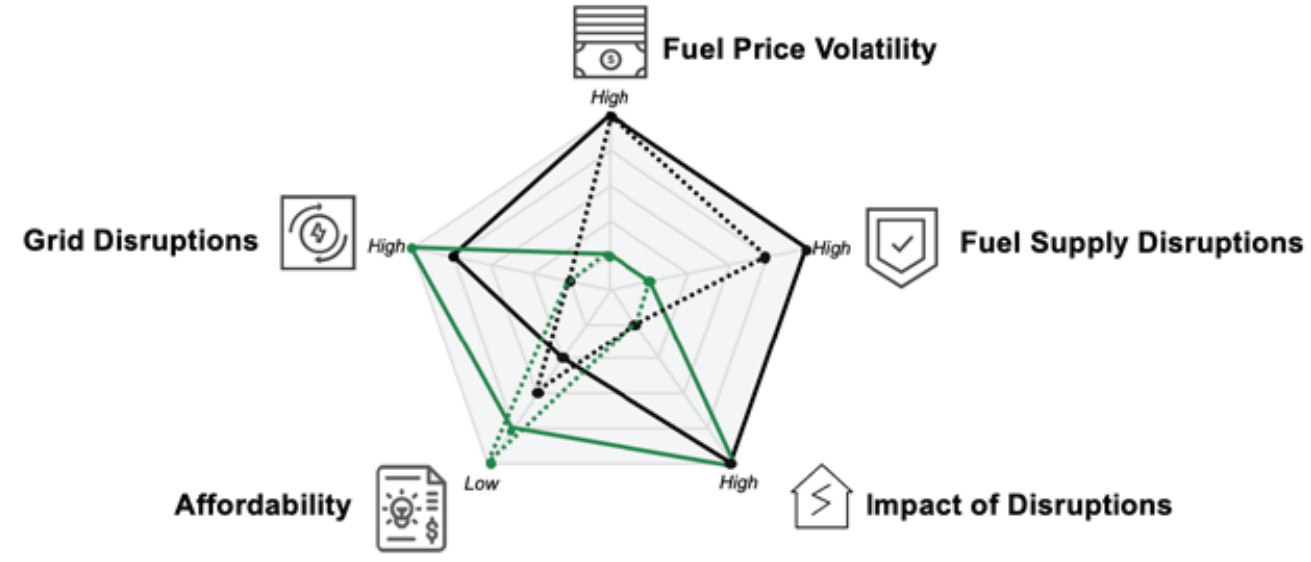

$\rightarrow$ Utility-scale (thermal)

.... Distributed (thermal)

$\rightarrow$ Utility-scale (RE)

... Distributed (RE)

As for fuel supply disruptions, both utility-scale and distributed thermal generation have a high level of vulnerability, though distributed generation has the slight advantage of being able to procure fuel in smaller amounts, which could be easier to transport (and smuggle!). ${ }^{97}$ Clearly, renewables, at any scale, are free of this vulnerability, which is one of their major advantages.

In the case of centralized power plants, disruptions may also emerge from the transmission and distribution systems. Grid disruptions can be either physical, such as those resulting from a military attack or a natural disaster; ${ }^{98}$ or cyberbased, in which the grid control system is attacked. ${ }^{99}$ Such vulnerabilities are significantly reduced by the shift towards distributed systems. In the case of Hurricane Maria in Puerto Rico in 2017, the natural disaster led to a complete blackout of the country, except where generators where installed. In the aftermath of the hurricane, small-scale solar PV systems and batteries contributed to providing power in the absence of grid connections. ${ }^{100}$ The prompt deployment of distributed renewables in Puerto Rico and other places around the world after a natural disaster is directly linked to the concept of "energy resilience." By eliminating dependency on vulnerable grid infrastructure, distributed power generation is inherently more resilient compared to centralized power plants.

In the extended definition of energy security discussed above, affordability is recognized as a major component. In the current situation with the renewable energy market in Lebanon and given the high upfront capital costs of solar PV

94 If, for example, a diesel generator stopped working, the operator might use a back-up one or the customer might choose to shift to another operator.

95 See: https://www.worldbank.org/en/news/press-release/2018/10/10/improving-energy-security-in-gaza-throughsolar-energy

96 See: https://blogs.worldbank.org/arabvoices/glimpse-light-yemen-enabling-booming-solar-industry-throughentrepreneurship-and-innovation

97 In fact, some of the diesel fuel used by owners of diesel generators, especially those located close to the Lebanon-Syria borders, is smuggled from Syria. Smuggled Syrian petrol is sold at a lower price than that sold in Lebanon. See: http://nnaleb.gov.lb/en/show-news/92102/nna-leb.gov.lb/en

98 Such as the case with the damage induced by Hurricane Maria that hit Puerto Rico in 2017.

99 Such as the cyberattack against the power grid of Ukraine in 2017, allegedly by Russian hackers.

100 In fact, in a report published by the US Department of Energy (DOE), microgrid consisting of solar PV and storage systems have been recommended to provide resilience enhancement. See: https://www.energy.gov/sites/prod/files/2018/06/f53/ DOE\%20Report_Energy\%20Resilience\%20Solutions\%20for\%20the\%20PR\%20Grid\%20Final\%20June\%202018.pdf 
systems, this is the only component in which renewables are at a disadvantage compared to thermal systems. This is especially true for distributed renewables, given the negative impact of the diseconomies of scale. ${ }^{101}$

Beside the components shown in Figure 26, both social acceptability and environmental impact are also essential components, yet they are often overlooked in the Lebanese context. While the environmental impact of distributed diesel generators is discussed in details in Chapter 12 below, generally speaking, distributed renewables have a better social acceptability in Lebanon than the demonized diesel generators and their operators.

\section{Environmental Impact}

Reliance on diesel generators to provide electricity during EDL outages entails some serious environmental and health consequences, which are magnified by the fact that most generators are deployed in densely populated urban areas. Since the use of diesel generators is widespread in Lebanon, there have been several studies conducted on their impact on public health.

\subsection{Diesel generator emissions}

Figure 27 shows the estimated 2018 Greenhouse Gases Inventory (GHI) on the national, energy sector and electricity sector level. The national GHI in 2018 is estimated at $31 \mathrm{Gg} \mathrm{CO2eq.} \mathrm{This} \mathrm{value} \mathrm{was} \mathrm{calculated} \mathrm{based} \mathrm{on} \mathrm{the} \mathrm{latest} \mathrm{official}$ $\mathrm{GHI}$ value estimated for the year $2013(26.28 \mathrm{Gg} \mathrm{CO} 2 \mathrm{eq})$ and the average annual growth factor of $3.4 \% .{ }^{102}$ Based on 2013 numbers, and assuming that the same ratio has been maintained, the energy sector contributed $79 \%$ of the national $\mathrm{GHI}$, which is equivalent to about $25 \mathrm{Gg} \mathrm{CO2eq} \mathrm{in} \mathrm{2018.} \mathrm{Similarly,} \mathrm{35.6 \%} \mathrm{of} \mathrm{the} \mathrm{energy} \mathrm{sector's} \mathrm{GHI} \mathrm{is} \mathrm{attributed} \mathrm{to} \mathrm{power}$ generation, which is equal to about $9 \mathrm{Gg}$ CO2eq.

Figure 27: Estimated national, energy sector and electricity sector GHI in 2018

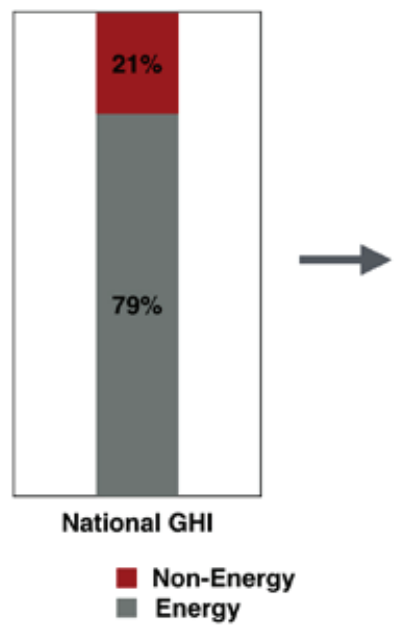

31000 Gg CO2eq

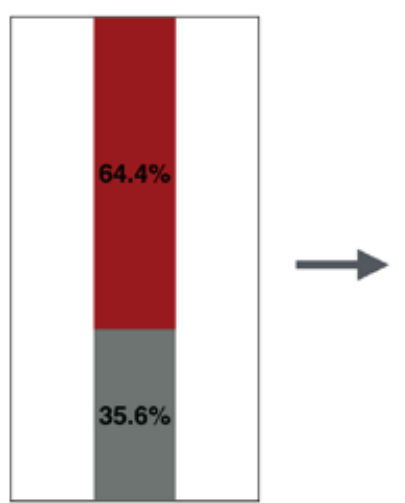

Energy GHI

- Other

Energy Industries

$25000 \mathrm{Gg} \mathrm{CO} e \mathrm{eq}$

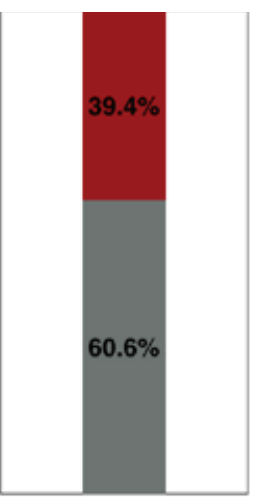

Electricity GHI

Diesel Generators

- EDL

$9000 \mathrm{Gg} \mathrm{CO2eq}$

Table 25 shows that private diesel power generation comprises around 37\% of the total electricity in Lebanon in 2018 . Applying the emission factors for both EDL and generator electricity, diesel generators are estimated to have contributed around $39 \%$ of the total electricity $\mathrm{GHI}$ in 2018 , which is equivalent to $3400 \mathrm{Gg}$ CO2eq, $11.4 \%$ of Lebanon's total GHI emissions. ${ }^{103}$

The content of emissions released by the combustion of the diesel oil used in private generators depends on the emission factors of the used diesel fuel and its chemical composition. First, the data shown in Table 25 is used to estimate the

101 It should be noted that affordability here refers to the upfront capital cost requirements and not to the levelized, per kWh, cost of electricity.

102 See Lebanon's Second Biennial Update Report to the UNFCCC. http://climatechange.moe.gov.lb/Library/Files/ Uploaded\%20Files/Lebanon\%20BURII\%202017.pdf

103 The applied grid emission factors are 0.667096 and 0.710861 for EDL and private generation, respectively. Source: Lebanon's Second Biennial Update Report to the UNFCCC. 
amount of diesel fuel consumed in 2018 (in kg). ${ }^{104}$ The emission factors for the main pollutants other than CO2 (carbon monoxide, nitrogen oxide and sulfur oxide), shown in Table 26, were used to estimate the amount generated by the operations of diesel generators. ${ }^{105}$

Table 25: Estimate of the amount of diesel fuel consumed for private generation in 2018

\begin{tabular}{lll}
\hline Parameter & Unit & Value \\
\hline Private power generation & TWh & 8.1 \\
Generators' T\&D losses & $\%$ & $5 \%$ \\
Thermal generation & TWh & 8.5 \\
Average energy conversion rate & $\mathrm{kWh} / \mathrm{L}$ & 3.2 \\
Estimated amount of diesel fuel & $\mathrm{L}$ & 2664473684 \\
Estimated amount of diesel fuel & $\mathrm{kg}$ & 2264802632
\end{tabular}

Additionally, the release of fine particulate matter (PM) has also been linked to serious impacts on human health. Clearly, the size of the particles plays a major factor in their impact, with small particles (less than 10 micrometers in diameter) having the biggest impact as they can more easily get in to critical organs such as lungs and even blood stream. ${ }^{106}$ Beirut City is characterized by high levels of air pollution and PM. ${ }^{107}$ Although PM mostly originates from the transport sector, diesel generators were also shown to be contributing to the high levels.

Table 26: Emissions of private diesel generators in 2018

$\begin{array}{lll}\text { Pollutant } & \text { Emission Factor }(\mathbf{g} / \mathbf{k g}) & \text { Emissions }(\mathbf{1 0 0 0} \text { ton) } \\ \text { CO } & 15 & 33.97 \\ \text { NOx } & 25.28 & 57.25 \\ \text { SOx } & 3.68 & 8.33 \\ \text { PM } & 1.28 & 2.90\end{array}$

According to an ongoing AUB study on air pollution resulting from diesel generators deployed within Beirut City, the most important factor in mitigating the effects of generators' emissions is the location of the generator stack. Stacks that extended to the building rooftop and above were shown to create a significantly lower concentration of emissions compared to generators placed at the street level.

In terms of health impact, according to a 2013 AUB study, the use of diesel generators for only three hours per day accounted for $38 \%$ of the daily carcinogen exposure in the Hamra area of Beirut. This represents an increased exposure of approximately $60 \%$ over the background levels had no generators been present. ${ }^{108}$ Likewise, the noise generated by the running of diesel generators in large numbers in densely populated areas is an often-overlooked type of pollution, which can lead to adverse health impacts such as hearing impairment, hypertension, ischemic heart disease, anxiety, andsleepdisturbance. ${ }^{109}$

104 Using a specific density of diesel oil of 0.85

105 The emission factors in Table 26 were obtained from a recent study on the environmental impact of back-up diesel generators. See: https://www.sciencedirect.com/science/article/abs/pii/S1309104218302824

106 For more details on this, see: https://www.epa.gov/pm-pollution/health-and-environmental-effects-particulate-matterpm

107 According to a 2015 study, the annual average concentrations of PM $_{10}$ and PM ${ }_{2.5}$ exceeded WHO's annual average limits by $150 \%$ and $200 \%$ respectively. See: https://www.ncbi.nlm.nih.gov/pmc/articles/PMC4491268/

108 Effect of distributed electric power generation on household exposure to airborne carcinogens in Beirut. http://www.aub. edu.lb/ifi/Documents/publications/research_reports/2012-2013/20130207ifi_rsr_cc_effect\%20Diesel.pdf

109 See: https://www.ncbi.nlm.nih.gov/pmc/articles/PMC1637786/ 


\subsection{Environmental impact of scaling-up distributed RE systems}

Scaling-up of renewable energy sources for both utility-scale and distributed power generation will ultimately have the result of reducing Lebanon's GHI. The scale of such reduction would depend on the level of RE penetration in the country's energy mix. Figure 28 shows the reduction of CO2eq levels under different assumed scenarios. The descriptions of the examined scenarios are listed in Table 27 .Based on Figure 28, replacing all diesel generator capacity with the existing EDL mix of generation (Scenario B) yields around only $6 \%$ reduction in emissions. This is because private and EDL generation have similar emission factors of 0.71 and $0.67 \mathrm{tCO} e q$, respectively. This is primarily because most of EDL power is generated with diesel and heavy fuel oil. Scenario C, where the reduction in emissions is more substantial, at $27 \%$, reflects a case in which all the diesel generator capacity is replaced with power plants fueled by natural gas

Table 27: Description of scenarios shown in Figure 28

$\begin{array}{ll}\text { Scenario } & \text { Description } \\ \text { A } & \text { Baseline scenario (2018 emission levels) } \\ \text { B } & \text { Generators are replaced by existing EDL mix } \\ \text { C } & \text { Generators are replaced by gas-fired plants } \\ \text { D } & 100 \mathrm{MWp} \text { of solar PV (distributed) } \\ \text { E } & 100 \mathrm{MWp} \text { of solar PV (utility-scale) }\end{array}$

The impact of introducing RE (solar PV) is shown in scenarios D and E. In Scenario D, 100 MWp of solar PV is installed to replace the diesel generators, while in Scenario E, the same capacity is added as a utility-scale project(s). Since distributed generators have a higher emission factor, replacing them with RE yields bigger reductions. For each MWp added to the distributed generation in Lebanon, approximately 1000 tCO2eq is removed.

Figure 28: Reduction in CO2eq emissions under various scenarios
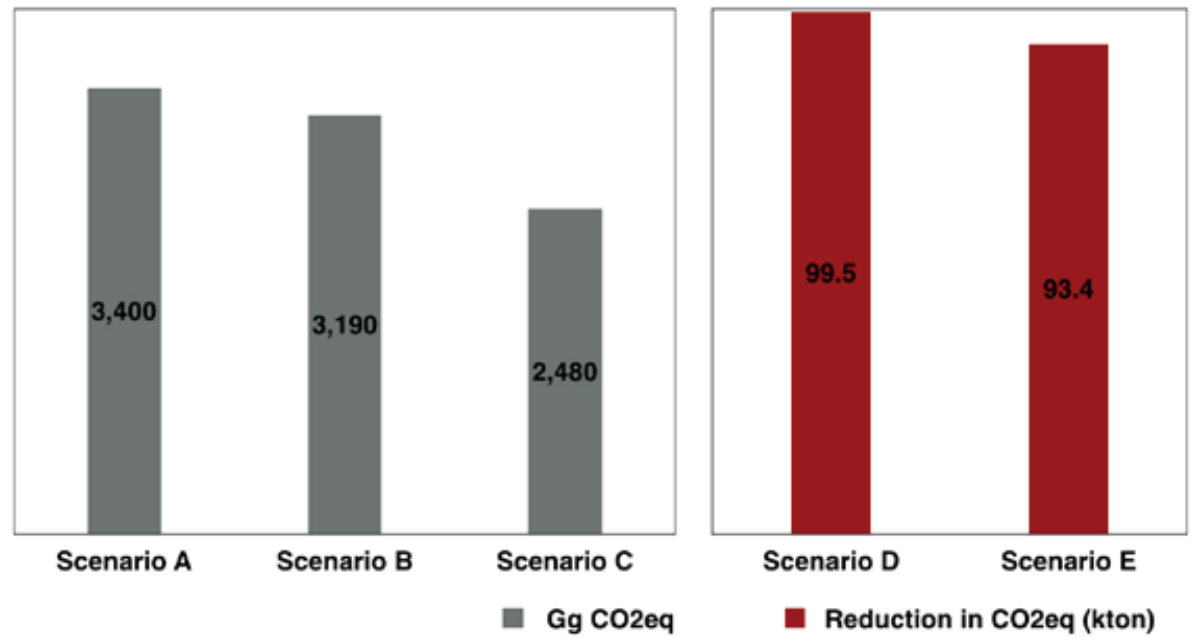
ANNEXES 


\section{APPENDIX A: CURRENT POLICY INSTRUMENTS}

\section{A.1 NEEREA Mechanism}

The National Energy Efficiency and Renewable Energy Action (NEEREA), is a green financing initiative that was launched by the Central Bank of Lebanon (BDL) in November 2010, in collaboration with MOEW, MOF, UNDP, and the EU. The mechanism stipulates that BDL provides subsidized "green" loans to individuals, commercial and industrial firms to support projects that target either improving energy efficiency or renewable energy power generation (for self-consumption). The loans are given through Lebanese commercial banks and supported by BDL with a low interest rate (currently standing at $2.75 \%)$ with a repayment period of up to 14 years. Currently, NEEREA covers the following activities: ${ }^{110}$

- Interior and exterior efficient lighting systems

- Efficient ventilation and heating systems

- Building envelope applications

- Solar, wind, hydro, geothermal and biomass applications

In 2017, the total investments in distributed solar PV reached $\$ 18.23$ million, three quarter of which (\$13.19 million) are financed through the NEEREA mechanism. In terms of capacity, 64\% of total installed capacity up to 2017 is NEEREAfinanced. This shows both the impact of NEEREA and the dependency on it in the Lebanese distributed solar energy market. In fact, interviewed solar companies have all emphasized the impact of the increase in NEEREA's interest rates on slowing down the growth rates of the solar energy market in Lebanon. NEEREA was designed to kick off the deployment of distributed renewables, especially solar PV systems; however, it is not a financially sustainable tool in the long-term. NEEREA could serve as an important bridging mechanism until learning has been established and costs decrease further. However, the economic impact of distributed renewables should be measured based on unsubsidized cost estimates that are reflective of their real cost on Lebanon's economy.

Furthermore, the sustainability of the NEEREA mechanism is under pressure given the escalating fiscal crisis in Lebanon. BDL and the involved commercial banks were not able to continue offering green loan subsidization as of March 2018 due to quota depletion, similar to what happened with housing loans. After rounds of reviews and discussions, the green energy loans were re-initiated at the end of 2018/beginning of 2019 but with higher interest rates reaching around $2.75 \%$ instead of the $0 \%$ and $1 \%$ given in the earlier phase.

\section{A.2 Net-Metering}

Net-metering is a globally recognized incentive to encourage consumers to benefit from distributed, grid-tied, renewables, particularly solar PV, by lowering their electricity bill. In Lebanon, the potential benefits of net-metering go beyond the consumer level to directly benefit EDL, as its losses proportionally increase with the amount of power it generates. Given that the average EDL tariff is 9 cents/kWh and its cost of production is between 16 and 20 cents/kWh, every kWh generated on the distributed level by solar power or other sources saves EDL between 7 and 11 cents.

Net-metering in Lebanon was launched by the MOEW and EDL in 2011. The mechanism stipulates that a bidirectional meter is installed on the end-user level, which measures the electricity flow from and to EDL's grid. The end-user is then billed based on the net energy consumption. At the end of each year, the remaining balance between both parties is zeroed, and the counter starts again. ${ }^{111}$ So far, most of the net-metering users belong to the commercial and industrial sectors for the reasons mentioned in Section 3.1 above. However, net metering in Lebanon suffers some serious technical challenges that will be discussed in detail later.

From a procedural perspective, while there is a set of "expected" technical requirements to connect to EDL's grid on a net-metering arrangement, there is no enforcement or penalty mechanism, except that EDL's contract states that the owner of the distributed system must take care of all protection measures, such as the installation of disconnectors.

110 According to LCEC's numbers, the financing tool has covered around 400 green projects until 2016.

111 This aspect may prove to be a challenge, especially for users whose energy generation exceeded their consumption and who may want to carry over their balance to the next fiscal year. While the magnitude of this issue is not yet clear, it indicates that some of the net-metering adopted policies and measures may need to be regularly revised to make the process more fair and efficient. 
After an application is submitted to EDL, the utility then checks for the eligibility conditions and studies the file and supportive documents. This process takes around three months to be completed. Once approved, the applicant and EDL sign a contract, which will be followed by technical support visits by EDL engineers and technicians to ensure proper connections and compliance.

According to current procedures, EDL considers net-metering applications on a case-by-case basis. ${ }^{112}$ It should be noted that based on current laws and regulations, private wheeling - where private producers sell to private consumers - is not allowed. ${ }^{113}$ Distributed solar can only be supplied to EDL's grid under a net-metering arrangement or if given a special concession by the government, but again, only to sell electricity to EDL's grid. ${ }^{114}$

\section{A.3 Other Green Financing Mechanisms}

In addition to the above mechanisms, there are a number of avenues available for financing local renewable energy projects in Lebanon.

One such pathway is the Lebanon Energy Efficiency and Renewable Energy Financing Facility (LEEREFF), which provides dedicated financing for local green energy projects, as well as free technical assistance by international team of engineers. Developed by the European Investment Bank (EIB), the French Development Agency (AFD) and Banque du Liban (BDL), the facility aims to support investments in energy efficiency, renewable energy, and green building by private companies in Lebanon, both large and small. LEEREFF offers standard loans of 40,000 to 250,000 euros for small projects that will achieve at least a 20 percent energy savings and nonstandard investment loans of 250,000 to 15 million euros for a diverse range of larger projects.

The Green Economy Financing Facility (GEFF) offers another potential pathway. With 4 billion euros in funding from the European Bank for Reconstruction and Development (EBRD), the project aims to reduce greenhouse gas emissions by financing green energy projects around the world. The facility operates through a network of more than 130 local financial institutions across 24 countries, providing credit lines to local institutions so they, in turn, can fund local beneficiaries. More than 120,000 clients have benefited from the program to date and, as a result, have avoided more than 7 million tons of carbon dioxide emissions. GEFF also provides advisory services aimed at helping financial institutions and their clients improve their market practices. In Lebanon, specifically, the facility will provide up to $\$ 190$ million to local commercial banks to finance energy efficiency, renewable energy, and resource efficiency projects.

112 See the application page that gives the sort of question EDL asks in their net-metering applications: http://edlnetmetering. com/ar/application

113 Wheeling is only practiced by EDL when power is purchased from either power ships or from Syria.

114 You can find a net-metering template contract on this link: http://www.edl.gov.lb/media/docs/NetMetering.pdf. The link also includes all the forms to be filled by the applicant. 


\section{APPENDIX B: EVOLUTION OF GOVERNMENT'S POLICIES TOWARDS DISTRIBUTED POWER GENERATION}

\section{B.1 Evolution of regulations and control over the operations of commercial diesel generator owners}

\begin{tabular}{|c|c|c|c|}
\hline Date & $\begin{array}{l}\text { Document Type } \\
\text { and number }\end{array}$ & Issued By & Description \\
\hline $14 / 12 / 2011$ & Decree \# 2 & $\mathrm{COM}$ & $\begin{array}{l}\text { Mandating MOEW, MOET and MOI to take the necessary } \\
\text { measures to enforce the implementation of the diesel generator } \\
\text { tariff issued by the MOEW }\end{array}$ \\
\hline $29 / 07 / 2013$ & Circular \# 11/1 & MOE & $\begin{array}{l}\text { Controlling the operations of diesel generators with capacity } \\
\text { higher than } 0.25 \mathrm{MW} \text { and specifies emissions limits values }\end{array}$ \\
\hline $21 / 01 / 2014$ & Decision \# 59/1 & MOF & $\begin{array}{l}\text { Imposing a } 30 \% \text { average income tax on commercial diesel } \\
\text { generator owners }\end{array}$ \\
\hline $15 / 05 / 2017$ & Decision \# 2617 & MOJ & $\begin{array}{l}\text { Requesting the High Judicial Council to impose more intense } \\
\text { sanctions in the face of violations by generator owners }\end{array}$ \\
\hline 28/07/2017 & Decision \# 135 & MOET & $\begin{array}{l}\text { Laying out the MOET's requirements that must be followed by } \\
\text { generator owners including installing meters and implementing } \\
\text { the tariff structure set by the MOEW }\end{array}$ \\
\hline $9 / 7 / 18$ & $\begin{array}{l}\text { Letter to Ministry } \\
\text { of Interiors \& } \\
\text { Municipalities }\end{array}$ & MOET & $\begin{array}{l}\text { Laying out the MOET's requirements that must be followed by } \\
\text { generator owners including installing meters and implementing } \\
\text { the tariff structure set by the MOEW }\end{array}$ \\
\hline $12 / 7 / 18$ & Circular No. 4/1 & MOET & $\begin{array}{l}\text { Obligation of installing meters for each subscriber and } \\
\text { monitoring the pricing of private generators' tariffs }\end{array}$ \\
\hline $12 / 7 / 18$ & Circular No. 5/1 & MOET & $\begin{array}{l}\text { Ensuring to supply the demanded electro-mechanic meters as } \\
\text { per the acceptable specifications and the standards set by EDL }\end{array}$ \\
\hline $28 / 9 / 2018$ & Decision No. 176 & MOET & $\begin{array}{l}\text { Detailing the specifications, cost, place of installation and } \\
\text { metering responsibilities }\end{array}$ \\
\hline
\end{tabular}




\section{B.2 Evolution of RE laws, regulations and government policies}

\begin{tabular}{|c|c|c|c|}
\hline Year & $\begin{array}{l}\text { Document Type } \\
\text { and number }\end{array}$ & Issued By & Description \\
\hline 2002 & Law 462 & $\begin{array}{l}\text { COM; } \\
\text { Ratified by } \\
\text { Parliament }\end{array}$ & $\begin{array}{l}\text { Provided the legal framework for privatization, liberalization and } \\
\text { unbundling of the electricity sector and establishment of an Electricity } \\
\text { Regulatory Authority }\end{array}$ \\
\hline 2010 & $\begin{array}{l}2010 \text { Electricity } \\
\text { Policy Paper }\end{array}$ & MOEW & $\begin{array}{l}\text { Committed to "launching, supporting, and reinforcing all public, private } \\
\text { and individual initiatives to adopt the utilization of renewable energies } \\
\text { to reach } 12 \% \text { of electric and thermal supply" }\end{array}$ \\
\hline 2010 & Circular 236 & $\mathrm{BDL}$ & $\begin{array}{l}\text { Initiated NEEREA, a green financing mechanism that provided low } \\
\text { interest loans for energy efficiency and renewable energy projects. }\end{array}$ \\
\hline 2011 & Circular 32-318 & EDL & $\begin{array}{l}\text { Net-metering mechanism adopted by EDL, which allows owners of } \\
\text { renewable energy systems to export the excess energy produced to } \\
\text { EDL's grid, and in return benefit from an equivalent deduction in their } \\
\text { bill }\end{array}$ \\
\hline 2011 & Decision \#26 & COM & Adoption of National Energy Efficiency Action Plan (NEEAP) \\
\hline 2014 & Law 228 & $\begin{array}{l}\text { COM; } \\
\text { Ratified by } \\
\text { Parliament }\end{array}$ & $\begin{array}{l}\text { Gives the Council of Ministers COM the ability to license independent } \\
\text { power production, upon recommendations by MOEW and MOF, for a } \\
\text { two-year period until a regulatory authority is established. Law } 228 \\
\text { has been extended by law } 139 / 2019 \text { to } 2021\end{array}$ \\
\hline 2016 & Document & MOEW & $\begin{array}{l}\text { NEEAP I| 2016-2020: presented the national targets for RE and } \\
\text { highlighted policies and roadmaps for implementation }\end{array}$ \\
\hline 2018 & PPA Agreement & MOEW & $\begin{array}{l}\text { Signing of three power production agreements for a } 200-\mathrm{MW} \text { wind } \\
\text { farm in the northern governorate of Akkar }\end{array}$ \\
\hline 2019 & $\begin{array}{l}2019 \text { Electricity } \\
\text { Plan }\end{array}$ & MOET & Commits to installing $1 \mathrm{GW}$ of electricity from wind and solar \\
\hline
\end{tabular}

\section{B.3 Role of various ministries and public entities in dealing with distributed RE in Lebanon}

Entity Role

Ministry of Energy and Water (including LCEC)
Ministry of Finance (MoF)
Role

- Setting necessary policies, regulations, decrees and the needed mechanisms to support the implementation of its previously approved plans and policy paper (2010, updated in 2019) in relation to meeting the Renewable Energy targets for both the 2020 goal (12\%) and the 2030 goal (30\%).

- As per Law 288/2014 and its extension, 129/2019, the MOEW is allowed, along with the MOF, to recommend to Council of Ministers RE IPPs for award licenses until the Electricity Regulatory Authority (ERA) is formed.

- The LCEC acts as the technical arm of the MOEW in all issues related to renewable energy, energy efficiency and green buildings. The center assesses project proposals, issues licenses, and monitors implementation of the several projects and initiatives under its mandate.

- Within the framework of Law 129/2019, the MOF is a co-signatory with MOEW on awarding licenses for RE IPPs until the NERA is formed. MOF shall also be represented at the opening of the technical and financial offers for any renewable energy bid. 


\section{Entity}

Ministry of

Environment (MOE)

Bank Du Liban (BDL)

Municipal Authorities

EDL

Parliament
Role

- The MOE coordinates all efforts related to Lebanon's commitments to internationally agreed targets such as the COP21 Paris Agreement. Additionally, the MOE is also concerned in supervising and monitoring all Strategic Environmental Assessments (SEA) and Environmental Impact Assessments (EIA) related to RE projects' implementation.

- Providing and supporting subsidized loans and green financing mechanisms for energy projects as well as setting the necessary initiatives for it, such as NEEREA.

- Developing RE projects within their area of jurisdiction (examples: Kabrikha in the South, and Bchaaleh in the North)

- Implementing the net-metering mechanism and providing technical support.

- Passing and ratifying the necessary laws needed to de-risk renewable energy implementation in Lebanon and removing any potential legal, institutional and constitutional bottlenecks that might arise. 


\section{APPENDIX C: ESTIMATE OF THE NUMBER OF DIESEL GENERATORS IN LEBANON}

Although the energy generated by diesel generators can be easily estimated, it is difficult to obtain an accurate number of generators in Lebanon due to the variable capacities deployed and the lack of data. However, one can estimate the total number of generators using available data and assumptions as well as insights extracted from the conducted interviews.

Two methods were used to estimate the total number of diesel generators in Lebanon. The estimates were based on two methods $A$ and $B$ shown in. Method A is based the imports data of diesel generators, where the data is split into three categories: below 75 KVA, between 75 and 375 KVA and above 375 KVA. The percentage of generators deployed in Lebanon in each category is assumed to be equal to the average percentage of imports of generators in the same category for the last three years. ${ }^{115}$

Figure 29: Estimate of the total number of diesel generators in Lebanon
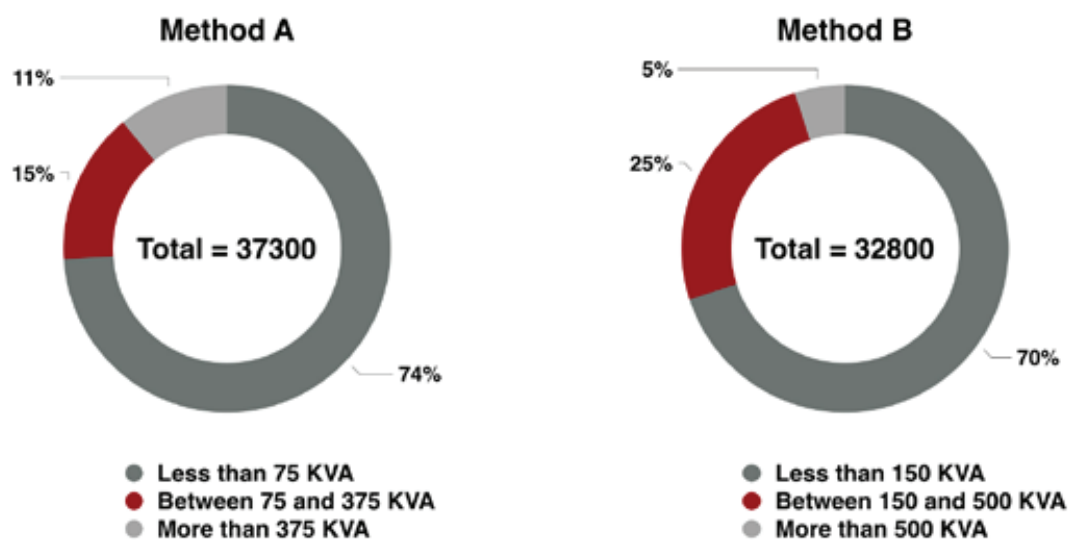

Method B is based on information gathered from interviews with agents and dealers of diesel generators in Lebanon, who provided market insights and approximate percentages in each category. Figure 30 shows the percentage distribution in each category for methods $A$ and $B$. The total number of generators based on method $A$ is about 37,300 while it is 32,800 according to method $B$. The difference between methods $A$ and $B$ is an indicative range of the expected numbers of generators in the country.

Table 28: Number of diesel generators based on methods A and B

\begin{tabular}{lll}
\hline Variable & Unit & Value \\
\hline Total generator capacity & MVA & $\mathbf{1 , 7 3 8}$ \\
\hline DG below 75 KVA & $74.0 \%$ \\
DGs between 75 and 375 KVA & $15.0 \%$ \\
DG above 375 KVA & $11.0 \%$ \\
Average DG capacity for bin below 75 KVA & 37.5 \\
Average DG capacity for bin between 75 and 375 KVA & 100 \\
Average DG capacity for bin higher than 375 KVA & KVA & 500 \\
Estimated number of DG for bin below 75 KVA & KVA & 34,294 \\
Estimated number of DG for bin between 75 and 375 KVA & 2,607 \\
Estimated number of DG for bin between 375 and 750 KVA & 382 \\
Method A: Total Number of Generators & & $\mathbf{3 7 , 2 8 4}$
\end{tabular}

115 This assumption is not fully accurate since a portion of the imported generators are exported back at a later stage. 


\begin{tabular}{|c|c|c|}
\hline Variable & Unit & Value \\
\hline DG below 150 KVA & & $70.0 \%$ \\
\hline DGs between 150 and 500 KVA & & $25.0 \%$ \\
\hline DG above 500 & & $5.0 \%$ \\
\hline Average (weighted) DG capacity for bin below 150 KVA & KVA & 40 \\
\hline Average (weighted) DG capacity for bin between 150 and 500 KVA & KVA & 200 \\
\hline Average (weighted) DG capacity for bin higher than 500 KVA & KVA & 500 \\
\hline Estimated number of DG for bin below $150 \mathrm{KVA}$ & & 30,413 \\
\hline Estimated number of DG for bin between 150 and 500 KVA & & 2,172 \\
\hline Estimated number of DG for bin higher than $500 \mathrm{KVA}$ & & 174 \\
\hline Method B: Total Number of Generators & & 32,759 \\
\hline
\end{tabular}

In terms of individual institutions, lists the capacities of the largest owners of generators in Lebanon, as shared by the interviewed agents and dealers. The power, telecom, military and security sectors are the economic sectors with the highest deployment of back-up diesel generator capacities. It should be noted that some industrial users rely completely on diesel generators, even when EDL power is available, to avoid the risk of sudden power loss, which can be very costly.

As mentioned above, there is no accurate data on the capacity distribution of diesel generators in Lebanon. However, data obtained from agents and dealers show that the highest concentration is in the low-capacity range below 150 KVA, with around $50 \%$ of their sales falling into this category. In terms of commercial generators, their capacity range is between 200 and 500 KVA. ${ }^{116}$ In parallel, data about the capacity of the generators used in 225 buildings located in the Hamra area were obtained for an ongoing study at the American University of Beirut. The capacity distribution of this small sample is shown in Figure 30. The numbers shown in confirm the insights obtained from agents and dealers on the capacity range distribution, as the total percentage of generators of capacity of $150 \mathrm{KVA}$ or less, according to the AUB data, is about $45 \%$, which is close to the $50 \%$ estimate given by the interviewed dealers and agents.

Table 29: Largest users of diesel generators in Lebanon

\begin{tabular}{lll} 
Institution & Sector & Number of DGs/ KVA \\
\hline EDZ & Power & 269 MVA \\
Touch & Telecom & $>500$ \\
Alfa & Telecom & $>500$ \\
Ogero & Telecom & $>300$ \\
Lebanese Army & Military & Unknown \\
General Security & Security & $>300$ \\
Solideir & Real Estate & Unknown \\
Port of Beirut & Public Infrastructure & 6,000 KVA
\end{tabular}

116 Based on interviews with commercial generator owners, if they need to install a capacity of 1,000 KVA, they would still opt for purchasing two 500 KVA generators instead of one 1,000 KVA because 500 KVA ones are more readily available in the market and thus cheaper to obtain than the 1,000 ones, which have higher import and shipping costs. 
Figure 30: Sample distribution of capacities of diesel generators in the Hamra area in Beirut (sample size = 225; source: AUB study)

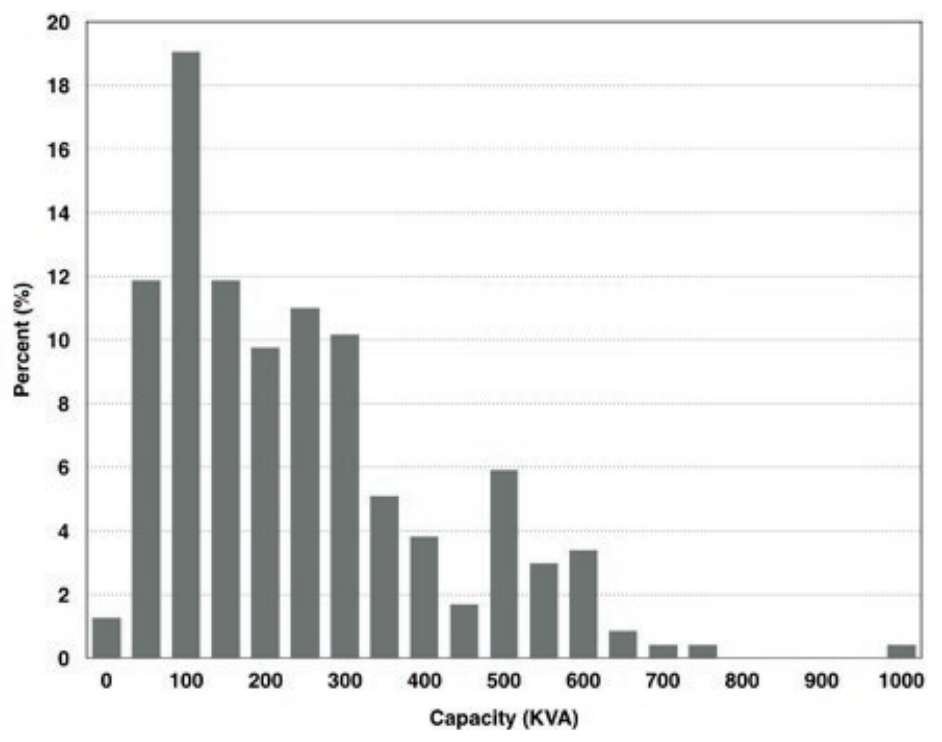




\section{APPENDIX D: METHODS}

\section{D.1 Levelized cost of electricity}

The conventional way to compare the cost of electricity generated by different sources is to calculate the levelized cost of electricity (LCOE). This follows from the standard discounted cash flow methodology, which accounts for the time-value of money. ${ }^{117}$ This methodology is used in this analysis to calculate the life cycle cost of producing distributed electricity from solar PV, Solar PV plus storage and diesel generators. The levelized cost is the ratio of the total cost to the benefits (in this case the electricity produced) with all figures being discounted to the same baseline year (2019). In a way, the LCOE is the break-even price at which electricity must be sold to yield a zero net present value (NPV), and can be expressed as:

$$
L C O E=k+f+v
$$

Where $k, f$ and $v$ are the time-discounted, per kWh, capital, fixed and variable costs, respectively. These three parameters can be expressed as follows:

$$
\begin{gathered}
k=\frac{K}{\sum_{i}^{T} E_{i} \times \alpha_{i}} \\
f=\frac{\sum_{i}^{T} F_{i} \times \alpha_{i}}{\sum_{i}^{T} E_{i} \times \alpha_{i}} \\
v=\sum_{i}^{T} V_{i} \times E_{i} \times \alpha_{i}
\end{gathered}
$$

Where: $i$ denotes the year, $\mathrm{T}$ is the lifetime of the project, $K$ is the overnight capital cost, $E_{i}$ is the annual electricity produced, $F$ is the annual fixed costs, $\mathrm{V}$ is the annual variable cost. All these parameters are discounted by $\alpha_{i}$ the discounting factor expressed as:

$$
\alpha_{i}=\frac{1}{1+r}
$$

Where $r$ is the discount rate.

It should be noted that in the diesel generator case, distribution and infrastructure costs are taken into account and included in the capital cost value, based on the cost analysis presented in the report "Understanding the Diesel Generator Market in Lebanon".

In such type of analyses, an important factor is the discount rate. For the base case, a discount rate of $8 \%$ is assumed. This number is obtained from interviews with financiers and bankers based on their demand for a weighted average cost of capital (WACC) given Lebanon's credit risk rates and fiscal challenges. Also, it should be noted that this is a real discount rate, and inflation is implicitly taken into account. Other (subsidized) scenarios studied below used lower interest rates.

Generally speaking, the cost of electricity produced depends not just on the number of years in which they are delivering power but also the precise distribution of annual capital expenditures. However, for the case of studying distributed energy systems with relatively small-capital requirements, all capital costs are assumed to be spent overnight.

Another factor that strongly affects the relative economics of the different energy systems examined is the capacity factor, which is the ratio of the energy produced in a given year to the amount that could have been produced if the system were to operate at full power all the time. Based on interviews with solar PV companies in Lebanon, the availability factor is somewhere between $16-17 \%$, leading to a specific yield of around $1400 \mathrm{kWh} / \mathrm{kWp} .{ }^{118}$ On the other hand, the capacity factor of diesel generators is assumed at $40 \%$ based on the average power outages (outside Beirut). This value has also been verified by owners of diesel generators who have been interviewed for this study.

For capital costs, the numbers used were based on latest 2019 numbers obtained from interviews with solar PV companies working in the Lebanese market. The current range of costs offered to customers for an on-grid, $500 \mathrm{kWp}$,

117 Richard A Brealey and Stewart C Myers, Principles of Corporate Finance, vol. 6 (Boston: Irwin McGraw-Hill, 2000)

118 In Beirut and coastal cities. 
project is between $\$ 800$ to $\$ 1000$ per $\mathrm{kWh} .{ }^{119}$ As for projects with storage, the average cost for projects across Lebanon has been obtained from the latest UNDP-DREG annual review (2017). As for the diesel generator, the capital costs were obtained from the preceding report.

The ratios of fixed $0 \& M$ costs were also obtained through the combination of interviews with solar companies and the literature. For on-grid systems, solar companies estimate that the fixed annual costs at $2 \%$ of a project's capital costs. As for systems with storage, the ratio is understandably higher due to the presence of extra equipment and a value of $3.6 \%$ has been chosen based on Lazard's latest annual review of levelized cost of storage. ${ }^{120}$ As for diesel generators, they, expectedly, have a much higher fixed costs ratio, which has been estimated at $31.7 \%$ based on cost information included in the previous report.

Finally, the economic lifetime of the solar system is 25 years and that of a diesel generator is around 15000 hours, which translates into 5 years assuming a capacity factor of $40 \%$ as mentioned above. This methodology is implemented in an Excel financial simulation tool that has been developed for this project.

\section{D.2 Feasibility of rooftop solar PV systems}

The methodology is based on the availability of a dataset of around 13000 buildings in Beirut City. ${ }^{121}$ As shown in Figure 31 , the dataset includes information on rooftop space available per building. Consequently, each building is considered as a "decision unit". Other input parameters such as cost of solar systems and specific yield were obtained from interviewed solar companies. The effective tariff (weighted average of EDL and generator tariffs) is dependent on the number of hours of EDL network outages; and the rooftop occupancy factor, which is the fraction of the rooftop that is usable to mount solar PV module on it, is treated as a variable to generate the low and high scenarios. In terms of model's output, it produces the theoretical capacity available to be installed in $\mathrm{kWp}$, the annual energy generated and the potential annual savings and the corresponding net present value of each individual project (building).

\section{Figure 31: Input and output parameters of the solar PV adoption model}

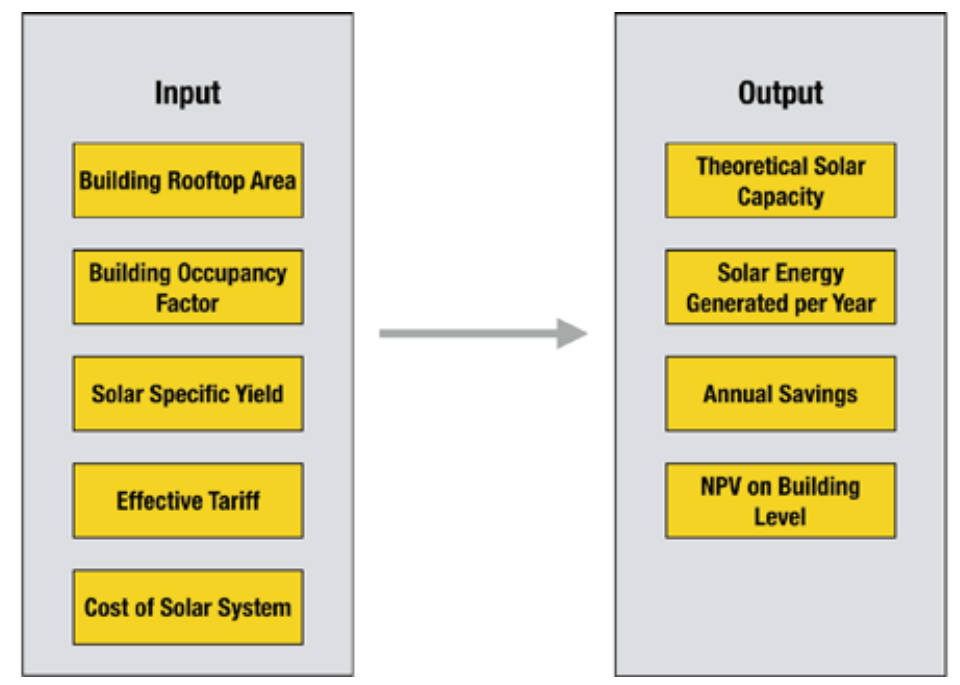

The assessment of the solar resources available for building $j$ is based on the following formulas:

$$
\text { Available Space }\left(S_{j}^{a v}\right)=\beta_{j} \times A_{j}
$$

Where $S_{j}^{a v}$ is the available space for solar panels in $\mathrm{m}^{2}, \beta$ is the occupancy factor and $A$ is the rooftop area of building $j$. Therefore, the available solar resource for building $j$ can be expressed as:

$$
E_{j}^{P V}=S_{j}^{a v} \times\left(\frac{1}{a}\right) \times \varepsilon
$$

119 This is a turnkey price

120 See: https://www.lazard.com/media/450774/lazards-levelized-cost-of-storage-version-40-vfinal.pdf

121 The estimated total number of buildings in Beirut is around 17000. 
Where $E_{j}^{P V}$ is the annual generated solar energy in building $j$, is the area required to install one $\mathrm{kWp}\left(8 \mathrm{~m}^{2}\right)$, and is specific yield, which is currently estimated at $1400 \mathrm{kWh} / \mathrm{kWp}$ based on data collected from Lebanese solar companies.

As for the capital cost of the solar PV system in building $j, E_{j}^{P V}$, it can be estimated using the following:

$$
K_{j}^{P V}=\frac{S_{j}^{a v}}{A_{k W p}} \times k
$$

Where $A_{k W p}$ is the area required for one $\mathrm{kWp}$ and $\mathrm{k}$ is the capital cost in $\$ / \mathrm{kWp}$.

The annual savings that result from installing rooftop solar PV panels, $\Phi_{j}$, can be then estimated using the following equation:

$$
\Phi_{j}=E_{j}^{P V} \times T_{e f f}
$$

Where $T_{\text {eff }}$ is the effective tariff paid by the consumer. ${ }^{122}$ On the other hand, the $N P V(j)$ can be calculated as follows:

$$
N P V(j)=\Phi_{j} \times \omega-K_{j}^{P V}
$$

Where $\omega$ is the discounting factor over the life time of the PV system (25 years), expressed as:

$$
\omega=\sum_{1}^{n=25} \frac{1}{(1+r)^{n-1}}
$$

Where $r$ is the discount rate.

Finally, it should be noted that two types of outlier buildings have been removed from the studied dataset: buildings with rooftops below $40 \mathrm{~m}^{2}$ and buildings with zero electricity consumption. The assumptions used in studying the feasibility of rooftop solar PV systems in the provided sample are listed in Table 30.

Table 30: Assumptions used in studying the feasibility of rooftop solar PV systems

\begin{tabular}{ll} 
Parameter & Value \\
\hline Discount Rate & Variable \\
Effective tariff & Variable \\
Capital cost $(\$ / \mathrm{kWp})$ & Variable \\
Rooftop occupancy factor & $50 \%(\mathrm{LoW})-75 \%$ (High) \\
Specific yield & $1400 \mathrm{kWh} / \mathrm{kWp}$ \\
Area required per $1 \mathrm{kWp}$ & $8 \mathrm{~m} 2$ \\
System lifetime & 25 Years \\
\hline
\end{tabular}

122 This assumes that all energy generated is compensated for either by direct utilization by the consumer or by export to EDL's grid under the net-metering arrangement. 


\section{APPENDIX E: DIESEL GENERATOR COSTS}

\section{E.1 Lifetime maintenance cost data of a typical diesel generator}

\section{DG Maintenance Cost Component}

Cost of lubricating oil

Cost of oil filters replacement

Cost of bypass filter replacement

Cost of oil filter replacement

Cost of fuel-water filter replacement

Cost of air filter replacement

Cost of coolant filter replacement

Cost of Drive belt alternator replacement

Cost of Drive belt fan replacement

Cost of coolant circulation pump replacement

Cost of thermostat replacement

Cost of fan replacement

Cost of injector

Cost of Gasket valve cover

Cost of fuel transport

Cost of maintenance contract

Cost of auxiliary battery replacement

Cost of coolant liquid replacement

Total Costs

\section{Value (\$)}

6,244

2,081

1,045

2,602

3,902

2,352

530

588

1,176

1,724

353

1,175

11,758

627

10,982

5,000

1,500

500

\section{4,138}

\section{E.2 Distribution infrastructure costs of a typical generator network}

Item Value

$\begin{array}{ll}\text { Typical Residential Building Width } & 30\end{array}$

$\begin{array}{ll}\text { Floors per Building } & 7\end{array}$

Apartments per Floor 3

Customers per Building $\quad 21$

Spacing Between Buildings (m) 5

Sparsity Factor 1

Total Buildings Supplied per Generator $\quad 15$

Total Cabling Length Between Buildings (m) 530 
Generator Distance from Nearest Building (m)

\section{5}

Total Required Distribution Cable Length per Generator (m)

Distribution Cable Unit Price $(\$ / m)$

Total Distribution Cable Price (\$)

Distribution Pole Unit Cost $(\$)$

0

Distance Between Distribution Poles (m) 30

Number or required Distribution Poles

18

End-User Distribution Cable XLPE/PVC Cross Section (mm2)

50

End-User Distribution Cable Unit Price $(\$ / \mathrm{m})$

0

Distance Between Pole and Building $(\mathrm{m})$

Total Required End-User Distribution Cable Length per Generator (m)

Total End-Use Distribution Cable Price (\$)

Balance of System and Installation (\%)

15

\section{E.3: Variable $0 \& M$ costs of the generator business}

\begin{tabular}{|c|c|c|c|}
\hline Component & Parameter & Value & Unit \\
\hline & Generator lifetime & 15,000 & h \\
\hline \multirow[t]{2}{*}{ Lubricating oil } & Lubricating oil consumption rate & 0.05 & $\mathrm{~L} / \mathrm{h}$ \\
\hline & Price of Lubricating oil (+11\% VAT) & 8.325 & $\$ / L$ \\
\hline \multirow[t]{3}{*}{ Oil filters } & Oil filter replacement period & 128 & h \\
\hline & Number of filters over lifetime & 117 & \\
\hline & Price of oil filter (+11\% VAT) & 17.76 & $\$ /$ filter \\
\hline \multirow[t]{3}{*}{ Bypass filters } & Bypass oil filters replacement period & 255 & h \\
\hline & Number of bypass filters over lifetime & 59 & \\
\hline & Price of bypass filters (+11\% VAT) & 17.76 & $\$ /$ filter \\
\hline \multirow[t]{3}{*}{ Fuel filters } & Fuel filters replacement period & 128 & h \\
\hline & Number of fuel filters over lifetime & 117 & \\
\hline & Price of fuel filters (+11\% VAT) & 22.2 & $\$ /$ filter \\
\hline \multirow[t]{3}{*}{ Fuel-water filters } & Fuel-water filters replacement period & 128 & h \\
\hline & Number of fuel-water filters over lifetime & 117 & \\
\hline & Price of oil filters (+11\% VAT) & 33.3 & $\$ /$ filter \\
\hline \multirow[t]{3}{*}{ Air filters } & Air filters replacement period & 531 & h \\
\hline & Number of air filters over lifetime & 28 & \\
\hline & Price of air filters (+11\% VAT) & 83.25 & $\$ /$ filter \\
\hline \multirow[t]{2}{*}{ Coolant filters } & Coolant filters replacement period & 723 & $\mathrm{~h}$ \\
\hline & Number of coolant filters over lifetime & 21 & \\
\hline
\end{tabular}




\begin{tabular}{|c|c|c|c|}
\hline Component & Parameter & Value & Unit \\
\hline & Price of coolant filters (+11\% VAT) & 25.53 & $\$ /$ filter \\
\hline \multirow[t]{3}{*}{ Drive belt alternator } & Drive belt alternator replacement period & 1,416 & $\mathrm{~h}$ \\
\hline & Number of Drive belt alternator over lifetime & 11 & \\
\hline & Price of Drive belt alternator (+11\% VAT) & 55.5 & \$/alternator \\
\hline \multirow{3}{*}{ Drive belt fan } & Drive belt fan replacement period & 1,416 & $\mathrm{~h}$ \\
\hline & Number of Drive belt fan over lifetime & 11 & \\
\hline & Price of Drive belt fan $(+11 \%$ VAT) & 111 & $\$ /$ fan \\
\hline \multirow{3}{*}{$\begin{array}{l}\text { Coolant circulation } \\
\text { pump }\end{array}$} & Coolant circulation pump replacement period & 4,250 & h \\
\hline & Number of coolant circulation pump over lifetime & 4 & \\
\hline & Price of coolant circulation pump (+11\% VAT) & 488.4 & $\$ /$ pump \\
\hline \multirow[t]{3}{*}{ Thermostat } & Thermostat replacement period & 4,250 & $\mathrm{~h}$ \\
\hline & Number of thermostats over lifetime & 4 & \\
\hline & Price of thermostats (+11\% VAT) & 99.9 & $\$ /$ thermostat \\
\hline \multirow[t]{3}{*}{ Fan } & Fan replacement period & 4,250 & $\mathrm{~h}$ \\
\hline & Number of fan over lifetime & 4 & \\
\hline & Price of fan $(+11 \%$ VAT) & 333 & $\$ /$ fan \\
\hline \multirow[t]{3}{*}{ Injector } & Injector replacement period & 708 & $\mathrm{~h}$ \\
\hline & Number of injectors over lifetime & 21 & \\
\hline & Price of injector (+11\% VAT) & 555 & \$/injector \\
\hline \multirow[t]{3}{*}{ Gasket valve cover } & Gasket valve cover replacement period & 2,125 & $\mathrm{~h}$ \\
\hline & Number of Gasket valve cover over lifetime & 7 & \\
\hline & Price of Gasket valve cover (+11\% VAT) & 88.8 & $\$ /$ cover \\
\hline \multirow[t]{7}{*}{ Fuel transport } & Average fuel consumption & 88 & $\mathrm{~L} / \mathrm{h}$ \\
\hline & Total fuel amount over lifetime (L) & $1,320,000$ & $\mathrm{~L}$ \\
\hline & Total fuel amount over lifetime (tons) & $1,098.24$ & Ton \\
\hline & Cost of fuel transport per ton & 10 & $\$ /$ ton \\
\hline & Price of maintenance contract per year & 1,000 & $\$$ \\
\hline & Generator lifetime in years & 5 & years \\
\hline & Auxiliary battery replacement & 1 & year \\
\hline \multirow[t]{2}{*}{ Auxiliary batteries } & Number of auxiliary battery over lifetime & 5 & \\
\hline & Price of auxiliary batteries & 300 & $\$ /$ battery \\
\hline \multirow[t]{4}{*}{ Coolant liquid } & Coolant liquid replacement & 2 & year \\
\hline & Number of coolant liquid replacements over lifetime & 2.5 & \\
\hline & Price of coolant liquid & 5 & $\$ / L$ \\
\hline & Volume of coolant liquid & 40 & $L$ \\
\hline \multirow[t]{2}{*}{ Fuel } & Price of fuel (LBP) & 20,000 & $\mathrm{LBP} / 20 \mathrm{~L}$ \\
\hline & Price of fuel $(\$)$ & 0.67 & $\$ / L$ \\
\hline Additional costs & $\begin{array}{l}\text { Lighting strikes, unexpected events, equipment failure, } \\
\text { sabotage, etc. }\end{array}$ & 5,000 & $\$$ \\
\hline
\end{tabular}




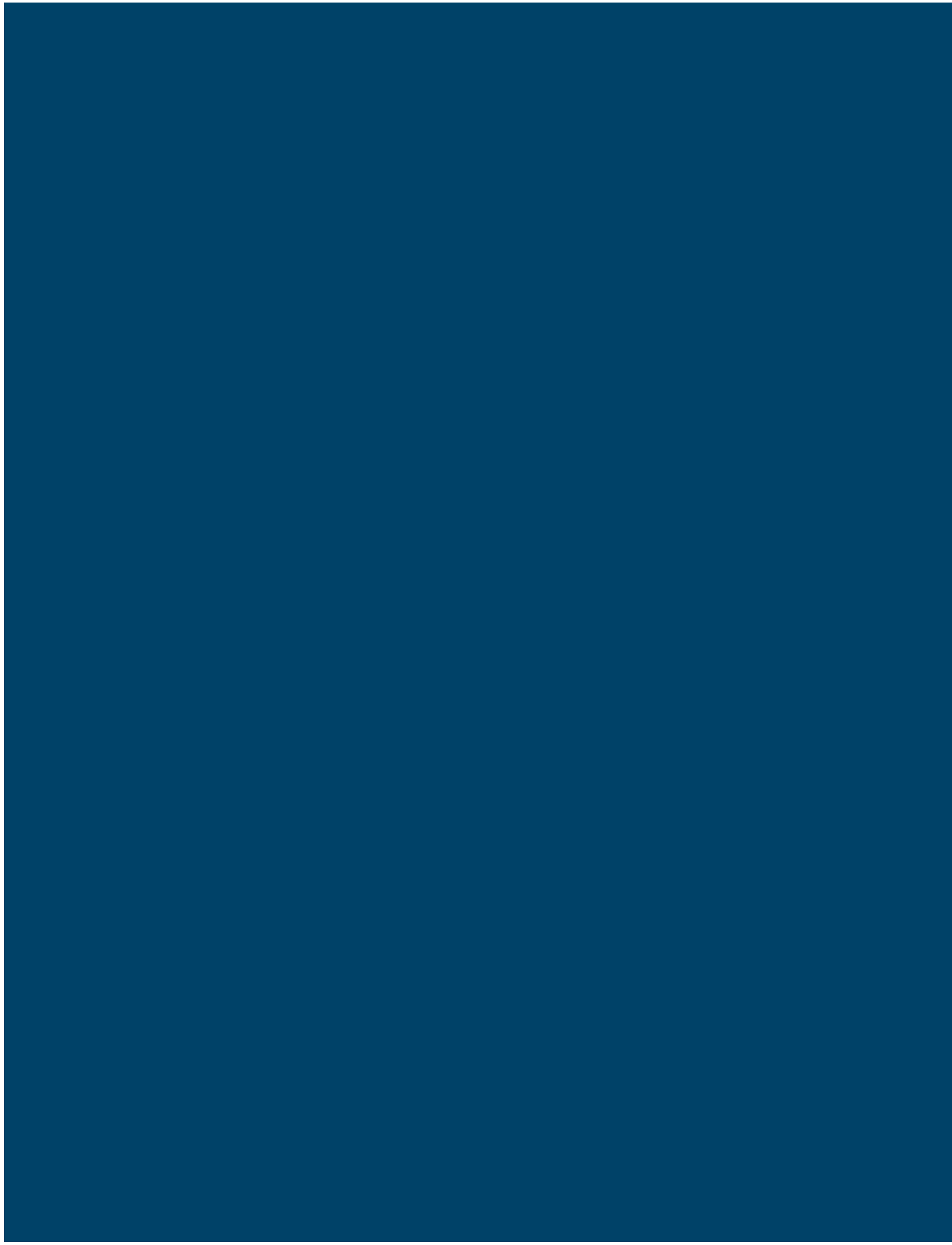

